
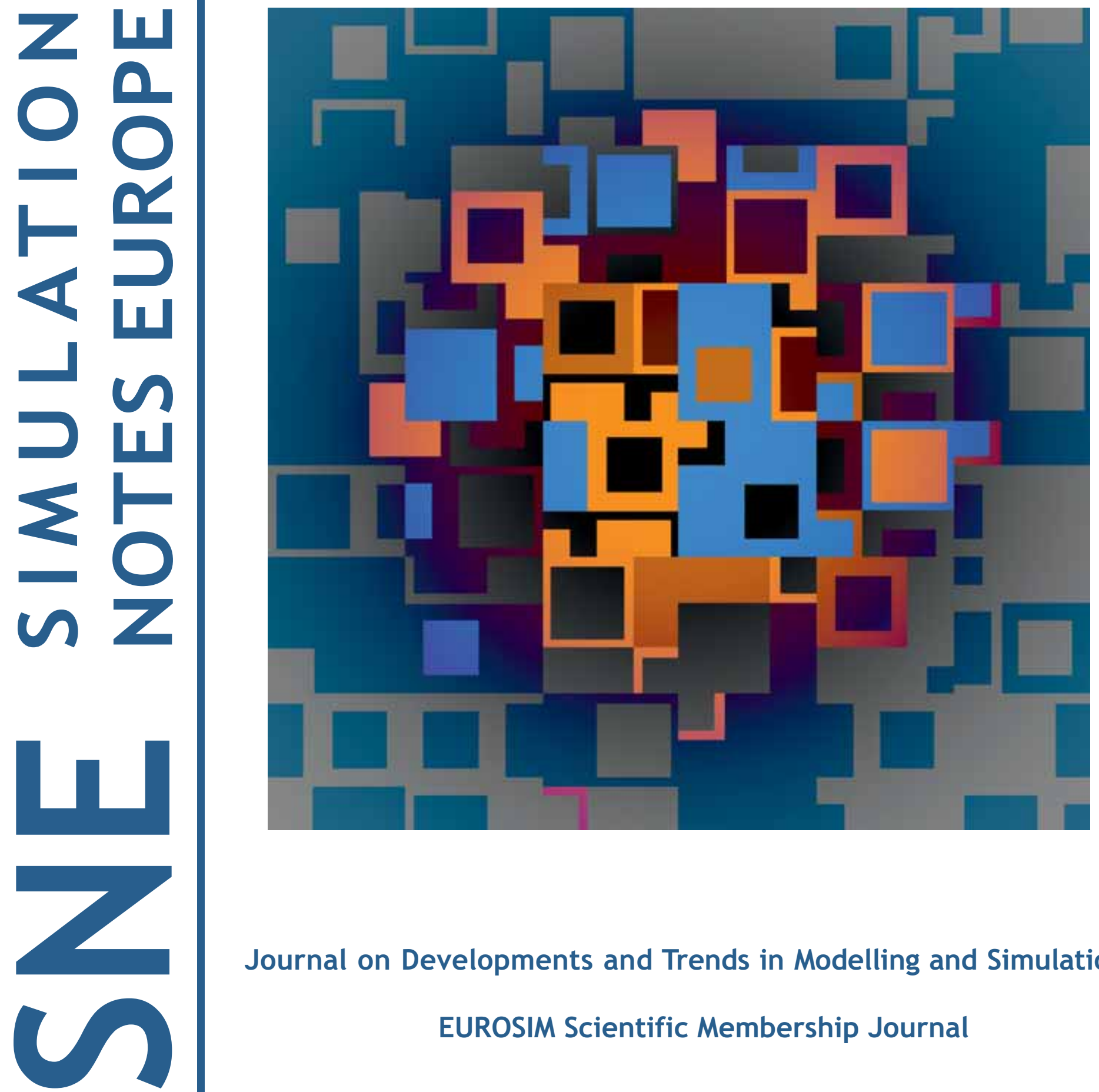

Journal on Developments and Trends in Modelling and Simulation EUROSIM Scientific Membership Journal 


\section{SNE Aims \& Scope}

Simulation Notes Europe (SNE) provides an international, high-quality forum for presentation of new ideas and approaches in simulation - from modelling to experiment analysis, from implementation to verification, from validation to identification, from numerics to visualisation - in context of the simulation process.

SNE seeks to serve scientists, researchers, developers and users of the simulation process across a variety of theoretical and applied fields in pursuit of novel ideas in simulation and to enable the exchange of experience and knowledge through descriptions of specific applications. SNE follows the recent developments and trends of modelling and simulation in new and/or joining application areas, as complex systems and big data. SNE puts special emphasis on the overall view in simulation, and on comparative investigations, as benchmarks and comparisons in methodology and application. For this purpose, SNE documents the ARGESIM Benchmarks on Modelling Approaches and Simulation Implementations with publication of definitions, solutions and discussions. SNE welcomes also contributions in education in/for/with simulation.

A News Section in SNE provides information on EUROSIM Simulation Societies and Simulation Groups.

SNE, primarily an electronic journal, follows an open access strategy, with free download in basic layout. SNE is the official membership journal of EUROSIM, the Federation of European Simulation Societies and Simulation Groups www.eurosim.info. Members of EUROSIM societies are entitled to download SNE in an elaborate and extended layout, and to access additional sources of benchmark publications, model sources, etc. Print SNE is available for specific groups of EUROSIM societies, and starting with Volume 27 (2017) as printon-demand from TU Verlag, TU Wien. SNE is DOI indexed by CrossRef, identified by DOI prefix 10.11128 , assigned to the SNE publisher ARGESIM (www.argesim.org).

Author's Info. Individual submissions of scientific papers are welcome, as well as post-conference publications of contributions from conferences of EUROSIM societies. SNE welcomes special issues, either dedicated to special areas and/or new developments, or on occasion of events as conferences and workshops with special emphasis.

Authors are invited to submit contributions which have not been published and have not being considered for publication elsewhere to the SNE Editorial Office.

SNE distinguishes different types of contributions (Notes), i.e.

- TN Technical Note, 6-10 p. EN Education Note-6-8 p.

- PN Project Note 6-8 p. - SN Short Note, max. 6 p.

- SW Software Note, 4-6 p. - BN Benchmark Note, 4-8 p.

- ON Overview Note - only upon invitation, up to $14 \mathrm{p}$.

Further info and templates (doc, tex) at SNE's website. www.sne-journal.org

\section{SNE Editorial Board}

SNE - Simulation Notes Europe is advised and supervised by an international scientific editorial board. This board is taking care on peer reviewing of submissions to SNE.

David Al-Dabass, david.al-dabass@ntu.ac.uk, Nottingham Trent University, UK

Felix Breitenecker, Felix.Breitenecker@tuwien.ac.at TU Wien, Math. Modelling, Austria, Editor-in-chief

Maja Atanasijevic-Kunc, maja.atanasijevic@fe.uni-lj.si Univ. of Ljubljana, Lab. Modelling \& Control, Slovenia

Aleš Belič, ales.belic@sandoz.com Sandoz / National Inst. f. Chemistry, Slovenia

Peter Breedveld, P.C.Breedveld@el.utwente.nl University of Twenty, Netherlands

Agostino Bruzzone, agostino@itim.unige.it Universita degli Studi di Genova, Italy

Francois Cellier,fcellier@inf.ethz.ch, ETH Zurich, Switzerland

Vlatko Čerić, vceric@efzg.hr, Univ. Zagreb, Croatia

Russell Cheng,rchc@maths.soton.ac.uk University of Southampton, UK

Roberto Cianci,cianci@dime.unige.it, Math. Eng. and Simulation, Univ. Genova, Italy

Eric Dahlquist, erik.dahlquist@mdh.se, Mälardalen Univ., Sweden Umut Durak,umut.durak@dlr.de German Aerospace Center (DLR)Braunschweig, Germany

Horst Ecker, Horst.Ecker@tuwien.ac.at TU Wien, Inst. f. Mechanics, Austria

Vadim Engelson,vadim.engelson@mathcore.com MathCore Engineering, Linköping, Sweden

Edmond Hajrizi, ehajrizi@ubt-uni.net University for Business and Technology, Pristina, Kosovo

EskoJuuso,esko.juuso@oulu.fi Univ. Oulu, Dept. Process/Environmental Eng., Finland

Kaj Juslin, kaj.juslin@enbuscon.com, Enbuscon Ltd, Finland Andreas Körner, andreas.koerner@tuwien.ac.at TU Wien, Math. E-Learning Dpt., Vienna, Austria

Francesco Longo, f.longo@unical.it Univ. of Calabria, Mechanical Department, Italy

Yuri Merkuryev, merkur@itl.rtu.lv, Riga Technical Univ.

David Murray-Smith, d.murray-smith@elec.gla.ac.uk University of Glasgow, Fac. Electrical Engineering, UK

Gasper Music, gasper.music@fe.uni-lj.si Univ. of Ljubljana, Fac. Electrical Engineering, Slovenia

Thorsten Pawletta, thorsten.pawletta@hs-wismar.de Univ. Wismar, Dept. Comp. Engineering, Wismar, Germany

Niki Popper,niki.popper@dwh.at, dwh Simulation Services, Austria

Kozeta Sevrani, kozeta.sevrani@unitir.edu.al Univ. Tirana, Inst.f. Statistics, Albania

Thomas Schriber, schriber@umich.edu University of Michigan, Business School, USA

Yuri Senichenkov,sneyb@dcn.infos.ru St. Petersburg Technical University, Russia

Oliver Ullrich, oullrich@cs.1u.edu Florida International University, USA

Siegfried Wassertheurer,Siegfried.Wassertheurer@ait.ac.at AIT Austrian Inst. of Technology, Vienna, Austria

Sigrid Wenzel,S.Wenzel@uni-kassel.de Univ. Kassel, Inst. f. Production Technique, Germany

Grégory Zacharewicz, gregory.zacharewicz@mines-ales.fr IMT École des Mines d'Alès, France 


\section{Editorial}

Dear Readers - This SNE special issue 'Short Papers $9^{\text {th }}$ EUROSIM Congress, Oulu, 2016', the third SNE issue of 2018, SNE 28(3), was initiated and compiled by SIMS, the Scandinavian Simulation Society. Following SNE's publication strategy aiming for short contributions on new ideas and for post-conference publication of EUROSIM societies, this issue presents selected short papers presented at the EUROSIM the $9^{\text {th }}$ EUROSIM congress in Oulu, September 2016. It again shows the broad variety of modelling and simulation, from simulation for control via conceptual modelling to simulation for evacuation and archaeology. This issue also continues with SNE's cover graphics from Vlatko Čerić's algorithmic art series - the third graphic from the series BIRTH.

I would like to thank all authors of EUROSIM 2016 Short Papers for preparing the revised contributions for SNE. And many thanks especially to Esko Juuso, for compiling this special issue as editor, and to his colleagues in SIMS for selecting and reviewing the contributions. And last but not least thanks to the SNE Editorial Office for layout, typesetting, preparations for printing, and especially for electronic publishing work with DOI indexing.

Felix Breitenecker, SNE Editor-in-Chief,eic@sne-journal.org; felix.breitenecker@tuwien.ac.at

\section{Contents SNE 28(3)}

\section{Special Issue 'Short Papers $9^{\text {th }}$ EUROSIM Congress, Oulu, 2016'}

Online SNE 28(3) DOI 10.11128/sne.28.3.1042

Print SNE 28(3) Print-on-Demand ISBN 978-3-903024-76-2

Print-on-Demand, TU Verlag Vienna, www.tuverlag.at

Monitoring and Control in Mining. A. Koistinen 81

Actuator Fault Tolerant Control for a Rotary Wing Aircraft. E. Kiyak, A. Ermeydan

Utilizing Optical Monitoring to Predict the Effluent Quality

in the Activated Sludge Processes. J. Tomperi

Fault Tolerant Control for a Rotary Wing Aircraft.

G. Unal, E. Kiyak

Simplified Mechanistic Model of the Multiple Hearth Furnace for Control Development. J. V. Gómez Fuentes, S.-L. Jämsä-Jounela

SolarTherm: A New Modelica Library and Simulation Platform for Concentrating Solar Thermal Power Systems. A. de la Calle, J. Hinkley, P. Scott, J. Pye

Concept for Mathematical Models for Subprocesses in the Manufacture of Particleboards.

C. Pöll, M. Riegler, F. Breitenecker

Possibilities in State Event Modelling of Hybrid Systems.

A. Körner, S. Winkler, F. Breitenecker

Plant Disease Outbreak - Prediction by Advanced Data

Analysis. O. Mäyrä, M. Ruusunen, M. Jalli,

L. Jauhiainen, K. Leiviskä

Mean-Field Approximation of a Microscopic Population

Model for Austria. M. Bicher, N. Popper

Estimation of Discontinuities from Point Cloud

Based on Variable-Box Segmentation Method.

S. Matsukawa, K. Itakura, Y. Suzuki, A. Hayano

Synaptic Learning of the Resonator Network Interacting with Oscillatory Background and Noise.

T. Matsumura, T. Kitajima, T. Yuasa, S. Kang
Falsification by Modelling and Simulation for Investigations in Hallstatt Archaeology. J. Tanzler, N. Popper, G. Wurzer, A. Bacher, K. Kowarik, H. Reschreiter, F. Breitenecker ..... 129 A Simulation Model of a School's Evacuation.

A. Korolko, V. Abrams, N. Kucerenko, D. Lolans 133

Interactive Modelling and Simulation of Micromirror MEMS Devices. S. Rasheed

EUROSIM Societies Short Info $\mathrm{N} 1-\mathrm{N} 7$

\section{SNE Contact \& Info}

SNE Online ISSN 2306-0271, SNE Print ISSN 2305-9974

$\rightarrow$ www.sne-journal.org

玤: office@sne-journal.org, eic@sne-journal.org

$\triangle$ SNE Editorial Office

Johannes Tanzler (Layout, Organisation), Irmgard Husinsky (Web, Electronic Publishing), Felix Breitenecker (Organisation, Authors) ARGESIM/Math. Modelling \& Simulation Group, Inst. f. Analysis and Scientific Computing, TU Wien Wiedner Hauptstrasse 8-10, 1040 Vienna , Austria

\section{SNE Simulation NOTES EUROPE}

WEB: $\rightarrow$ www.sne-journal.org, DOI prefix 10.11128/sne

Scope: Developments and trends in modelling and simulation in various areas and in application and theory; comparative studies and benchmarks (documentation of ARGESIM Benchmarks on modelling approaches and simulation implementations); modelling and simulation in and for education, simulation-based e-learning; society information and membership information for EUROSIM members (Federation of European Simulation Societies and Groups).

Editor-in-Chief: Felix Breitenecker, TU Wien, Math. Modelling Group 莑三” Felix.Breitenecker@tuwien.ac.at, 邦 eic@sne-journal.org

Print SNE and Print-on-Demand: Grafisches Zentrum and TU-Verlag, TU Wien, Wiedner Hauptstrasse 8-10, 1040, Vienna, Austria www.tuverlag.at

Publisher: ARGESIM ARbeitsgemeinschaft Simulation NeWS c/o Math. Modelling and Simulation Group,

Vienna Univ. of Technology / 101, Wiedner Hauptstrasse 8-10, 1040 Vienna, Austria; www.argesim.org, 奉 info@argesim.org on behalf of ASIM www.asim-gi.org and EUROSIM $\rightarrow$ www.eurosim.info (c) ARGESIM / EUROSIM / ASIM 2018 


\section{Editorial SNE Special Issue 'Short Papers $9^{\text {th }}$ EUROSIM Congress, Oulu, 2016'}

The $9^{\text {th }}$ EUROSIM Congress was organized by Scandinavian Simulation Society (SIMS), Finnish Society of Automation, and University of Oulu. The purpose of EUROSIM is to provide a European forum for regional and national simulation societies to promote the advancement of modelling and simulation in industry, research and development. The event was co-sponsored by several technical committees of IFAC, by the IEEE Computer Society, and by the IEEE Finland Section. The congress had a multi-conference structure with several special topics related to methodologies, functionalities and application areas. This special issue complements the Proceedings of 9th EUROSIM Congress on Modelling and Simulation - EUROSIM 2016 and 57th SIMS Conference on Simulation and Modelling - SIMS 2016.

The short papers of this special issue cover the congress topics widely. Applications in technical systems are in versatile topics: rotary wing aircraft, mining, process, manufacturing, wastewater treatment, solar thermal power systems, microelectromechanical systems and tunnels. Papers on bioand ecological systems discus on human brain states and plant diseases in modern agriculture. Papers of social systems include school evacuation and archaeology. Functionalities cover risk management, fault diagnosis, optimization, monitoring and control, including fault tolerant and model predictive control. Methodologies include intelligent systems, variable selection, feature extraction, agent-based simulation, population models, simplification and linearization of models, continuous and discrete models in hybrid systems.

The issue starts with the contribution of Antti Koistinen Monitoring and Control in Mining investigating risk management by using predictive indirect measurements in three risk areas: water handling in vast mining environment, condition monitoring of machines and process device, and health and safety of personnel. 3D digital surface models combined with watershed information are useful in developing more detailed models for watershed management. Environmental impacts monitoring focuses mainly on detecting changes in surface waters, groundwater and air. Modelling is an efficient tool for predicting process operation and generating new soft sensors for advanced control methods. Optimally running processes ensure minimal environmental effects. Decision-making is based on situation awareness built by combining data and expertise in the environmental monitoring concept.

The paper Actuator Fault Tolerant Control for a Rotary Wing Aircraft by Emre Kiyak and Ahmet Ermeydan proposes a fault tolerant control strategy for a quadrotor in the presence of actuator faults. The linear model of the quadrotor is derived from nonlinear equations. The faults are isolated by Generalized Observer Scheme (GOS) based on detecting with Unknown Input Observer (UIO). The authors demonstrate the performance of the active fault tolerant method by a simulation study.

The third paper by Jani Tomperi Utilizing Optical Monitoring to Predict the Effluent Quality in the Activated Sludge Processes addresses optical monitoring in industrial and municipal activated sludge processes for predicting important effluent quality parameters to enable the optimization of process control. The process should efficiently remove oxygen-demanding substances, excessive nutrients and toxicants from wastewater. The monitoring method includes several morphological characterization variables. The nonlinear scaling method was used and several variable selection methods compared. The municipal process is more temperature related than the industrial. The optical monitoring device is a valuable tool for monitoring the changes in floc morphology.

The paper Fault Tolerant Control for a Rotary Wing Aircraft, by Gulay Unal and Emre Kiyak, compares nonlinear and linear models by using MATLAB/Simulink. Linear and nonlinear models show similar performances when simulated with a PD controller. An improved PID structure is presented to overcome the integral wind-up problem. The linear model is faster for the PID control.

The paper of Jose V. Gómez Fuentes and Sirkka-Liisa Jämsä-Jounela Simplified Mechanistic Model of the Multiple Hearth Furnace for Control Development simplifies the mechanistic model of a Multiple Hearth Furnace (MHF). The nonlinear Hammerstein-Wiener model aims to preserve the key physical-chemical phenomena for Model Predictive Control (MPC) implementation. The comparison confirms that the dynamics of the simplified model accurately follows the mechanistic model outputs.

Alberto de la Calle, Jim Hinkley, Paul Scott and John Pye describe in their paper SolarTherm: A New Modelica Library and Simulation Platform for Concentrating Solar Thermal Power Systems a new alternative platform for conventional simulation tools. The systems are full-editable and runnable with the main Modelica environments and Python-based tools and scripts. The work-in-progress aims to improve the efficiency and capacity of CST power systems.

The paper Concept for Mathematical Models for Subprocesses in the Manufacture of Particleboards by Carina Pöll, Martin Riegler and Felix Breitenecker analyzes the combination of physical processes and connections of different models in a manufacturing process with special emphasis on the drying and pressing stages. To analyze the combination 
of physical processes, the connection of different models is considered crucial. More and more production steps can be included and the submodels can be used with different levels of detail.

The paper Possibilities in State Event Modelling of Hybrid Systems, by Andreas Körner, Stefanie Winkler and Felix Breitenecker, describe hybrid combinations of mathematical models and state event models. The hybrid models include both continuous and discrete parts. The work-inprogress shows the first steps towards a conceptual simulation environment. The hybrid state event modelling should also support benchmarking and categorization of different existing optimization approaches. The overall structure has to be optimized together.

The paper of Outi Mäyrä, Mika Ruusunen, Marja Jalli, Lauri Jauhiainen and Kauko Leiviskä Plant Disease Outbreak - Prediction by Advanced Data Analysis focusses on plant disease modelling in modern agriculture. The paper introduces a novel point of view for the net blotch prediction by combining weather data with previous net blotch observations. A databased prediction system is introduced. The estimation scheme is demonstrated with selected observation field data. The compact structure is easy to adapt to other observation fields.

Martin Bicher and Niki Popper present in their discussion paper Mean-Field Approximation of a Microscopic Population Model for Austria an approach for improving the verification and validation process of large agent base models and apply it on an agent-based population model for Austria. These parameters were worked out of the data provided by the Austrian Bureau of Statistics. The model was implemented in Python 3. The calculation process was improved by using the mean-field approximation for developing a closed, aggregated equationbased model. The resulting partial-differential equation (PDE) model is a fast, useful tool for gaining first insights to support validation and verification in this case.

The paper Estimation of Discontinuities from Point Cloud Based on Variable-Box Segmentation Method by Shun Matsukawa, Ken-ichi Itakura, Yukinori Suzuki and Akira Hayano introduces a variable-box segmentation (VBS) method for finding a fracture plane from a point cloud of LiDAR data recorded from long tunnels. VBS uses two steps of refining bounding boxes and combining of boxes to produce suitable planes. The VBS algorithm can find discontinuities from fractured planes.

The paper Synaptic Learning of the Resonator Network Interacting with Oscillatory Background and Noise, by Taishi Matsumura, Tatsuo Kitajima, Tetsuya Yuasa and Siu Kang, presents a numerical simulation of the network with subthreshold resonance and examines robustness for the external stimuli with various temporal jitters and randomness.
The computational study demonstrates several properties of a resonator network related with oscillatory activities in the brain which often reflect internal states. Through the formation of non-uniform connectivity, the network could store the spatial information about external stimuli in frequencydependent manner.

The paper of Johannes Tanzler, Niki Popper, Gabriel Wurzer, Anke Bacher, Kerstin Kowarik, Hans Reschreiter and Felix Breitenecker Falsification by Modelling and Simulation for Investigations in Hallstatt Archaeology presents simulation studies, which allow to study short-term mining processes and long-term population dynamics and agricultural working processes. The falsification study allows excluding some assumptions on working processes in the salt mine and in the agricultural environment.

Aleksandrs Korolko, Valdis Abrams, Natalja Kucerenko and Dins Lolans describe in their paper A Simulation Model of a School's Evacuation a decision support system for evaluating evacuation efficiency. Various simulation software systems are compared and AnyLogic methodology is studied closely. The system supplies information about the problem areas. Recommendations were developed for increasing the efficiency of the evacuation process and adjusting the model for buildings with similar layouts.

The last paper Interactive Modelling and Simulation of Micromirror, by Sarbast Rasheed, presents an interactive software package for the modelling and simulation of microelectromechanical system (MEMS) devices utilizing the MATLAB environment. The developed software package, which consists of several graphical user interfaces, is useful for computing the forces and torques for different micromirror geometries. The goal is to enable better understanding of MEMS and help in the design and fabrication of MEMS to achieve optimum performance.

I would like to thank colleagues in SIMS for selecting and reviewing the contributions. Furthermore, I would like to express our gratitude to all authors for their co-operation and efforts - and last but not least thanks to the SNE Editorial Office for the support in compiling this special issue.

EskoJuuso, Guest editor, esko.juuso@oulu.fi

University of Oulu, Oulu, Finland 



\title{
Monitoring and Control in Mining
}

\author{
Antti Koistinen*
}

Control Engineering, University of Oulu, Pentti Kaiteran katu 1, 90014 Oulu, Finland; *antti.koistinen@oulu.fi

SNE 28(3), 2018, 81 - 84, DOI: 10.11128/sne.28.sn.10421

Received: Sept. 15, 2016 (Selected EUROSIM Congress 2016

Postconf. Publ.), Revised July 30, Accepted: August 25, 2018

SNE - Simulation Notes Europe, ARGESIM Publisher Vienna,

ISSN Print 2305-9974, Online 2306-0271, www.sne-journal.org

Abstract. Reliable risk management is based on informative decision making. The key to improve decision making is to combine information and create new predictive measurements. Predictive indirect measurements can include open data, process measurements, and modelling. Varying information sources enables viewing the situation from several differing angles and can give the decision maker more time to react. Different datasources strengthen each other narrowing the uncertainty of predictions. Robust self-monitoring is also needed for the predictive system to be reliable. Mining industry has three major risk sources: water handling in the environmental focus area, condition of machines and process devices, and health and safety of personnel. This article focuses on environmental monitoring in vast mining environment and its surroundings but connects process monitoring and control to subject.

\section{Introduction}

Environmental risks are the number one concern of mining companies when it comes to socio-economic relations and maintaining the company image. When dealing with large outdoor areas for water treatment, there is always a great risk of leaks. Leakage detection can take some time and in many cases, the residents detect the leakage from the surrounding lakes and environment. This leads to socio-economic pressure and reductions in company value. Mining companies are very interested in techniques for detecting small amounts of metals in water streams around the mining area [1].

Comprehensive use of varying data sources together with modelling provides great foundations for informed decision-making. The operator needs to be able to maintain the control of its process and assets.
Improvements in this field require advanced process monitoring methods, which include predictive algorithms and new measurement technologies. Working environmental monitoring system and optimal process control can ensure the future acceptance for mining operations among the wider population.

\section{Waterflow models}

MMEA project introduced the digital surface model (DSM) of Agnico Eagle gold mine area in Kittilä, Finland. The Model was done using photogrammetric processing of airborne image data. DSM can be combined with watershed information for creating a model for watershed management presented in Figure 1. The aerial photography for DSM was done in the MMEA project using a small airplane, which is expensive, compared with modern applications using drones. Tong et al. [2] introduces technique for integrating uav-based photogrammetry with terrestrial laser scanning. They built three 3D models of open-pit mine areas. These new techniques can be used for creating more detailed models for watershed management.

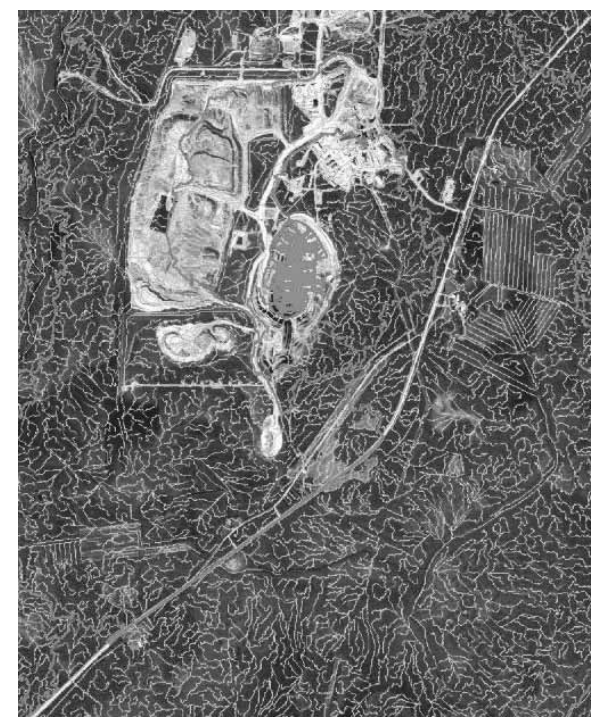

Figure 1: Watershed management. Main watersheds (red) with standard flowpaths (blue). 


\section{Environmental Monitoring}

\subsection{Environmental impacts monitoring}

Wastewaters are the greatest concern in mining area since they can transport particles and chemicals effectively to wide areas in environment. Wastewater is treated in several stages in settling ponds or tailing dams before released back into surrounding environment. Environmental impacts monitoring focuses mainly on detecting changes in surface waters, groundwater, and air. Commonly measured parameters from process wastewater are the total heavy metal concentrations, $\mathrm{pH}$, sulfate, and nitrogen. It is especially important to monitor and control sulphate discharges as they can form sulfuric acid and hydrogen sulfide that influences strongly water quality [3] [1].

Measurements and watershed models should be combined with open data to form estimates for leakage distributions in environment. These combined models can act as information source for damage control in case of accidents or determining the concentration variations at the different times of year. Variations and error from the expected values indicate the need for closer inspections.

\subsection{Environmental measurements}

Mining companies depicted in [1] that they are very interested in measuring ppb level amounts of heavy metals in water streams surrounding mining area. Report presented most promising methods for online detection at that time. Technologies for on-line measurements have been developing since that report was made. Technology development has continued since the MMEA project and in Finland, there are several companies focused on these new online measurement methods that can reach ppb level detection accuracies. Meoline has MEO+ heavy metals analyser based on electrochemical analysis. Sensmet $\mu$ DOES is a multi element analyser for trace metals based in Micro-discharge Optical Emission Spectroscopy. EHP Environment provides very widely used monitoring stations for several different elements including heavy metals in waters.

Another good indicator for detecting changes in surrounding environment is a crowdsourced measurement. The idea is that anyone can take measurements from the environment using a standardized way. Measurements are then gathered into a database where data is treated with outlier detection and stored for the users.
These measurements are not necessarily very accurate but can detect changes when a sufficient number of measurements are reached. Another good thing about the crowdsourcing is that it can act as a rather comprehensive measurement network that is cheap and does not need constant maintenance [3].

\section{Process Control}

Optimally the working process ensures that there is a minimal amount of emissions. Modern control methods can be used for optimal process control. H2020 Spire project 'Intensified by Design' (IbD) aimed in process intensification and Minesense project that focused on optical measurements for the sustainable mineral beneficiation process provided new information for better process control. Figure 2 illustrates the plan for comprehensive process control that is the ultimate aim of these projects.

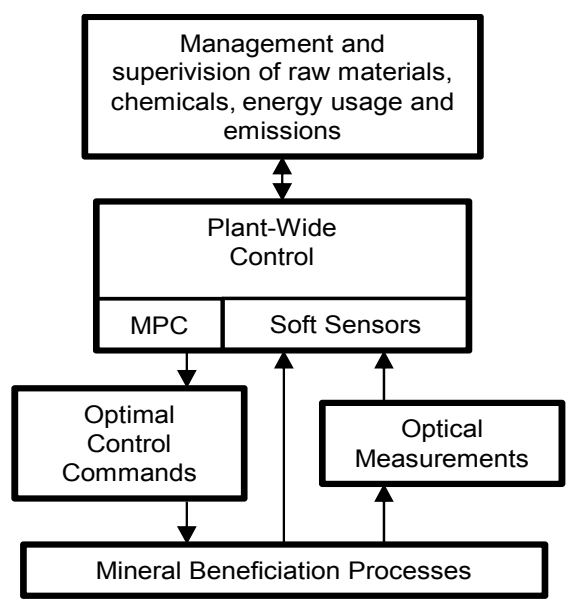

Figure 2: Wide control plan for minerals processing.

IbD focused on grinding process intensification through optimal control actions, coarse flotation, soft sensors, and new measurements. This work was presented in IFAC MMM 2018 conference [4] and it included good results for model adaptation using the differential evolution algorithm.

Modeling is an efficient tool for predicting process operation and generating new soft sensors for advanced control methods. Modelling and simulation for efficient minerals processing is reviewed in [5] and [6] using minipilot scale mineral beneficiation plant as a real life process. Optical sensors can be used in the monitoring of the flotation enrichment process [7]. Optical measurements can enable advanced process control for the typically hard to measure the flotation process. 


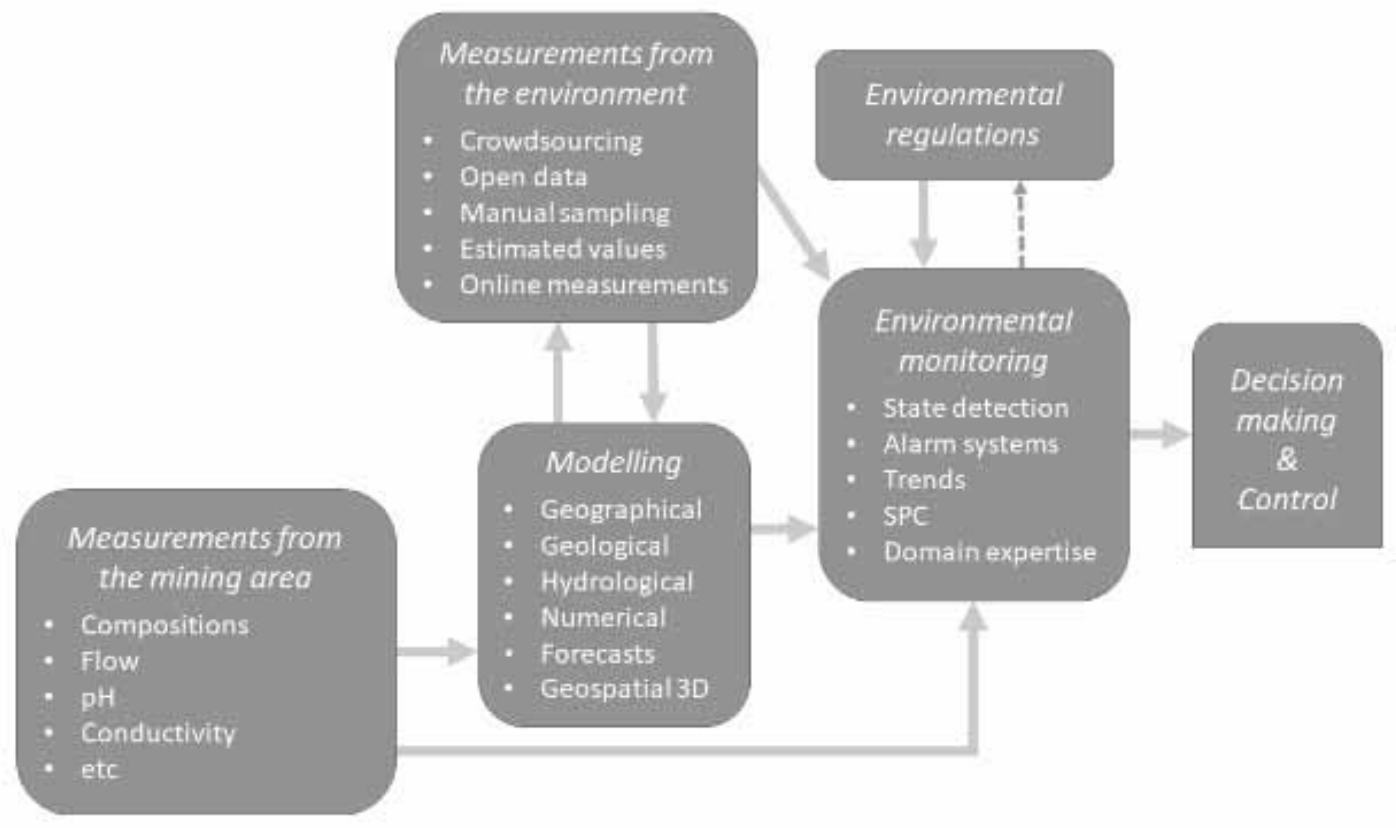

Figure 3: Environmental monitoring concept [3].

\subsection{Condition monitoring}

Condition monitoring is a vital part of comprehensive process control. We need to know our assets are in good working condition for optimal operation. Advanced methods provide intelligent indicators for monitoring changing condition. Indicators can be scaled to the realvalued interval $[-2,2][8]$. Generalised norms and moments are excellent tools for indicating current condition or change in the current operating state [9]-[11].

Good process control is linked to the environmental risks. By keeping a process running optimally, we can ensure minimal environmental effects. Fluctuations in process operation increases unexpected situations, which are difficult to control. Reduced fluctuations in process operation also ensure better predictions about how the process is going to act in future. This gives more time to react when abnormal operation is detected.

\section{Decision Support and Risk Management}

Decision-making is based on situation awareness from combining data from several sources with wide domain expertise using intelligent analyzers (Figure 3) [3].
Developments in modeling and increasing accuracy in measurement technologies build a solid base for future decision support systems. Leaps in development are needed to ensure the sustainable mining operations and social acceptance. Survey for environmental decision support tools and general methods are presented in [12] including wide amount of sources for varying methods and software tools.

Online monitoring methods are currently used as a fast response system in case of a leakage. Interest in the environmental measurements is a good sign that the environmental issues are taken seriously and that there is a motivation to prevent any unwanted effluent streams getting into surrounding environment. Correlations between different variables like water stream turbidity and arsenic can be used for indirect monitoring and these soft sensors can trigger actions for more detailed analysis.

The wide use of these methods would require standardization and accepting them as valid proofing methods for the environmental permit. Current legislation only approves scarce laboratory analyses to be used in the validation of the environmental permit. Continuous measurements would include the information on dynamics, which could increase the knowledge about the effects of mining operations to the environment. 


\section{Conclusions}

Work done for better advanced process control and decreased environmental impact is a great basis for pursuing goals in sustainable development. Technological leaps enable the realization of previously outlined innovations. Co-operation between experts in varying fields provide that the expert knowledge develop with the technologies to generate the monitoring systems of the future.

\section{References}

[1] Keskimölö A, Koistinen A, Juuso E, Tornberg J, Nieminen P, Karlsson S, Pyysalo U, Kytökari J, Honkavaara E, Ruokokoski P. Mining Monitoring Concept MMEA WP5.2.7.1 Report. 2014. Helsinki. ISBN 978-952-594759-5.

[2] Tong X, Liu X, Chen P, Liu S, Luan K, Li L, Liu S, Liu $\mathrm{X}$, Xie H, Jin Y, Hong Z, Tong X, Liu X, Chen P, Liu S, Luan K, Li L, Liu S, Liu X, Xie H, Jin Y, Hong Z. Integration of UAV-Based Photogrammetry and Terrestrial Laser Scanning For The Three-Dimensional Mapping and Monitoring of Open-Pit Mine Areas. Remote Sensing. 2015; 7(6): 6635-6662.

[3] Juuso E, Koistinen A. Forecasting Environmental Impact MMEA WP5.2.76 Report. 2015. Helsinki. ISBN 978952-5947-89-2.

[4] Ohenoja M, Ruusunen M, Koistinen A, Kaartinen J, Paaso J, Isokangas A, Paavola M. Towards Mineral Beneficiation Process Chain Intensification. The 5th workshop on Mining, Mineral and Metal Processing - IFAC MMM2018; 2018 Aug; Shanghai.
[5] Seppälä P, Sorsa A, Paavola M, Remes A, Ruuska J, Leiviskä K. Pilot Plant Simulation as a Tool for More Efficient Mineral Processing. IFAC Proceedings Volumes. 2014; 47(3): 11506-11511.

[6] Seppälä P, Sorsa A, Paavola M, Ruuska J, Remes A, Kumar H, Lamberg P, Leiviskä K. Development and Calibration of A Dynamic Flotation Circuit Model. Minerals Engineering. 2016; 96-97: 168-176.

[7] Paavola M. Optical Measurements for Flotation Monitoring and Diagnostics. 57th Annual British Conference on Non-Destructive Testing - NDT2018; 2018 Sep; Nottingham.

[8] Juuso E. Integration of Intelligent Systems in Development of Smart Adaptive Systems. International Journal of Approximate Reasoning. 2004; 35(3): 307-337.

[9] Koistinen A, Juuso E. Stress Monitoring of Underground Load Haul Dumper Front Axle with Intelligent Indices. IFAC-PapersOnLine. 2015; 48(17): 69-73.

[10] Lahdelma S, Juuso E. Signal Processing and Feature Extraction by Using Real Order Derivatives and Generalised Norms. Part 2: Applications. International Journal of Condition Monitoring. 2011; 1(2): 54-66.

[11] Nissilä J, Lahdelma S, Laurila J. Condition Monitoring of the Front Axle of a Load Haul Dumper with Real Order Derivatives and Generalised Norms. 11th International Conference on Condition Monitoring and Machinery Failure Prevention Technologies CM/MFPT2014; 2014; Manchester.

[12] Juuso E, Koistinen A. Decision Support for Risk Management in Mining Industry MMEA WP5.2.7.3 Report. 2015. Helsinki. ISBN 978-952-5947-87-8. 


\title{
Actuator Fault Tolerant Control for a Rotary Wing Aircraft
}

\author{
Emre Kiyak* , Ahmet Ermeydan \\ Avionics Department, Faculty of Aeronautics and Astronautics, Eskisehir Technical University, \\ Eskisehir, Turkey; *ekiyak@anadolu.edu.tr
}

SNE 28(3), 2018, 85 - 88, DOI: 10.11128/sne.28.sn.10422 Received: Sept. 15, 2016 (Selected EUROSIM Congress 2016 Postconf. Publ.), Revised July 30, Accepted: August 25, 2018 SNE - Simulation Notes Europe, ARGESIM Publisher Vienna, ISSN Print 2305-9974, Online 2306-0271, www.sne-journal.org

Abstract. Quadrotor is the one of the most popular rotary wing aircraft in control problems. There may be some problems in this system. In this case, quadrotor will not fly and do its duty effectively. In this study, a fault tolerant control strategy for a quadrotor is proposed in the presence of actuator faults. A linear mathematical model which is derived from a nonlinear model. The observer based state estimation approach is widely used in fault tolerant area. Here, this approach is used to detect and isolate faults in a quadrotor system. Generalized Observer Scheme (GOS) based Unknown Input Observer (UIO) is used for the isolation. Simulation results are presented to demonstrate the performance of the proposed fault tolerant control strategy.

\section{Introduction}

Mini-flying vehicles with four rotors which are called quadcopters have attracted many researchers in recent years. Vertical Take Off and Landing (VTOL), high maneuverability capabilities and indoor/outdoor navigation features make them popular. Besides that, by developing technology, especially in sensor devices, it is easy to obtain one of those vehicles. Therefore, a lot of studies implemented on these vehicles can be found in the literature. Many of them are generally related to different types of linear and nonlinear control techniques such as LQR (Bouabdallah et al, 2004), PID (Hoffman et al, 2010), backstepping (Madani and Benallegue, 2007) and nonlinear $\mathrm{H} \infty$ (Raffo et al, 2010) since quadcopters need autonomous stabilization systems to fly unlike airplanes. All of these works are focusing on healthy quadrotor systems. When a fault occurs in any of actuators, reliability should be maintained by detecting and isolating fault and modifying control scheme according to that fault case which is called fault tolerant control. There are various types of papers which present different solutions to this problem.

Sadeghzadeh et al. propose an active fault tolerant control method based on gain-scheduled PID in the presence of actuator faults for a quadrotor. An actuator fault detection system is presented using Thau's observer approach (Sadeghzadeh et al, 2012).

$\mathrm{Yu}$ et al. make a comparison between linear quadratic regulator and model predictive control for the height control of quadrotor with and without actuator faults (Yu et al, 2013).

A fuzzy gain-scheduled PID structure is proposed for the fault-tolerant control of a quadrotor when actuator faults occur (Amoozgar et al, 2012).

$\mathrm{He}$ and Zhao propose an Internal Model Control (IMC) design method based on quasi-LPV (Linear Parameter Varying) system. In their method, the nonlinear model is firstly transformed to the linear model based on the quasi-LPV method; then nonlinear motion function of the quadrotor is transformed to a transfer function matrix based on the transformation model from the state space to the transfer function. The performance of the controller proposed is tested by tracking for three reference trajectories with drastic changes and the simulation results indicate that the proposed control method has stronger robustness to parameters uncertainty and disturbance rejection performance (He and Zhao, 2015).

In this study, the problem of actuator fault detection, isolation and reconfiguration is addressed by an active fault tolerant method for a quadrotor. In detection and isolation part, the UIO method is used to find which actuator is faulty. In reconfiguration part, LQT switches to LQR with integral action to remove the steady-state error. The simulation study illustrates that the proposed actuator fault detection and isolation scheme is capable of detecting and identifying actuator failures in a variety of situations. The actuator faults are correctly detected and isolated for different conditions. 


\section{UIO Theory}

There are several model-based fault diagnosis methods in the literature, such as Kalman Filter based stochastic approach, observer-based approach, parity relation approach, parameter estimation approach. This study focuses on the UIO based fault detection and isolation of actuator faults. The main idea behind UIO approach is to estimate the state variables of the system utilizing mathematical model for generating residuals by subtracting the measured states from the estimated ones. In the fault isolation process, GOS is used to isolate the faulty actuator. This scheme consists of a bank of observers designed to make each residual to be sensitive to faults in all but one of the actuators.

The state space representation of a linear timeinvariant system with unknown input vector $d(t) \in$ $\mathbb{R}^{\mathrm{q} \times 1}$ can be described as following (Chen and Patton, 1999):

$$
\begin{aligned}
\dot{\mathrm{x}}(\mathrm{t})=\mathrm{Ax}(\mathrm{t}) & +\mathrm{Bu}(\mathrm{t})+\mathrm{Ed}(\mathrm{t}), \\
\mathrm{y}(\mathrm{t}) & =\mathrm{Cx}(\mathrm{t}),
\end{aligned}
$$

where $\mathrm{x}(\mathrm{t}) \in \mathbb{R}^{\mathrm{nx} 1}$ is the state vector, $\mathrm{u}(\mathrm{t}) \in \mathbb{R}^{\mathrm{mx} 1}$ is the input vector, $y(t) \in \mathbb{R}^{\mathrm{nx} 1}$ is the output vector of the aircraft model, $A \in \mathbb{R}^{\mathrm{nxn}}$ is system matrix, $B \in \mathbb{R}^{\mathrm{nxm}}$ is control distribution matrix, $E \in \mathbb{R}^{\text {nxq }}$ is unknown input distribution matrix and $C \in \mathbb{R}^{\mathrm{nxn}}$ is measurement distribution matrix.

UIO structure can be defined as follows:

$$
\begin{gathered}
\dot{\mathrm{z}}(\mathrm{t})=\mathrm{Fz}(\mathrm{t})+\mathrm{TBu}(\mathrm{t})+\mathrm{Ky}(\mathrm{t}), \\
\hat{\mathrm{x}}(\mathrm{t})=\mathrm{z}(\mathrm{t})+\mathrm{Hy}(\mathrm{t}),
\end{gathered}
$$

where $\hat{x}(t) \in \mathbb{R}^{n x 1}$ is the estimated state vector, $z(t) \in \mathbb{R}^{n x q}$ is the observation vector and $F, T, K, H \in$ $\mathbb{R}^{n x n}$ are the matrices to be designed so that error vector converges to zero. The error vector is defined as:

$$
e(t)=x(t)-\hat{x}(t)
$$

Provided that $\hat{\mathrm{x}}(\mathrm{t})$ in (5) is replaced by (4), the following yields:

$$
e(t)=(I-H C) x(t)-z(t) .
$$

Provided that the following conditions are satisfied and eigenvalues of the matrix $\mathrm{F}$ are selected in the open left half of the complex plane, the error goes to zero asymptotically:

$$
\begin{gathered}
(\mathrm{HC}-\mathrm{I}) \mathrm{E}=0, \\
\mathrm{~T}=\mathrm{I}-\mathrm{HC}, \\
\mathrm{F}=\mathrm{A}-\mathrm{HCA}-\mathrm{K}_{1} \mathrm{C}, \\
\mathrm{K}_{2}=\mathrm{FH}, \\
\mathrm{K}=\mathrm{K}_{1}+\mathrm{K}_{2} .
\end{gathered}
$$

To construct robust actuator fault isolation scheme, all sensors are accepted to be fault-free and system equation can be written as:

$$
\begin{gathered}
\dot{x}(t)=A x(t)+B^{i} u^{i}(t)+B^{i} f_{a}^{i}(t)+E^{i} d^{i}(t) \\
y=C x(t)
\end{gathered}
$$

where $b_{i} \in \mathbb{R}^{n}$ is the $i_{\text {th }}$ column of the matrix $B$, $B_{i} \in \mathbb{R}^{\mathrm{nx}(\mathrm{m}-1)}$ is obtained from the matrix $\mathrm{B}$ by deleting the $\mathrm{i}_{\text {th }}$ column $\mathrm{b}_{\mathrm{i}}, \mathrm{u}_{\mathrm{i}}$ is the $\mathrm{i}_{\mathrm{th}}$ component of $\mathrm{u}, \mathrm{u}_{\mathrm{i}} \in \mathbb{R}^{\mathrm{m}-1}$ is obtained from vector $u$ by deleting the $i_{\text {th }}$ component $\mathrm{u}_{\mathrm{i}}$, and

$$
E^{i}=\left[\begin{array}{ll}
E & b_{i}
\end{array}\right] ; d^{i}(t)=\left[\begin{array}{c}
d(t) \\
u_{i}(t)+f_{a i}(t)
\end{array}\right] .
$$

Based on the description above, UIOs and residual generators can be written as:

$$
\begin{gathered}
\dot{z}^{i}(t)=F^{i} z^{i}(t)+T^{i} B^{i} u^{i}(t)+K^{j} y(t) \\
r^{i}(t)=\left(I-C H^{i}\right) y(t)-C z^{i}(t) ; \quad \mathbf{l}=1,2 \ldots \mu
\end{gathered}
$$

\section{Equations Modelling of Quadrotor}

In this section, the nonlinear dynamics of the quadrotor is introduced and its linearization around equilibrium point is presented. Quadcopter movements, forces and coordinate frames are shown in Figure 1. $\left(\mathrm{x}_{\mathrm{i}}, \mathrm{y}_{\mathrm{i}}, \mathrm{z}_{\mathrm{i}}\right)$ and $\left(\mathrm{x}_{\mathrm{b}}, \mathrm{y}_{\mathrm{b}}, \mathrm{z}_{\mathrm{b}}\right)$ denotes inertial frame and body-fixed frame, respectively. $(\psi, \theta, \phi)$ refer to yaw, pitch and roll, respectively (Bresciani, 2008).

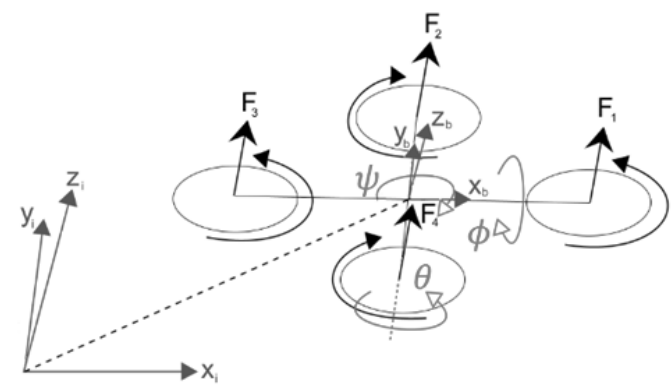

Figure 1. Quadrotor coordinate system. 
A nonlinear system can be expressed as follows:

$$
\dot{\mathbf{x}}=\mathrm{f}(\mathbf{x}, \mathbf{u})
$$

The state vector is chosen as following:

$$
\mathbf{x}=\left[\begin{array}{lllll}
x & y & z
\end{array} \theta \psi \dot{x} \dot{y} \dot{z} \dot{\phi} \dot{\theta} \dot{\psi}\right] \text {. }
$$

Since the quadrotor system is underactuated, four inputs can be defined as:

$$
\begin{gathered}
u_{1}=F_{1}+F_{2}+F_{3}+F_{4}, \\
u_{2}=l\left(F_{2}-F_{4}\right), \\
u_{3}=l\left(F_{1}-F_{3}\right), \\
u_{4}=\frac{d}{b}\left(F_{1}-F_{2}+F_{3}-F_{4}\right),
\end{gathered}
$$

where $b$ is thrust factor $\left(\mathrm{Ns}^{2}\right), d$ drag factor $\left(\mathrm{Nms}^{2}\right), l$ distance between propeller and center of gravity of quadrotor (m).

In this study, firstly, a quadrotor model is obtained in the simulation as seen Figure 2. Table 1 and 2 show gains for $\mathrm{X}, \mathrm{Y}$ and $\mathrm{Z}$ axis. Table 2 shows PID gains for $\mathrm{Z}$ axis.

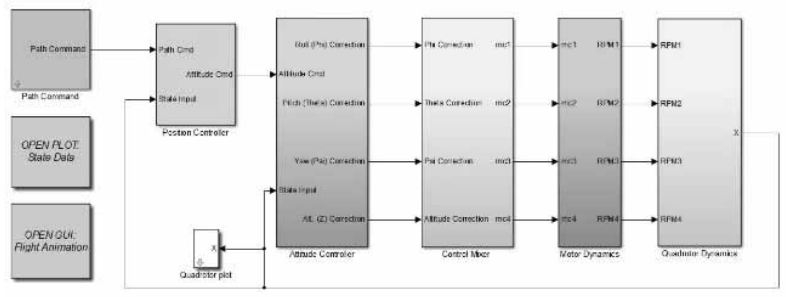

Figure 2. Nonlinear model of the quadrotor.

\begin{tabular}{|l|l|l|}
\hline & P & D \\
\hline X controller & 0.48 & 0.1 \\
\hline Y controller & 0.36 & 0.05 \\
\hline
\end{tabular}

Table 1. PD Gains for $X$ and $Y$ Axis.

\begin{tabular}{|l|l|l|l|}
\hline & P & I & D \\
\hline Z controller & 50 & 8 & 35 \\
\hline
\end{tabular}

Table 2. PID Gains for Z Axis.

Improved PID structure is proposed in Figure 3 for control. This PID structure presents the derivative action directly and prevents integral wind-up by limiting its maximum and minimum values. Saturation is introduced to integral part of PID controller defining a minimum and maximum value of which integral cannot go out. So it restores its linear behavior quickly.

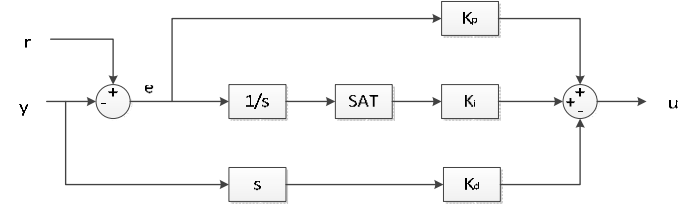

Figure 3. Improved PID structure.

\section{Results and Discussions}

It can be seen from the Figure 4 that LQT response is faster than LQR with integral action as expected due to integral effect but in the faulty case which is $10 \%$ throttle loss injected in $7 \mathrm{sec}$ of simulation time, the quadcopter with LQT controller tracks the given $\mathrm{X}$ and $\mathrm{Z}$ references with steady-state error. In contrary, LQR with integral action compensates steady-state error quickly. Y state is unaffected by the fault because the mathematical model used in the simulation is linear, so there is no coupling between channels.
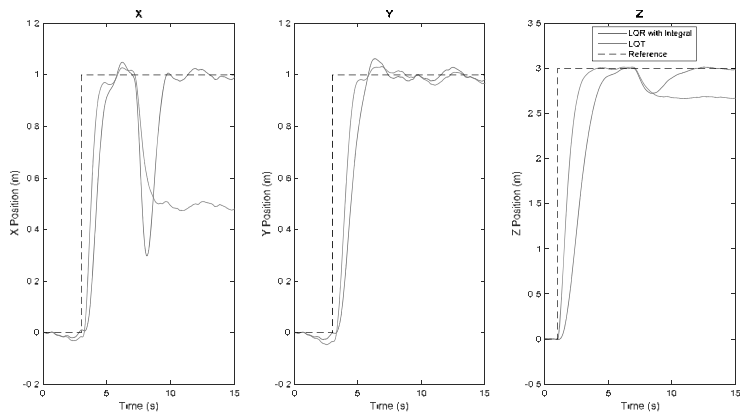

Figure 4. $X, Y$ and $Z$ response of LQT and LQR with integral with $10 \%$ fault on motor 1 .

The fault applied in the system is detected by UIO scheme. A bank of observers is designed based on GOS to isolate the fault in motor 2. Each observer is sensitive to a certain group of faults except one actuator. So motor 1 residual is nearly zero but remaining residuals are fired as presented in Figure 5.

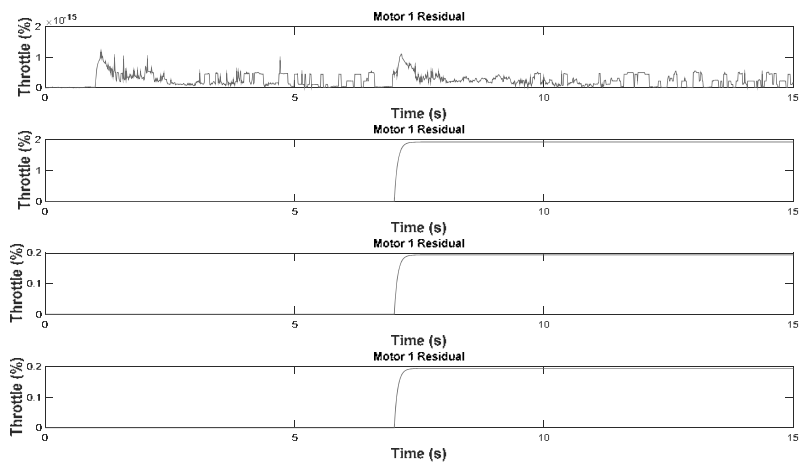

Figure 5. Residuals generated by UIO. 
After decision making by considering the structured residuals, LQR with integral action is engaged in the simulation instead of LQT. It can be easily seen in Figure 6 that the steady-state error is compensated quickly.
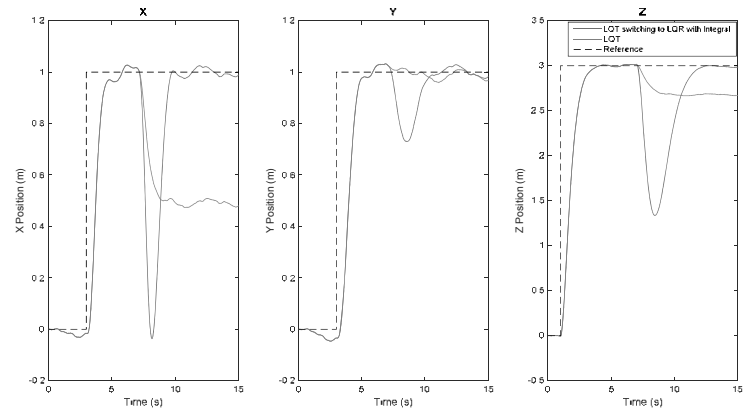

Figure 6. Height response of switching structure with $10 \%$ throttle fault on motor 1 .

\section{Conclusion}

In this study, a fault tolerant control method is introduced for the actuator faults in the quadrotor vehicle. The linear model of the quadrotor is derived from nonlinear equations. UIO is used as a method of detecting the fault and GOS to isolate it. Since LQT has no steady-state error in normal operation condition, there is no need to include integral effect when there is no fault. When it comes to faulty cases, it is seen that LQT could not compensate steady-state error. To eliminate the steady-state error, switching from LQT to LQR with integral action is performed. Results show that the proposed method represents fast response combining with the elimination of the error.

\section{References}

[1] Amoozgar MH, Chamseddine A, Zhang Y. FaultTolerant Fuzzy Gain-Scheduled PID for a Quadrotor Helicopter Testbed in the Presence of Actuator Faults, IFAC Conference on Advances in PID Control, Brescia, Italy, 2012.

[2] Bouabdallah S, Noth A, Siegwart R. PID vs LQ Control Techniques Applied to an Indoor Micro Quadrotor, IEEE/RSJ International Conference on Intelligent Robots and Systems, Vol. 3, pp.2451-2456, 2004.

[3] Bresciani T. Modelling, identification and control of a quadrotor helicopter, Msc Thesis, Lund University, Sweden. 2008.

[4] Chen J, Patton R. Robust Model-Based Fault Diagnosis for Dynamic Systems, Kluwer Academic Publishers, 1999.

[5] He Z, Zhao L. Quadrotor Trajectory Tracking Based on Quasi-LPV System and Internal Model Control, Mathematical Problems in Engineering, vol. 2015, pp.1-13, 2015.

[6] Henriques BSM. Estimation and Control of a Quadrotor Attitude, Msc Thesis, Universidade Tecnica de Lisboa, Portugal. 2011.

[7] Hoffman F, Goddemeier N, Bertram T. Attitude Estimation and Control of a Quadrocopter, IEEE/RSJ International Conference on Intelligent Robots and Systems, pp.1072-1077. 2010.

[8] Madani T, Benallegue A. Backstepping Control with Exact 2-Sliding Mode Estimation for a Quadrotor Unmanned Aerial Vehicle, IEEE/RSJ International Conference on Intelligent Robots and Systems, pp.141-146. 2007.

[9] Raffo GV, Ortega MG, Rubio FR. An Integral Predictive/Nonlinear $H_{\infty}$ Control Structure for a Quadrotor Helicopter, Automatica, Vol. 46, pp.29-39, 2010.

[10] Sadeghzadeh I, Mehta A, Chamseddine A, Zhang Y. Active Fault Tolerant Control of a Quadrotor UAV Based On Gain-Scheduled PID Control, 25th IEEE Canadian Conference on Electrical and Computer Engineering, pp.1-4. 2012.

[11] Yu B, Zhang Y, Minchala I, Qu Y. Fault-tolerant Control with Linear Quadratic and Model Predictive Control Techniques Against Actuator Faults in a Quadrotor UAV, Conference on Control and Fault-Tolerant Systems, France, pp.661-666, 2013. 


\section{Utilizing Optical Monitoring to Predict the Effluent Quality in the Activated Sludge Processes}

\author{
${ }^{1}$ Control Engineering, University Oulu; *jani.tomperi@oulu.fi
}

Jani Tomperi*

\begin{abstract}
The optical monitoring device was used for imaging industrial and municipal activated sludge processes. The results were utilized to predict the important effluent quality parameters (BOD, COD, N, P, SS) indicating the efficiency of the wastewater treatment processes. The optimal subsets of variables for each model were searched using mathematical variable selection methods. The models based on optical monitoring and process variables from the early stage of the treatment process can be used to predict the effluent quality hours in advance compared with traditional measurements, which enables the optimization of process control, keeping the process in a stable operating condition and avoiding environmental risks and excessive operation costs.
\end{abstract}

\section{Introduction}

A wastewater treatment process should efficiently remove oxygen-demanding substances, excessive nutrients and toxicants from wastewater. Both industrial and municipal wastewaters are most commonly treated in complex biological activated sludge processes (ASPs) where the operation of the treatment process is affected by several physical, chemical and microbiological factors. In an ASP, flocculation is in a critical role and the key element for the efficient operation of an ASP is a good bacterial balance in biomass, which is very sensitive to internal and external disturbances such as major changes in the quality and quantity of the influent.
The disturbances in the bacterial balance are most often shown as dysfunctional flocculation and settling properties. Recovering from the disturbances is slow which causes long-lasting challenges to process control and possible environmental damages as low-quality effluent is discharged to waterways [1-3].

More attention must be focused on the optimal operation of the wastewater treatment processes to meet the limitations to effluent discharges and keeping operating costs decent. Predictive information on the status of the process and the effluent quality enable the optimization of the process operation and thereby avoiding environmental risks and excessive operation costs. Conventional process measurements and expert knowledge, that are important in process operation, are, however, not adequate to give the early warnings of changes in the treated wastewater quality. Therefore, new measurement devices and methods are required.

Automatic optical monitoring of floc morphology characteristics in the ASP yields fast new objective information about the quality of the treatment process and reveals the reasons for settling problems. In addition, combined to predictive modelling, the quality of the treated wastewater is shown in advance, hours before problems occur and would be noticed by traditional process measurements [4-7]. This valuable predictive information can be used as assistance in optimizing the process control.

Study of utilizing the automatic optical monitoring of activated sludge process combined with mathematical variable selection and modelling have been carried out in the industrial and the municipal wastewater treatment processes, and are summarized in this paper. 


\section{Material and Methods}

\subsection{Industrial wastewater treatment plant}

The industrial wastewater treatment process treats in addition to the pulp making process wastewaters from two chemical processes located in the pulp and paper mill area. The average wastewater flow through the treatment process is around $30000 \mathrm{~m}^{3} /$ day. The collected data consisted of optical monitoring results and selected process measurements including the effluent quality parameters from a period of 13 consecutive months. The optical monitoring was carried out by regular but sparse intervals and therefore the dataset included only 54 measurement times.

\subsection{Municipal wastewater treatment plant}

The municipal WWTP treats mainly wastewaters from domestic sources $(85 \%$ of the influent flow). WWTP uses mechanical, biological and chemical processes to treat the wastewater of over 800,000 inhabitants. The average daily flow is $280,000 \mathrm{~m}^{3}$ of wastewater. The optical monitoring device was sited at one of the nine parallel activated sludge process lines. The collected data consisted of daily optical monitoring results, online process measurements, and various quality parameters that were measured by collecting grab samples only two to three times a week during a period of 16 months. Thus, the total amount of data was 94 measurement times.

\subsection{Optical monitoring and image analysis}

To replace a laborious, slow and subjective method to study wastewater samples manually using a microscope, a small-scale automatic optical monitoring device was designed especially for in-situ use [8]. The optical monitoring device was developed and tested in a laboratory and at a municipal wastewater treatment plant over an one-year period, and proved functional for reliable in-situ monitoring of floc morphology $[4,6]$.

The optical monitoring device (Figure 1) consists of the imaging unit, the sample handling unit and the control PC and electronics unit. The control PC and electronics unit controls the pump and valves synchronized with image acquisition. The wastewater samples taken from the aeration tank of ASP are diluded and pumped through the cuvette of the imaging unit. A cuvette is illuminated and imaged with a high resolution chargecoupled device (CCD) camera.

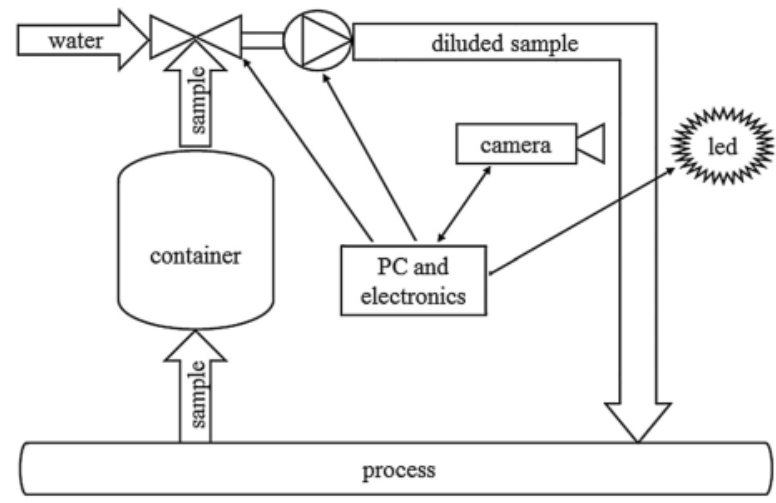

Figure 1: The online optical monitoring device for imaging activated sludge process [6].

The automated image analysis program analyzes the morphological parameters of flocs and filaments from the wastewater sample videos that consist of hundreds of images. The image analysis programme calculates and analyses various size (equivalent diameter, floc area, filament length, etc.) and shape (fractal dimension, form factor, roundness, etc.) parameters of each particle in each image. The parameters are calculated as an average of the values for individual objects over a single image. Image processing and analyses methods and the mathematical formulas of the calculated size and shape parameters are presented in detail in [8].

\subsection{Variable selection and modelling}

The measured optical monitoring variables were used together with the process measurements to develop predictive models for the traditional quality variables of treated wastewater including suspended solids (SS), eutrophication in waterways causing nitrogen $(\mathrm{N})$ and phosphorus (P), chemical oxygen demand (COD) and biochemical oxygen demand (BOD) that indicate the amount of dissolved oxygen required to oxidize the organic substances in wastewater [1]. All the data processing, variable selection and modelling were performed using Matlab (The MathWorks Inc.) and selfdeveloped scripts.

At first, dataset was inspected and unrealistic values were deleted and replaced with linear interpolation. Before variable selection and modelling, the dataset was scaled between $[-2,+2]$ using the nonlinear scaling method based on generalized moments, norms and skewness (presented in more detail in [9]). 
Five mathematical variable selection methods (correlation, stepwise, forward, genetic algorithm (GA), successive projections algorithm (SPA) + GA) that did not take into account any deterministic models or chemical or biological knowledge about the activated sludge process, were used to find the optimal subsets of input variables for the models. Variable selection is important step to reduce the number and choose the optimal input variables that have significant relationships with the output variable but are not strongly correlated to each other and do not include noise. Using too many input variables increase the risk to develop an over-fitted model which has an excellent training result but is not usable with a new upcoming data. For a very large dataset one variable selection method can be used for the variable elimination before the final variable selection by another method. The more detailed backgrounds of the above mentioned variable selection methods are presented for example in [6].

The quality of the developed model depends highly on the quality and length of the dataset. Data should include a sufficient number of samples and it should be fully representative of the full spectrum of all possible conditions. For efficient training and validation, both subsets of the data have to be long and representative enough of all possible conditions. Splitting the dataset to two subsets may cause a significant loss of data in training the model. Due to the small size of the dataset available in this study, a static split into the training and validation subsets of data was not a feasible approach. Instead, a 5-fold cross-validation was used to predict the fit of a model for a validation set without an explicit validation set. In k-fold cross-validation, the whole data is used for training and validating the model by randomly partitioning the dataset into $\mathrm{k}$ subsets of equal size and using k-1 parts of the data for training and one part for validation and repeating this $\mathrm{k}$ times until each of the subsets is used once as the validation data. Final estimation is produced by combining these $\mathrm{k}$ results of the folds $[10,11]$. In this study, multivariable linear regres- sion (MLR) was utilized to predict the output variable as a linear combination of selected input variables and the performance of the model was evaluated by the coefficient of determination $\left(\mathrm{R}^{2}\right)$ and Root Mean Square Error (RMSE).

\section{Results and Discussion}

The results of utilizing the automatic optical monitoring of activated sludge process combined with mathematical variable selection and modelling in the industrial [7] and municipal $[6,12]$ wastewater treatment plants are summarized in the following. It is important to bear in mind that the results based solely on a mathematical analysis may not accurately correspond the actual situation in the wastewater treatment process. The complexity of a wastewater treatment process easily causes quasicorrelations. A high correlation between variables not always mean strong real-world causality and there may be also many hidden factors that affect in the real process but are not shown in the data analysis due to the limited amount of data or measurements and due to the analysis method.

The best modelling results (industrial and municipal WWTP) are presented in Table 1 . In both studies, input variables selected by the GA method resulted the best models. However, for example forward selection, that is computationally much faster method that GA, yielded almost as good results. The behaviour of effluent COD model in the industrial WWTP is presented in Figure 2 and the behaviour of the effluent SS model in the municipal WWTP is presented in Figure 3. The results show that the models are not perfect but generally good and accurate to show the level and changes of the effluent quality variables in various operation conditions. The earlier studies have stated that based on the optical monitoring the settling problem in the industrial WWTP occurred during the study period was most likely caused by dispersed growth [13] and in the municipal ASP the poor settling was caused by filamentous bulking [4].

\begin{tabular}{lllllllllll}
\hline & BOD & \multicolumn{3}{c}{ COD } & & $\mathrm{N}$ & & $\mathrm{P}$ & & SS \\
& $\mathrm{R}^{2}$ & $\mathrm{RMSE}$ & $\mathrm{R}^{2}$ & $\mathrm{RMSE}$ & $\mathrm{R}^{2}$ & $\mathrm{RMSE}$ & $\mathrm{R}^{2}$ & $\mathrm{RMSE}$ & $\mathrm{R}^{2}$ & RMSE \\
\hline $\begin{array}{l}\text { Industrial WWTP } \\
\text { (GA subset) }\end{array}$ & 0.71 & 0.69 & 0.76 & 0.50 & 0.69 & 0.63 & 0.58 & 0.74 & 0.67 & 0.58 \\
$\begin{array}{l}\text { Municipal WWTP } \\
\text { (GA subset) }\end{array}$ & 0.55 & 0.64 & 0.55 & 0.64 & 0.63 & 0.61 & 0.69 & 0.52 & 0.79 & 0.47 \\
\hline
\end{tabular}

Table 1: The best modelling results for the industrial and municipal WWTP effluent quality parameters using input variables selected by GA. Modified from $[6,7]$. 
It was also discovered that according to the data analyses the municipal process is more temperature related than the industrial. The effluent quality has a clear seasonal pattern correlating the wastewater temperature $[6,7]$.

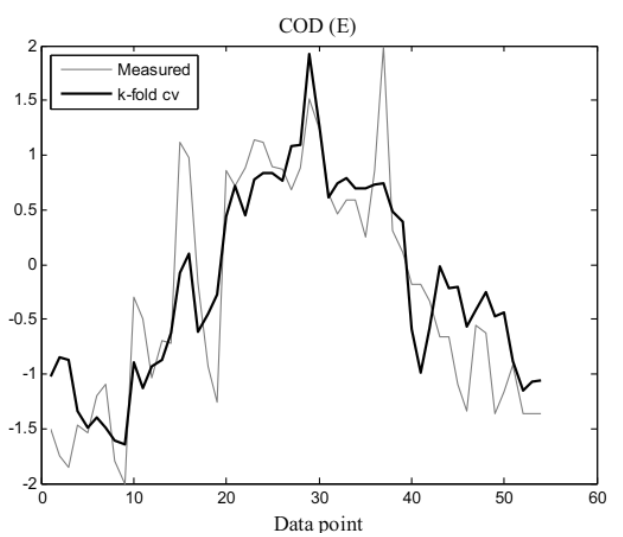

Figure 2: Model for effluent COD at the industrial WWTP [7].

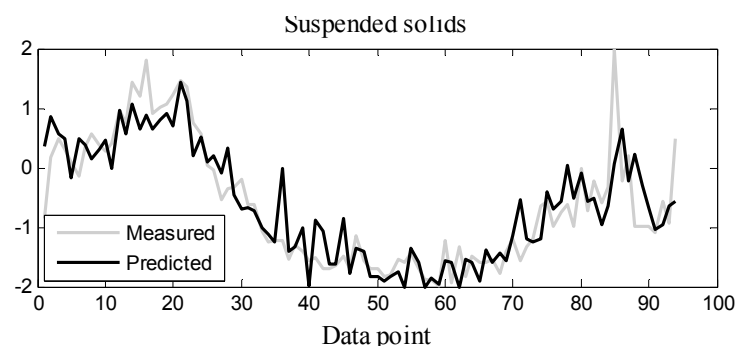

Figure 3: Model for effluent SS at the municipal WWTP [6].

\section{Conclusions}

The optical monitoring device is a valuable tool for monitoring the changes in floc morphology. The objective, continuous and fast method includes several morphological characterization variables and enables observing the changes in the wastewater quality. Combined to predictive modelling it has potential to be utilized in controlling the process, keeping the process in stable operating conditions and avoiding environmental risks.

\section{References}

[1] Tchobanoglous G, Burton FL, Stensel HD. Wastewater engineering: treatment and reuse. 4th ed. Boston: McGraw-Hill Education; 2003. 1819 p.

[2] Amaral AL, Ferreira EC. Activated sludge monitoring of a wastewater treatment plant using image analysis and partial least squares regression. Anal. Chim. Acta. 2005;544:246-253.
[3] Mesquita DP, Dias O, Amaral AL, Ferreira EC. Monitoring of activated sludge settling ability through image analysis: validation on full-scale wastewater treatment plants. Bioprocess Biosyst Eng. 2009;32:361-367.

[4] Koivuranta E, Stoor T, Hattuniemi J, Niinimäki J. Online optical monitoring of activated sludge floc morphology. J Water Process Eng. 2015;5:28-34. doi:10.1016/j.jwpe.2014.12.009

[5] Tomperi J, Koivuranta E, Kuokkanen A, Juuso E, Leiviskä K. Real-time optical monitoring of the wastewater treatment process. Environ Technol. 2016;37(3):344-351. doi:10.1080/09593330.2015.1069898

[6] Tomperi J, Koivuranta E, Kuokkanen A, Leiviskä K. Modelling effluent quality based on a real-time optical monitoring of the wastewater treatment process. Environ Technol. 2017;38(1):1-13. doi:10.1080/09593330.2016.1181674

[7] Tomperi J, Koivuranta E, Leiviskä K. Predicting the effluent quality of an industrial wastewater treatment plant by way of optical monitoring. Journal of Water Process Engineering. 12017;6:283-289. doi:10.1016/j.jwpe.2017.02.004

[8] Koivuranta E, Keskitalo, Haapala A, Stoor T, Sarén M, Niinimäki J. Optical monitoring of activated sludge flocs in bulking and non-bulking conditions. Environ Technol. 2013;34(5-8):679-686. doi:10.1080/09593330.2012.710410

[9] Juuso E. Integration of intelligent systems in development of smart adaptive systems: linguistic equation approach. Acta Universitatis Ouluensis. Series C, Technica 476. Oulu. Dissertation. 258. 2013. http://urn.fi/urn:isbn:9789526202891

[10] Rao RB, Fung G, Rosales R. On the dangers of crossvalidation: an experimental evaluation. In SIAM Data Mining, Philadelphia, PA. 2008.

[11] Arlot S, Celisse A. A survey of cross-validation procedures for model selection. Stat Surv. 2010;4:40-79.

[12] Tomperi J, Leiviskä K. Comparison of modelling accuracy with and without exploiting automated optical monitoring information in predicting the treated wastewater quality. Environ. Technol. 2018;39(11):1442-1449. doi:10.1080/09593330.2017.1331267.

[13] Koivuranta E, Keskitalo J, Stoor T, Hattuniemi J, Sarén M, Niinimäki J. A comparison between floc morphology and the effluent clarity at a full-scale activated sludge plant using optical monitoring. Environ. Technol. 2014;35(13): 1605-1610. doi:10.1080/09593330.2013.875065.

Note. The data were collected during the Measurement, Monitoring and Environmental Efficiency Assessment (MMEA) research programme. Aki Sorsa (D.Sc. (Tech.)) is acknowledged for help in variable selection issues and Elisa Koivuranta (D.Sc. (Tech.)) is acknowledged for producing the original optical monitoring data. 


\title{
Fault Tolerant Control for a Rotary Wing Aircraft
}

\author{
Gulay Unal*, Emre Kiyak \\ Avionics Department, Faculty of Aeronautics and Astronautics, Eskisehir Technical University, \\ Eskisehir, Turkey; *giyibaka@anadolu.edu.tr
}

SNE 28(3), 2018, 93 - 96, DOI: 10.11128/sne.28.sn.10424 Received: Sept. 15, 2016 (Selected EUROSIM Congress 2016 Postconf. Publ.), Revised July 30, Accepted: August 25, 2018 SNE - Simulation Notes Europe, ARGESIM Publisher Vienna, ISSN Print 2305-9974, Online 2306-0271, www.sne-journal.org

Abstract. In this study, a fault tolerant control strategy for a rotary wing aircraft is proposed in the presence of actuator faults. A linear mathematical model which is derived from the nonlinear model by using MATLAB/Simulink. An observer based state estimation approach is widely used in fault tolerant area. Generalized Observer Scheme (GOS) based on Unknown Input Observer (UIO) is utilized to detect and isolate the actuator faults. In fault-free conditions, Linear Quadratic Tracking (LQT) is preferred to stabilize the quadrotor to obtain a faster system response. When it comes to a faulty case, LQT cannot handle the compensation of steady-state error owing to power loss in the actuator. Therefore Linear Quadratic Regulator (LQR) with integral action is selected by the fault diagnosis unit to compensate steady-state error due to the actuator fault. Simulation results are presented to demonstrate the performance of the proposed fault tolerant control strategy.

\section{Introduction}

Mini-flying vehicles with four rotors which are called quadcopters have attracted many researchers in recent years.

He and Zhao adopt the attitude controller is a nonlinear controller for a quadrotor helicopter. It consists of a linear control part and a nonlinear control part, where the linear control part is a PD controller which parameters were tuned by Ziegler-Nichols rules, and the nonlinear control part is a feedback linearization item which converts a nonlinear system into a linear system. The linear parts are, respectively, PID controller with the PID controller parameters tuned by Ziegler-Nichols rules and $\mathrm{PD}$ controller with the $\mathrm{PD}$ controller parameters tuned by Genetic Algorithm.
They claim the attitude controller adopted is highly robust and the controller design method is a simple and practical one in engineering (He and Zhao, 2014).

Zhang et al. give a tutorial of the platform configuration, methodology of modeling, comprehensive nonlinear model, the aerodynamic effects, and model identification for a quadrotor (Zhang et al, 2014).

Jeong et al. propose a multilayered quadrotor control method that can move the quadrotor to the desired goal while resisting disturbance. Their proposed control system is modular, convenient to design and verify, and easy to extend. It comprises three layers: a physical layer, a displacement control layer, and an attitude control layer (Jeong et al, 2014).

Yang et al. built the affine nonlinear model for the quadrotor helicopter attitude system. With the consideration of unknown actuator faults such as the loss of effectiveness and lock-in-place, an adaptive fuzzy controller based on the sliding mode has been proposed to realize the direct self-repairing control for this attitude system. Through a series of simulations, it has verified the availability of the proposed method which can make the system recover from the actuator faults and has good tracking performance (Yang et al, 2014).

Zhang et al. present the newest research on quadrotor. First, they analyzed the actuator dynamic and aerodynamic effect of the quadrotor. Then, they established a reliable nonlinear dynamic model of the quadrotor. They designed a series of PID controllers with feedforward control and feedback linearization using the backstepping method. They claim real experiments were executed and the effectiveness of the proposed dynamic model and control method is demonstrated by the experimental result (Zhang et al, 2014).

Sadr et al. consider a quadrotor with a cablesuspended load with eight degrees of freedom. The purpose of the study is to control the position and attitude of the quadrotor on a desired trajectory in order to move the considered load with a constant length of cable (Sadr et al, 2014). 
An et al. propose a sliding mode observer design framework based on the Lie group method of numerical integration on manifolds, and they design a SecondOrder Geometric Sliding Mode Attitude Observer for the angular velocity estimation of quadrotor attitude (An et al, 2013).

Pipatpaibul and Ouyang propose a trajectory tracking control of UAVs utilizing online iterative learning control (ILC) methods. They claim simulation results prove the ability and effectiveness of the online ILCs to perform successfully certain missions in the presence of disturbances and uncertainties (Pipatpaibul and Ouyang, 2013).

\section{Control System of the Quadrotor}

In this study, firstly, a quadrotor model is obtained in the simulation as seen Figure 1. Secondly, a linear model is transformed from this nonlinear model. Two controllers, LQT and LQR with integral action, are designed to stabilize the quadrotor system. After the fine tuning of the controllers, $\mathrm{X}, \mathrm{Y}$ and $\mathrm{Z}$ response of the system are shown as in Figure 4-9.

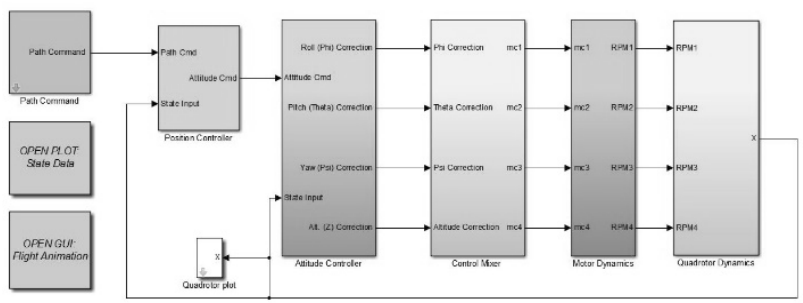

Figure 1. Nonlinear model of the quadrotor

The conventional PID structure consists of proportional, integral and derivative contributes as shown in Figure 2.

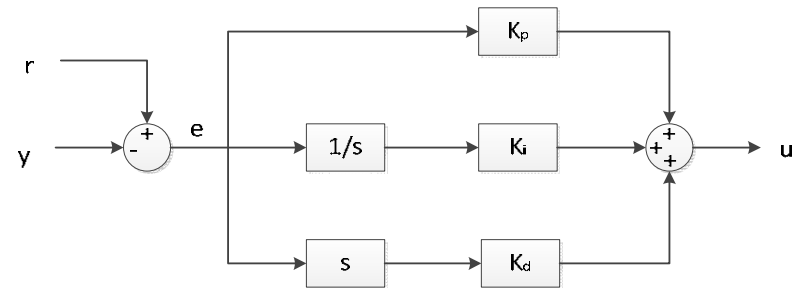

Figure 2. Conventional PID structure.

Equation

$$
u(t)=K_{p} e(t)+K_{i} \int_{0}^{t} e(v) d v+K_{d} \frac{d e(t)}{d t}
$$

Here, $\mathrm{u}$ is the controller output, e is the error between reference value ( $r$ ) and sensor value $(y), K_{p}$ is the proportional coefficient, $\mathrm{K}_{\mathrm{i}}$ is the integral coefficient and $K_{d}$ is the derivative coefficient.

Conventional PID structure has two main disadvantages. When the reference is a step input, the output of the derivation will be an impulse which can saturate the actuators since the derivative action is computed from the error. When the integral value is high and the error switches its sign, it takes a lot of time to restore its linear behavior. This problem is called integral wind-up. To overcome the problems described above, improved PID structure is proposed in Figure 3.

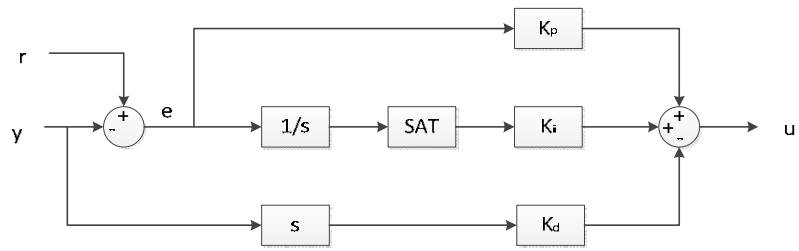

Figure 3. Improved PID structure

\section{Simulation Results}

As seen in Figure 4 and 5, simulating the model with a PD controller was an effective control solution. Here, $\mathrm{X}$ $=2 \mathrm{~m}$ for $4 \mathrm{sec}$. and $\mathrm{Y}=2 \mathrm{~m}$ for $6 \mathrm{sec}$. are used for reference input. The system is stable for other input values. Here, linear and nonlinear models show similar performances for inputs. There are no steady state errors. Table 1 shows $\mathrm{PD}$ gains for $\mathrm{X}$ and $\mathrm{Y}$ axis.

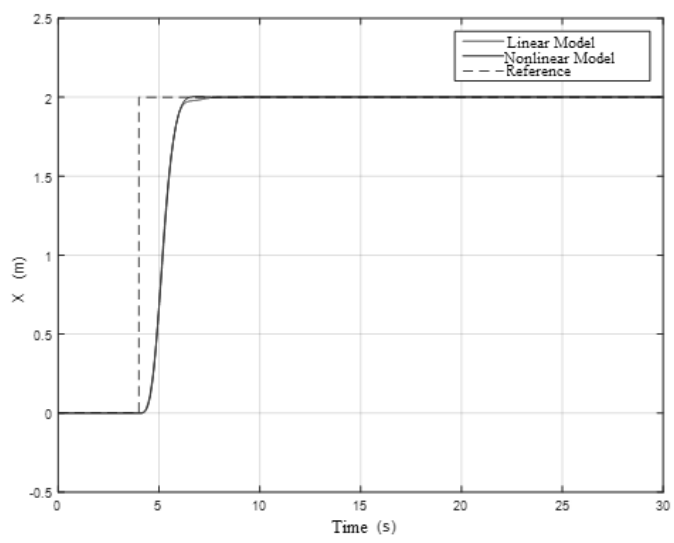

Figure 4. PD control for $\mathrm{X}$ axis.

demonstrates traditional PID. 


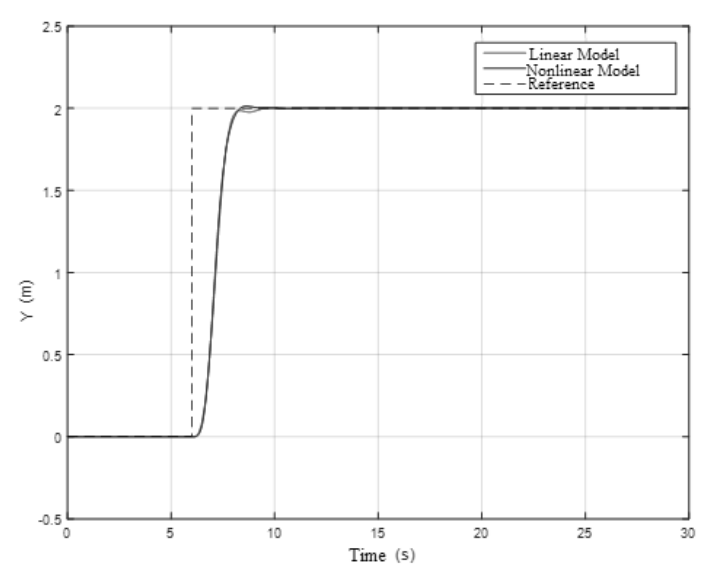

Figure 5. PD control for $\mathrm{Y}$ axis.

\begin{tabular}{|l|l|l|}
\hline & P & D \\
\hline X Controller & 0.48 & 0.1 \\
\hline Y Controller & 0.36 & 0.05 \\
\hline
\end{tabular}

Table 1. PD Gains for $\mathrm{X}$ and $\mathrm{Y}$ Axis

As seen in Figure 6, simulating the model with a PID controller was an effective control solution. Here, $Z=4 \mathrm{~m}$ for $0 \mathrm{sec}$. is used for reference input. Here, the linear model is faster than the nonlinear model. Both of them have maximum overshoot but both of them are stable and there are no steady state errors. Table 2 shows PID gains for $\mathrm{Z}$ axis.

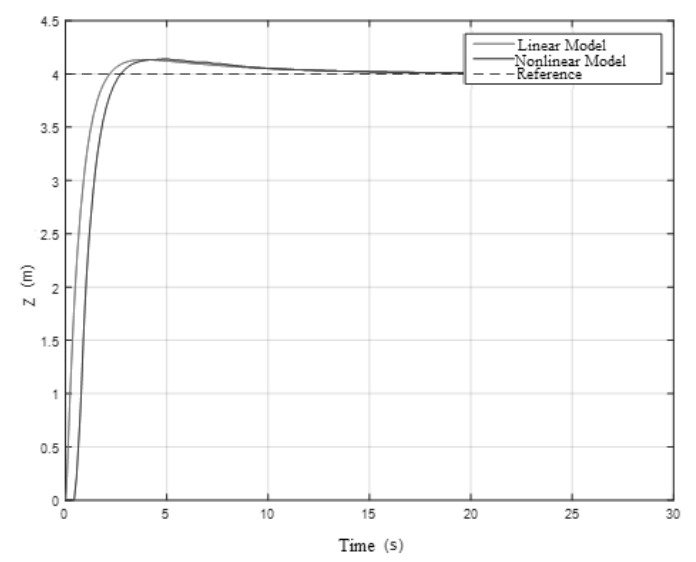

Figure 6. PID control for Z axis.

\begin{tabular}{|l|l|l|l|}
\hline & P & I & D \\
\hline Z Controller & 50 & 8 & 35 \\
\hline
\end{tabular}

Table 2. PID Gains for Z Axis

As seen in Figure 7, yaw angle is used 30 degree for 8 sec. for reference input. Here, linear model was faster than nonlinear model. Table 3 shows PID gains for yaw controller.

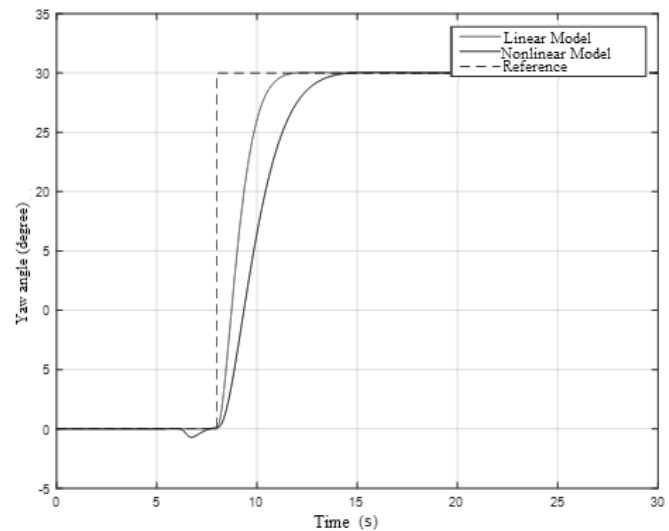

Figure 7. PID control for Z axis.

\begin{tabular}{|l|l|l|l|}
\hline & P & I & D \\
\hline Yaw Controller & 2 & 0 & 4.14 \\
\hline
\end{tabular}

Table 3. Yaw Controller Gains

As seen in Figure 8 and 9, both the linear and nonlinear model were nearly similar performances. The PID gains of the pitch and roll controller are shown in Table 4.

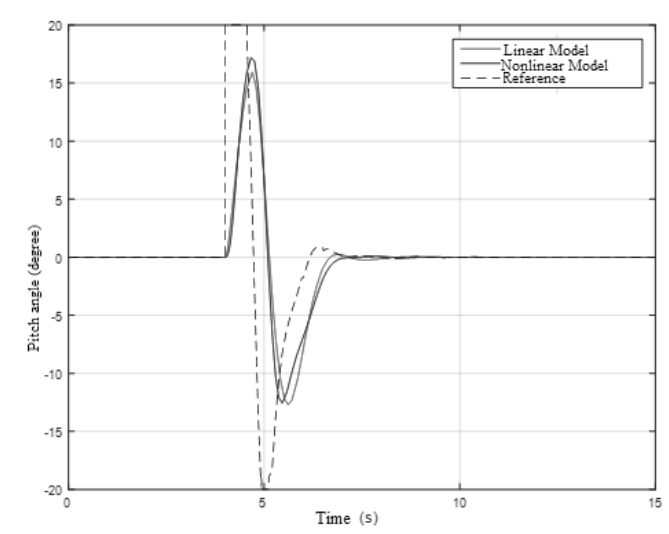

Figure 8. PID control for Z axis.

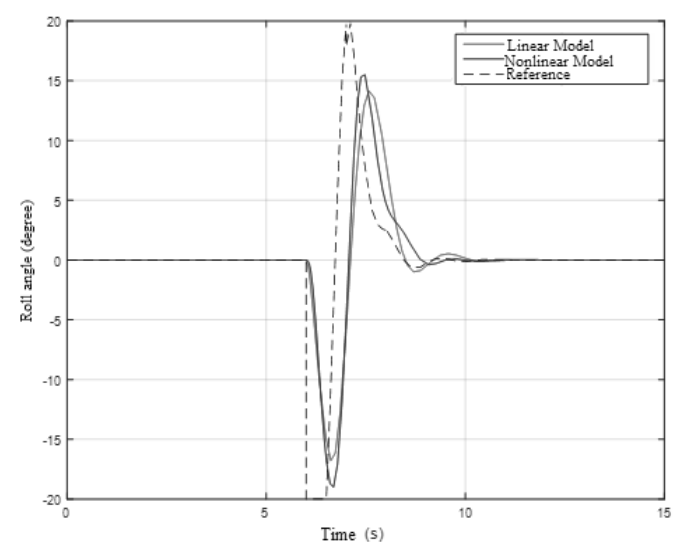

Figure 9. PID control for Z axis. 


\begin{tabular}{|l|l|l|l|}
\hline & P & I & D \\
\hline Pitch Controller & 3.3 & 0.5 & 1.5 \\
\hline Roll Controller & 3.3 & 0 & 1.2 \\
\hline
\end{tabular}

Table 4. Pitch and Roll Controller Gains.

\section{Conclusion}

In this study, an active fault tolerant control method is introduced for the actuator faults in the quadrotor vehicle. The linear model of the quadrotor is derived from nonlinear equations. This model is utilized in simulating actuator faults. The unknown input observer is used as a method of detecting the fault and GOS to isolate it. Since LQT has no steady-state error in normal operation condition, there is no need to include integral effect when there is no fault. When it comes to a faulty case, it is seen that LQT could not compensate steady-state error. To eliminate the steady-state error, switching from LQT to LQR with integral action is performed. Results show that the proposed method represents fast response combining with the elimination of the error.

\section{References}

[1] He, Z., L. Zhao, A Simple Attitude Control of Quadrotor Helicopter Based on Ziegler-Nichols Rules for Tuning PD Parameters, The Scientific World Journal, vol. 2014, pp.1-13, 2014.

[2] Zhang, X., X. Li, K. Wang, Y. Lu, A Survey of Modelling and Identification of Quadrotor Robot, Abstract and Applied Analysis, vol. 2014, pp.1-16, 2014.

[3] Jeong, H. J., M. Hwang, H. Jung, Y. G. Ha, Mathematical Modeling of a Multilayered Drift-Stabilization Method for Micro-UAVs Using Inertial Navigation Unit Sensor, Journal of Applied Mathematics, vol. 2014, pp.1-11, 2014.

[4] Yang, H., B. Jiang, K. Zhang, Direct Self-Repairing Control for Quadrotor Helicopter Attitude Systems, Mathematical Problems in Engineering, vol. 2014, pp.111, 2014.

[5] Zhang, D., H. Qi, X. Wu, Y. Xie, J. Xu, The Quadrotor Dynamic Modeling and Indoor Target Tracking Control Method, Mathematical Problems in Engineering, vol. 2014, pp.1-9, 2014.

[6] Sadr, S., S. A. A. Moosavian, P. Zarafshan, Dynamics Modeling and Control of a Quadrotor with Swing Load, Journal of Robotics, vol. 2014, pp.1-12, 2014.

[7] An, H., J. Li, J. Wang, J. Wang, H. Ma, Second-Order Geometric Sliding Mode Attitude Observer with Application to Quadrotor on a Test Bench, Mathematical Problems in Engineering, vol. 2013, pp.1-12, 2013.

[8] Pipatpaibul, P., P. R. Ouyang, Application of Online Iterative Learning Tracking Control for Quadrotor UAVs, ISRN Robotics, vol. 2013, pp.1-20, 2013. 


\title{
Simplified Mechanistic Model of the Multiple Hearth Furnace for Control Development
}

\author{
J. V. Gomez Fuentes*, S.-L. Jämsä-J ounela \\ Aalto University, School of Chemical Technology, Research Group on Process Control and Automation, \\ P.O.Box 16100, FI-00076, Aalto, Finland; *jose.gomezfuentes@aalto.fi
}

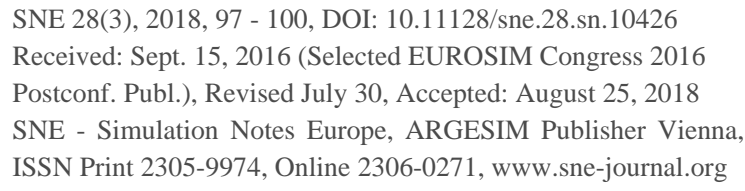

SNE 28(3), 2018, 97 - 100, DOI: 10.11128/sne.28.sn.10426 Received: Sept. 15, 2016 (Selected EUROSIM Congress 2016 Postconf. Publ.), Revised July 30, Accepted: August 25, 2018 SNE - Simulation Notes Europe, ARGESIM Publisher Vienna, ISSN Print 2305-9974, Online 2306-0271, www.sne-journal.org

Abstract. This paper presents the simplified mechanistic model of a Multiple Hearth Furnace (MHF), developed for process control implementation. The detailed mechanistic model of the MHF and its solving procedure are introduced. Based on the detailed model, the simplified model is developed in the nonlinear Hammerstein-Wiener form, which defines a specific type of nonlinear state space models suitable for example for Model Predictive Control (MPC) implementation.

The simplified model aims to preserve the key physicalchemical phenomena taking place in the furnace and to reproduce the nonlinear dependencies between the input and output variables. Finally, the paper presents the simulation results to compare the mechanistic and the simplified models. The comparison confirms that the dynamics of the simplified model accurately follows the mechanistic model outputs.

\section{I ntroduction}

Furnaces, such as the rotary kilns and multiple hearth furnaces, are widely used in industry for the calcination of clay minerals, such as kaolin. However, these processes continue to provide challenges in maintaining efficient process operations.

In particular, it is hard to control the final product quality, due to the difficulty in measuring the product characteristics, the solid temperature profile in the furnace, and the rates of the calcination reactions.

Instead, the existing control systems mostly rely on the gas temperature measurements and traditional control implementations, such as PID.
This strategy, however, does not allow achieving stable solid phase temperature profile and uniform product quality. In contrast, a Model Predictive Control (MPC), based on a model describing the physicalchemical phenomena in the furnace, would be able to stabilize the solid temperature and minimize the product quality variations.

\section{Process Description}

This paper considers a multiple hearth furnace used for kaolin calcination, having the counter-current solid and gas flows. The furnace has eight hearths, and eight burners, combusting natural gas to provide the heat necessary for the calcination reactions, are located in hearths 4 and 6 . The amount of air flow, supplied to the burners for the gas combustion, is calculated based on the stoichiometric ratio. The burners are placed with a tangential alignment.

Kaolin is supplied to the first hearth located at the top of the furnace. In the calciner, the material is moved by the metal plates, called blades, which are attached to the rotating rabble arms, designed with the intention of transporting the material outwards on even-numbered hearths and inwards on odd-numbered hearths. The kaolin traversing the even numbered hearths moves outward to descend through the holes at the outside border of the hearth, while in the odd-numbered hearths kaolin falls to the next hearth through a single annulus located around the shaft carrying the rabble arms.

The temperature of the solid increases as it travels down through the furnace and reaches its maximum in Hearth 6. Kaolinite transforms to metakaolin in the hearths 3, 4 and 5 at the temperature between 400-700 ${ }^{\circ} \mathrm{C}$. The metakaolin is released from hearth 5 at a temperature approximately $800{ }^{\circ} \mathrm{C}$, which continues elevating in the hearth 6 , where the transformation of metakaolin to the Al-Si spinel phase occurs [1]. 
Thus, the main objective of the hearth 6 is to increase the temperature in order to facilitate the absorption of aluminum into the silica phase. The control of temperature in the hearth 6 is essential to avoid overheating, which may result in the undesired formation of a more crystalline material that may generate some abrasion problems. The temperature of the solids begins to decrease in the hearths 7 and 8 , and the product leaves from the hearth 8 through two discharge holes at a temperature of $750{ }^{\circ} \mathrm{C}$.

\section{Dynamic Model of the MHF}

This section describes the mechanistic model of the MHF developed by Eskelinen et.al.[2]. The modeling equations are developed for the six parts of the MHF: the gas phase, solid bed, central shaft, walls, rabble arms, and the cooling air. The model comprises the calcination reaction kinetics, the mass and energy balances, the transport phenomena in the parts of the MHF, as well as additional equations describing the temperature dependent parameters, more details can be found in [3].

The following assumptions have been made to simplify the model development. The solid bed in the hearths is split into four or five homogenous annular volumes, depending on the rabble arm configuration. The volumes are assumed to be equal in mass content and radial direction. The mixing model, describing the solids movement in the hearths, assumes that one shaft rotation disseminates a part of the volume contents to the neighbor volumes. Thus, the solid mass distribution between the volumes of hearth $j$ can be calculated after one shaft rotation as follows:

$$
m_{t+1}^{j}=D_{j} \cdot\left(m_{t}^{j}-R_{r, t}^{j}\right)+m_{f e e d, t}^{j}
$$

Where $m_{f e e d, t}^{j}$ and $R_{r, t}^{j}$ connote the feed and the mass loss in the solid phase in Hearth $j$. The mixing matrix $D_{j}$ is used to transform the distribution of solids $m_{t}^{j}$ in Hearth $j$ after one central shaft rotation.

Specifically, the column $i$ of the matrix denotes the distribution of volume $i$ contents between the volumes of the hearth.

\section{Model Simplification}

This section describes the simplified model developed based on the mechanistic model presented in Section 2. A simplification of the mechanistic model is designed, describing the dynamics and the nonlinear behavior of the system separately. In more details, the simplified model is expressed as a Hammerstein-Wiener model (HWM), decomposing the model in blocks containing the nonlinearities in static form and the linear dynamics. The linear block, enclosing the dynamics of the process, is preceded and followed by a static non-linear blocks.

The dynamics of the MHF includes the very fast component related to the gas phase, and the slower component representing the solid state. For MPC implementation, the temperature of the solid has to be described dynamically. Furthermore, as the temperature of the inner layer of the walls has a direct effect on the solid-walls heat exchange, it is also considered as a model state. The simplified model is implemented as following:

$$
\begin{gathered}
x_{t+1}=a x_{t}+(1-\alpha) F\left(u_{t}\right) \\
y_{t}=G\left(u_{t}, x_{t}\right)
\end{gathered}
$$

where $u_{t}$ is a vector containing the process inputs (kaolin feed rate, gas flows to the Hearths 4 and 6), $x_{t}$ is the state vector contains the temperature of the solids in each volume of the furnace and the internal wall temperature in the hearths, $y_{t}$ contains the gas phase temperature next to the walls in the hearths, $\alpha$ is the time constant parameter of the linear dynamic part of the modeling equations. The time constant $\alpha$ is obtained for each modeling equation by identification performed using the MATLAB ${ }^{\circledR}$ identification toolbox. $F\left(u_{t}\right)$ is a static nonlinear function calculating the steady state of the furnace using the process input values. In order to implement the first function $F\left(u_{t}\right)$, a look up table has been created by running the mechanistic model simulations with different process inputs. The obtained values are interpolated as follows:

$$
\mathrm{F}\left(\mathrm{u}_{\mathrm{t}}\right)=\sum_{i=1}^{5} \sum_{j=1}^{5} \sum_{k=1}^{5} b_{i, j, k} h_{i}^{x}\left(F_{K}\right) h_{j}^{y}\left(F_{g 4}\right) h_{k}^{z}\left(F_{g 6}\right)
$$

where $b_{i, j, k}$ are the values from the look-up table and the piecewise linear basis functions $h_{i}^{x}, h_{j}^{y}$ and $h_{k}^{z}$ have been used for the interpolation. 
The second function $G\left(u_{t}, x_{t}\right)$, involved in the modeling equations (2), calculates the gas temperature profile next to the walls in the Hearths based on the current furnace state $x_{t}$ and the process inputs $u_{t}$. The function $G\left(u_{t}, x_{t}\right)$ is implemented by solving the energy balance for the gas phase derived from the mechanistic model.

\section{Simulation Results}

The simulation study has been conducted to evaluate the performance of the simplified model by comparing its predictions with the results of the detailed mechanistic model. Input series have been designed for the openloop tests to compare the dynamic response of the models. The shaft rotation period is used as the sampling time in the simulations, according to how it was made by the mechanistic model in [2]. The tests signals include a sequence of step and ramp changes in the input variables, including the kaolin feed rate, total gas flow ratio to the feed, and the ratio of hearth 4 gas flow to the total gas flow.

The results of the simplified model are shown as dashed lines, whereas the outputs of the mechanistic model are given as solid lines in the Figures 1 and 2, providing the simulation results [4]. The comparison of the gas phase temperature shows excellent simplified model accuracy for all hearths, specifically in hearths 1 to 4 and 7-8. For the solid phase temperature, presented in Figure 2, the comparison also confirms the accuracy of the simplified model, with the best results similarly achieved in hearths 1 to 4 and 7-8.

The quantification reference for the evaluation of the simulation results shown in Figure 1 and 2 is the coefficient of determination, denoted as $\mathrm{R}^{2}$. This coefficient provides a simple way to discern if the simplified model is accurately reproducing the results of the detailed mechanistic model.

In particular, the $\mathrm{R}^{2}$ values for hearths 1 to 4 and 7-8 are above 0.8 in almost all cases, while the captured variance statistic calculated for the results in hearths 5 and 6 is below 0.7 .

The reason for the elevated error of the simplified model obtained in Hearths 5 and 6 is the exothermic reaction actively ongoing in hearth 6 and complicating the temperature prediction in the hearth.

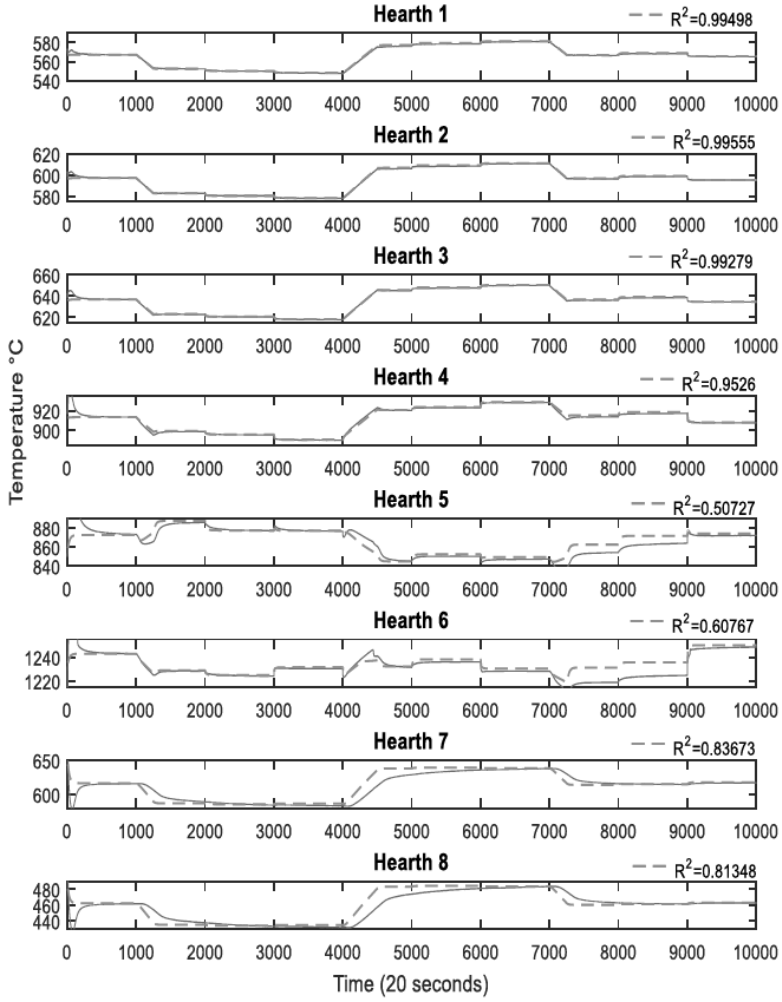

Figure 1. Comparison of models gas phase temperature.
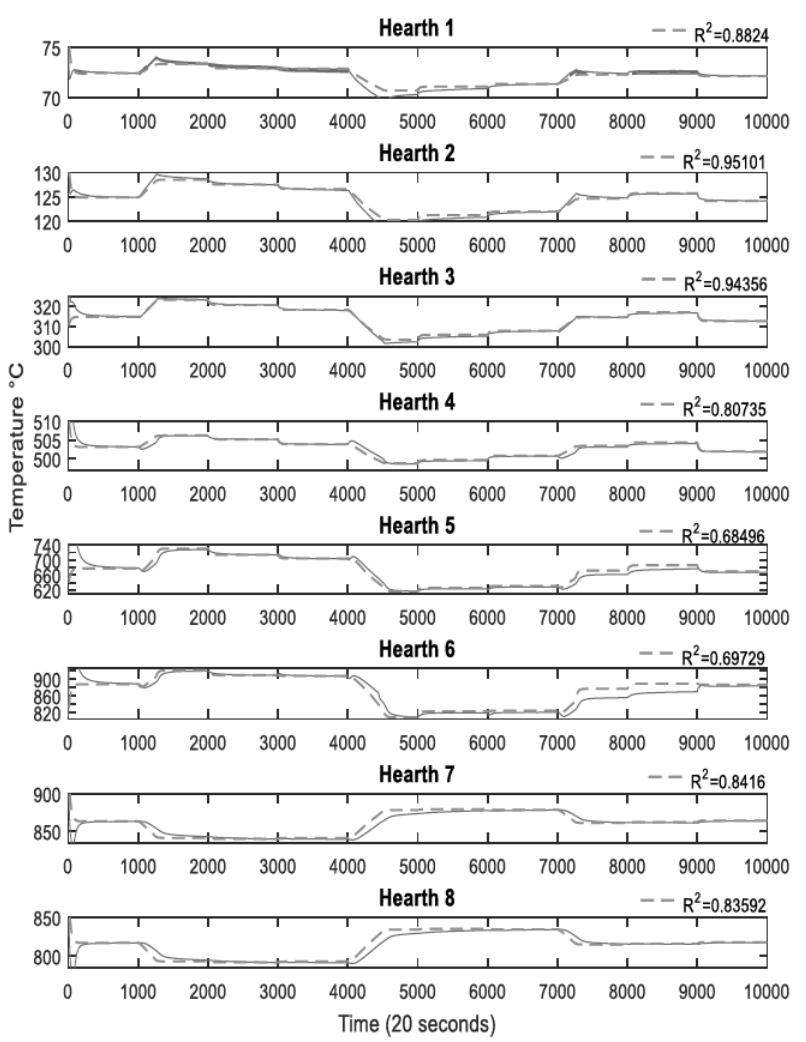

Figure 2. Comparison of models solid phase temperature. 


\section{Conclusions}

A simplified model of a MHF was developed in this paper, based on a mechanistic model developed previously. The simplified model is implemented in the form of Hammerstein-Wiener nonlinear dynamic model with a reduced number of dynamic equations and a state space structure, thus making model based control implementation possible. The results of the simplified model are compared against the mechanistic model and are found to be remarkable. For the gas and the solid phases, the results present higher accuracy, especially in the first four hearths and the last two hearths. The reason for the elevated simplified model error in hearths 5 and 6 can be the reaction occurring in hearth 6 , which is unpredictable. This issue will be addressed in the future research to improve the simplified model performance. The simplified model obtained in the paper enables implementation of different MPCs, such as EMPC, in the developed simulation environment of the MHF.

\section{References}

[1] Thomas RE. High Temperature Processing of Kaolinitic Materials. 2010.

[2] Eskelinen A et al. "Dynamic modeling of a multiple hearth furnace for kaolin calcination," AIChE J., vol. 61, (11), pp. 3683-3698, 2015.

[3] Eskelinen A et al. "Dynamic modelling of a multiple hearth furnace for kaolin calcination with a sensitivity analysis with respect to reaction rates," in 17th IFAC Symposium on Control, Optimization and Automation in Mining, Mineral and Metal Processing, 2016, .

[4] Gomez Fuentes JV. "Simulation Environment for Advanced Control Development of a Multiple Hearth Furnace." , 2016-05-17. 


\title{
SolarTherm: A New Modelica Library and Simulation Platform for Concentrating Solar Thermal Power Systems
}

\author{
Alberto de la Calle ${ }^{1 *}$, Jim Hinkley ${ }^{1}$, Paul Scott ${ }^{2}$, John Pye ${ }^{2}$ \\ ${ }^{1}$ CSIRO Energy, Newcastle (NSW), Australia; *alberto.delacallealonso@csiro.au \\ ${ }^{2}$ Australian National University, Canberra (ACT), Australia
}

SNE 28(3), 2018, 101-103, DOI: 10.11128/sne.28.sn.10427 Received: Sept. 15, 2016 (Selected EUROSIM Congress 2016

Postconf. Publ.), Revised Sept. 15, Accepted: Sept. 20, 2018

SNE - Simulation Notes Europe, ARGESIM Publisher Vienna,

ISSN Print 2305-9974, Online 2306-0271, www.sne-journal.org

Abstract. SolarTherm is a new CST technology simulation platform. Based on the Modelica language, it offers an easy and high-flexible alternative to the conventional CST simulation tools. SolarTherm is composed by a Modelica library of components and systems fulleditable and runnable with the main Modelica environments and Python-based tools and scripts that provides a simulation framework.

\section{Introduction}

According to the International Energy Agency (IEA), around the $11 \%$ of the global electricity production in 2050 would be generated by Concentrating Solar Thermal (CST) power systems [1]. With this scenario, CST technology has a high potential to become one of the key technologies in a decarbonised energy future.

To make this a reality, researchers and industry must strive to reduce the investment, operating and maintenance CST cost until this technology become competitive with other energy sources. Although solar thermal offers a number of benefits over other renewable energy technologies, its cost level is yet far from others technologies like the wind, hydro or photovoltaic power stations.

The Australia Solar Thermal Research Initiative (ASTRI) [2] is working to develop disruptive technologies that dramatically reduce CST costs. In order to achieve this goal, it focussed its effort on four strategic objectives:
- Increasing the capacity factor - extending operating hours to sell more electricity to the grid.

- Reducing capital expenditure for CST power plants.

- Improving efficiency of CST components and overall systems.

- Adding product value: through (a) solar fuels and (b) improving O\&M technologies yield and reduce cost.

It is necessary to collect and test all proposed ideas through the modelling and simulation. There are several simulating tools for carrying out system performance and financial simulations for CST power system, e.g. SAM [3] or Greenius [4]. Although these tools are suitable for modelling and simulation of conventional systems, it may be excessively complicated to simulate novel designs like some of the proposed systems in ASTRI project.

SolarTherm, presented here, aims to meets this need. It provides a simulation platform on which users can easily modify partial previous-designed systems and/or develop new ones.

\section{SolarTherm}

SolarTherm was created under the ASTRI program with the aim to provide solar thermal community with an easy tool to simulate and optimise CST power plants. The focus of this tool is the annual performance and the economic assessment of novel designs of solar thermal plants.

It consists of a CST component and system library along with a simulation framework. As other simulation tools, it allows a high-level process modelling through 
the connection of previous defined components where users can simulate systems configuring only few parameters such as the size of the storage or the receiver area. However the attraction of this tool is its high flexibility, where it is easy to replace, develop or customise new components. This makes SolarTherm a suitable tool to explore of new technologies related with CST power systems including thermochemical systems (i.e. solar fuels).

SolarTherm is a tool based on the object-oriented modelling Modelica language [5] for its component models and simulation. This language provides class encapsulation allowing a modular and hierarchical modelling with replaceable and customized components. Each of them can be formulated acausally, i.e. the translation of the physical equations into the formulation language is direct, making it very well suited for representing the physical structure of systems. Also, Modelica can be interfaced with external tools allowing a stochastic statistical analysis of the plant performance.

SolarTherm provides a range of Python-based tools and scripts that automate the process of testing, simulating, optimising and visualising the results [6]. Besides, if the user prefers to manage flow-sheet diagrams, Modelica library can be simulated with user-friendly graphical Modelica enviroments such as OMEdit [7] or Dymola [8].

One of the strengths of SolarTherm is that is a fully open source project. All the code is fully accessible and hackable including component models as well as the simulation framework on a GitHub server (https : / / github.com/solartherm/solartherm). Being fully open source and fully compatible with the freeopen source Modelica language simulator OpenModelica [7], it aims to become an attractive tool where researchers joint their efforts working on the future of the CST technology.

\subsection{Description of the library}

The component and system library has been implemented with the last available version of the the Modelica language (3.2.1) [5]. Modelica Fluid and Modelica Thermal connectors have been used in order to define the relationships between components. The thermodynamic properties have been calculated with medium models that extend the Modelica Media interface. These decisions guarantee that SolarTherm is compatible with any component from the Modelica Standard Library or another component that are imple-

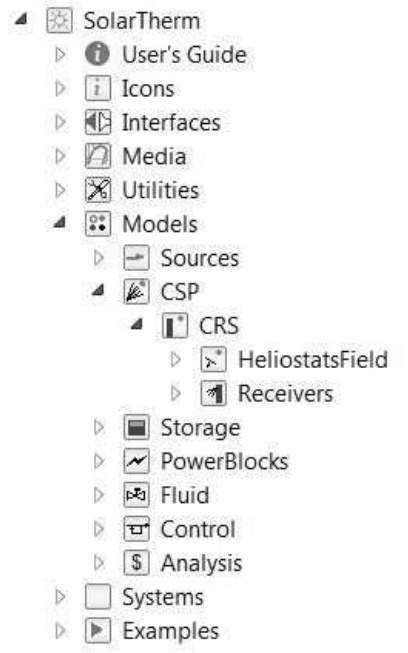

Figure 1: The SolarTherm library.

mented with the same interfaces. Also, all the components are locally balanced helping to ensure robust modelling and debugging [9].

Figure 1 shows the current main packages that composes the SolarTherm library. For the moment, the library is focused on Central Receiver Systems (CRS) with storage for electricity production. Some simple models for all these domains have been implemented including some fluid or control models to guarantee the stability of the systems.

An example of a CRS model implemented with SolarTherm library is depicted in Figure 2. A data file provides the input weather data necessary to run the system. The sun model provides the sun position and the Direct Normal Irradiance (DNI) to the heliostats field which calculates the total concentrated power into the receiver. Part of this energy is transferred to the working fluid (molten salts) which flows from the cold tank to the hot tank. The fluid returns to the cold tank after crossing the power block where the electricity produced by the plant is calculated. Two pumps with each automatic control systems drives the fluid from one tank to the other.

\section{Conclusion}

In this work we presented the work-in-progress to develop SolarTherm, a new CST technology simulation platform. It is designed to offer user an easy tool suitable for the modelling and simulation of CST power 


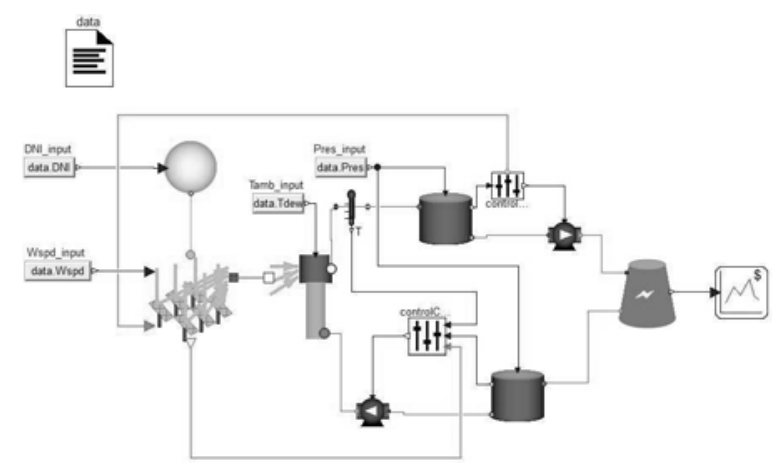

Figure 2: Flow-sheet diagram example.

systems including unconventional ones. SolarTherm is composed by a Modelica library of components and systems and Python-based tools and scripts that provides a simulation framework. It is also compatible with the user-friendly Modelica environments OMEdit and Dymola and it is developed with an open source philosophy, providing all the code in a GitHub server.

\section{Acknowledgement}

This work was performed as part of the ASTRI, a project supported by the Australian Government, through the Australian Renewable Energy Agency (ARENA).

\section{References}

[1] IEA. World Energy Outlook 2014. Tech. rep., International Energy Agency, Paris, France. 2014.

URL http: / / www. worldenergyoutlook .org/ publications/weo-2014/

[2] ASTRI. Australian Solar Thermal Research Initiative. 2016.

URL http: / / www . astri.org.au/

[3] SAM. Solar Advisor Model. 2016.

URL https: / / sam.nrel.gov/

[4] Greenius. The green energy system analysis tool. DLR, version 4. ed. 2016.

URL http: //freegreenius.dlr.de

[5] Modelica Association. Modelica Specification 3.3. 2016. URL www.modelica.org/documents

[6] Scott P, de la Calle A, Hinkley JT, Pye J. SolarTherm : A flexible Modelica-based simulator for CSP systems. In: SolarPaces Conference. Abu Dhabi, United Arab Emirates: Upcoming. 2016; .

[7] Open Source Modelica Consortium. OpenModelica. 2016.

URL https : / / openmodelica.org/

[8] Dassault Systemes. Dymola 2015 - Dynamic Modeling Laboratory. 2016.

URL www. $3 \mathrm{ds}$. com

[9] Olsson H, Otter M, Mattsson SE, Elmqvist H. Balanced Models in Modelica 3.0 for Increased Model Quality. In: Proc. 6th International Modelica Conference. Bielefeld, Germany. 2008; pp. 21-33. 



\title{
Concept for Mathematical Models for Subprocesses in the Manufacture of Particleboards
}

\author{
Carina Pöll ${ }^{1 *}$, Martin Riegler ${ }^{1}$, Felix Breitenecker ${ }^{2}$ \\ ${ }^{1}$ Kompetenzzentrum Holz GmbH, Austria, *c.poell@kplus-wood.at \\ ${ }^{2}$ Institute of Analysis and Scientific Computing, TU Wien, Austria
}

SNE 28(3), 2018, 105 - 107, DOI: 10.11128/sne.28.sn.10428

Received: Sept. 15, 2016 (Selected EUROSIM Congress 2016

Postconf. Publ.), Revised July 30, Accepted: August 25, 2018

SNE - Simulation Notes Europe, ARGESIM Publisher Vienna,

ISSN Print 2305-9974, Online 2306-0271, www.sne-journal.org

Abstract. In this paper a concept for modelling selected sub-processes of the manufacturing process of particleboards is presented. First, the entire process is described briefly, and then special attention is on the stages drying and pressing. Afterwards models for the dryer and press from literature are discussed. Furthermore, a concept for the planned models of the selected stages is presented. The future objective is to use the developed models of different stages of the manufacturing process to control the process using statistical models. Thus the impact of potential measures can be simulated. Finally there is a short conclusion including an outlook on future work.

\section{Introduction}

The particleboard was invented by Max Himmelheber and he took out patents since the beginning of the fifties, see (Jägersberg, 2004). The industrial manufacturing process of particleboards consists of several consecutive sub processes. The quality of the produced particleboard depends on the raw material and the different processing steps. To ensure a high quality of the final product, while optimizing the use of energy and resources, adjustable process parameters need to be continuously adapted (Riegler et al, 2013). Previous simulations of potential measures can predict the impact of these measures and hence avoid possible costs of rejects.
Therefore, models with different levels of detail of selected steps for the entire process need to be considered. By modelling the entire process, the interactions between different process stages can be studied. This generates a deeper understanding of the manufacturing process and enables a more efficient usage of resources. In this paper, mathematical models for two important process steps of the manufacturing process of particleboards are discussed.

\section{Manufacturing Process of Particleboards}

The description of the manufacturing process is mainly based on (Rowell, 2013). In general, round wood, wood residues and recovered wood are used for the production of particleboards. The amount of these raw materials depends on the availability, the system specifications and the type of the produced particleboard. Based on (Wagenführ, 2012) in Fig. 1, a schematic representation of the manufacturing process of particleboards is depicted. The considered process is called flat pressing process, i.e. the mattress passes the press horizontally. A particleboard consists of three layers. On the one hand the so-called surface layers, which in general constitute of fine particles, and on the other hand the core layer, where the larger particles are used. Therefore the sorting of the particles in different fractions is an important step. The resin metering is different for the surface and core layers due to the differences of the used particles. There are different adhesives, which can be used for the production. In most cases, urea-formaldehyde (UF) resin is used for the production. 


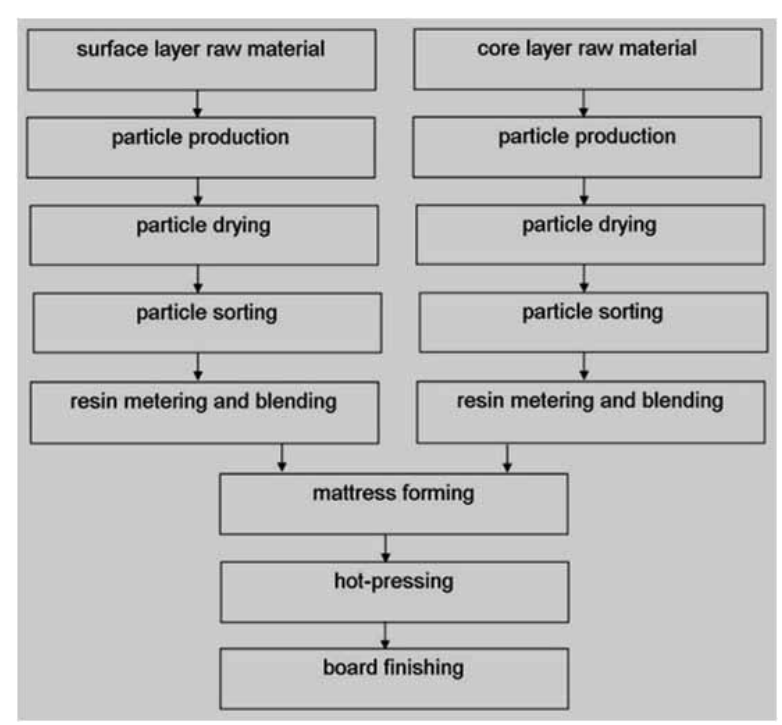

Figure 1. Manufacturing process of particleboards based on (Wagenführ, 2012).

Two stages of the manufacturing process are considered in more detail in the following.

\subsection{Dryer}

The moisture content of the particles is a crucial feature for the manufacturing process. Therefore, the drying is an important step. There are different types of dryers. One of the main differences is the method of heating. The two possibilities are direct or indirect heat, which, inter alia, cause different temperatures resulting in different drying processes, see (Wagenführ, 2012).

\subsection{Press}

The two important characteristics during pressing are temperature and pressure. These two factors influence the density of the product and the resin hardening during pressing. There are different types of presses: batch presses and continuous presses. In Fig. 2 a schematic illustration of a continuous press is depicted.

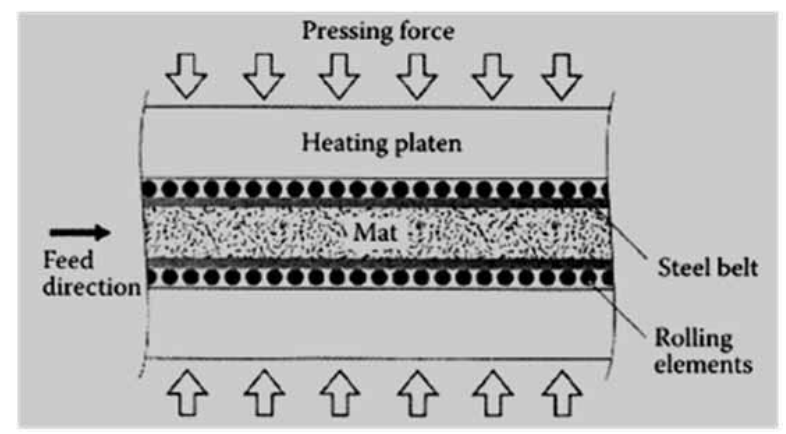

Figure 1. Schematic description of a continuous press (Rowell, 2013).

\section{Mathematical Model}

\subsection{Dryer}

In (Whitaker, 1977) based on the transport equations for continuous media, a theory of the simultaneous heat, mass and momentum transfer for porous media was developed. Two of the used equations are

- Darcy's law:

$$
q=-\frac{\kappa}{\mu}(\nabla p-\rho g)
$$

- Fick's law:

$$
\frac{\partial \varphi}{\partial t}=D \frac{\partial^{2} \varphi}{\partial x^{2}}
$$

The findings of (Whitaker, 1977) are used in (Younsi et $a l, 2006$ ) (heat and mass transfer during heat treatment of wood), (Perre, 1999) (3D drying model for porous media) and (Torres et al, 2011) (vacuum drying of wood), where models for different applications are developed. For the most applications in drying, different moisture phases (free water, bound water and water vapor) have to be considered. In (Fyhr, 1997) a twodimensional model for drying wood chips in superheated steam and especially under conditions in a pneumatic convective dryer is presented.

Based on models from literature, the decisive factors for modelling the drying of particles are worked out. Using these characteristics and the underlying physical laws, a model for the dryer will be developed. There will be a distinction of direct and indirect heat for the simulations. Furthermore, a more detailed model will include properties of the particles like for example the size. The goal of these simulations is to compute the moisture content of the particles. The dryer is rather at the beginning of the whole manufacturing process, therefore the moisture content is a state variable, which is important for most of the following steps.

\subsection{Press}

In (Thömen, 2010) a model of a hot-press is described. This model consists of three main parts: coupled heat and mass transfer, material compression, resin hardening. The simulation of the heat and mass transfer is realized using an approach based on finite-volume method. The simulation was applied on the manufacturing of medium-density fiberboards (MDF). 
The manufacturing process of MDF is similar to the process of particleboards, which is described in Fig. 1. The output of the simulation is the internal bond depending on the position in the mattress over the course of the hot-pressing process. The results of the simulation were compared with experimental results of onelayered MDF boards, produced in laboratory scale.

The moisture content of particles, which is computed with the model of the dryer, will be included in the model of the hot-press, i.e. the moisture content of the particles is an input variable for the model of the press. Moreover the geometry of the particles and the structure of the mattress are used for a detailed simulation of the hot-pressing. Using the structure of the mattress, the motion of steam during pressing can be simulated.

\section{Conclusion}

By means of the dryer and press it was shown, that there exist many models for different stages of the production of particleboards. To analyze the combination of physical processes, the connection of different models is considered to be crucial. By using strict input-output relations for the coupling of the different model parts it is possible to extend the model by including more and more production steps and also to use models with different levels of detail. Future work will include modelling of processes at different levels of detail and additional stages within the manufacturing process. The aim is to build a simulation of the most important steps of the process. It is planned to validate model results using experiments (laboratory or industrial scale). Based on the results of the models of the physical processes during the manufacturing of particleboards, statistical models for process control are computed similar to (Riegler et al, 2013).

\section{References}

[1] Fyhr C, Rasmuson A. "Some aspects of the modelling of wood chipy drying in superheated steam", International journal of heat and mass transfer, vol. 40(12), pp. 28252842, 1997.

[2] Jägersberg O. "Max Himmelheber zum 100. Geburtstag", Germany: Hirzel, 2004, p. 413 ff.

[3] Perré P, Turner IW. "A 3-D version of TransPore: a comprehensive heat and mass transfer computational model for simulating the drying of porous media", International Journal of heat and mass transfer, vol. 42(24), pp. 4501-4521, 1999.
[4] Riegler M, Spangl B, Weigl M, Wimmer R, Müller U. "Simulation of a real-time process adaptation in the manufacture of high-density fibreboards using multivariate regression analysis and feedforward control", Wood Science and Technology, vol. 47, pp. 1243-1259, 2013.

[5] Rowell RM. "Handbook of Wood Chemistry and Wood Composites", $2^{\text {nd }}$ ed., USA: CRC Press Taylor \& Francis Group, 2013, pp. 326-364.

[6] Thömen H. "Vom Holz zum Werkstoff - Grundlegende Untersuchungen zur Herstellung und Struktur von Holzwerkstoffen", Schweiz, 2010.

[7] Torres Ss, Jomaa W, Puiggali J-R, Avramidis S. "Multiphysics modeling of vacuum drying of wood", Applied Mathematical Modelling, vol. 35(10), pp. 5006-5016, 2011.

[8] Wagenführ A, Scholz F. "Taschenbuch der Holztechnik”, $2^{\text {nd }}$ ed., Germany: Carl Hanser Verlag GmbH \& Co. KG, 2012, pp. 206-231.

[9] Whitaker S. "Simultaneous Heat, Mass, and Momentum Transfer in Porous Media: A Theory of Drying", Adv. Heat Transfer, vol. 13, pp. 119-200, 1977.

[10] Younsi R, Kocaefe D, Poncsak S, Kocaefe Y. "Computational modelling of heat and mass transfer during the high-temperature heat treatment of wood", Applied thermal engineering, vol. 27(8), pp. 1424-1431, 2006. 



\title{
Possibilities in State Event Modelling of Hybrid Systems
}

\author{
Andreas Körner*, Stefanie Winkler, Felix Breitenecker \\ Institute of Analysis and Scientific Computing, TU Wien, Wiedner Hauptstraße 8-10, \\ 1040 Vienna, Austria; *andreas.koerner@tuwien.ac.at
}

SNE 28(3), 2018, 109-111, DOI: 10.11128/sne.28.sn.10429 Received: Sept. 15, 2016 (Selected EUROSIM Congress 2016 Postconf. Publ.), Revised Sept. 15, Accepted: Sept. 20, 2018 SNE - Simulation Notes Europe, ARGESIM Publisher Vienna, ISSN Print 2305-9974, Online 2306-0271, www.sne-journal.org

Abstract. This work-in-progress paper illustrates the idea of the conceptional separation between a mathematical model and a simulation model for state event models of dynamic hybrid systems. The traditional modelling and simulation process starts with a mathematical model, followed by an implementation of the model in a certain simulation environment and ends with the parametrisation of the numerical attributes followed by the simulation run. Current trends in simulation environments tends to go in the direction of graphical oriented modelling descriptions neglecting needs of conceptional (mathematical) models at the beginning of the process. This limits the modelling process and restricts efficiency. For comparison or benchmarking simulation environments as well as modelling languages, approaches and optimization for hybrid models, a conceptional model offers a framework to review these aspects.

\section{Introduction}

Modelling and simulation can not be used separately. Especially in the field of hybrid models this aspect is even more important, because in many cases the description refers to both the modelling and the simulation. Often algorithms are used to specify hybrid descriptions. There are various areas applying hybrid system models to analysis system behaviour, e.g. science, engineering, robotic systems, traffic management systems, sequential operations as well as embedded systems. [1]

\section{Hybrid Modelling}

The term hybrid has different meanings, the model structure or the mixture of used environments. In this paper the term hybrid means variation in the structure of the model. There are several changes in the model framework possible, which is discussed in details in [2]. The offered framework in this work discusses and analyzes the possibilities of hybrid modelling.

\section{State Event Modelling}

This modelling approach is closely related to hybrid modelling and provides a particular mathematical description regarding the numerical handling and execution of hybrid phenomena in a model description. The basic approach starts with the assumption of a certain dynamical system and performs the change in the model structure by a particular event depending on the state of the system. This state event changes the model framework and performs the continuing simulation run with changed model framework.

Hybrid modelling and state event modelling, address the same branch of systems but provide different approaches for modelling and simulation. Both modelling methods describe time sequential processing of different model descriptions. State event modelling, normally restricts the range of model description to ordinary differential equations (ODEs) or algebraic differential equations (DAEs), whereas the hybrid modelling approach can include different model descriptions and methodologies. In the following section the architecture of hybrid models and state event models respectively will be discussed. 


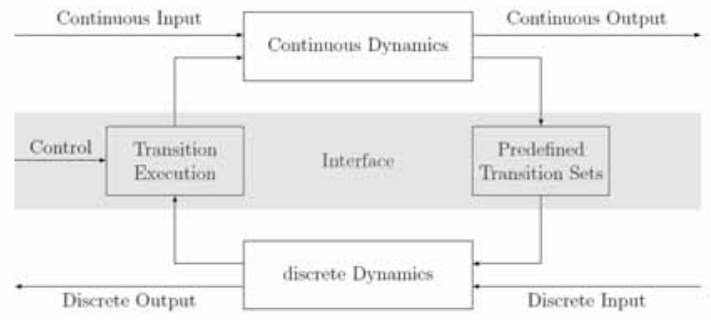

Figure 1: System architechture of Hybrid Dynamical Model.

\section{Hybrid Model Architecture}

Continuous controlled hybrid systems cover most of the discussed hybrid phenomena. The autonomous switches and jumps are covered in this environment, as required in [3], as well as the structure-variant systems introduced in [4]. Therefore the provided mathematical environment covers several system behaviours except for external controlled behaviour. An illustration of the architecture of this model description is given in Figure 1.

This system architecture requires a particular mathematical environment, which offers illustrated functionality. As a mathematical environment, the hybrid system consists of a given set of differential algebraic equations, which are assigned to the current state in which the system is currently working. The mathematical set-up is given by the following Definition.

The sixtupel $\left(L, X, W, F_{L}, G, J\right)$ denotes the generalised dynamic hybrid system automaton. $L$ denotes the finite set of states, $X$ the collection of corresponding state spaces, $W$ the set of collections of communication spaces and $F_{L}$ the set of differential algebraic equations. The collections $X$ and $W$ implements the opportunity to have in each state $l \in L$ a particular state space and vector of communication variables. Furthermore $\mathscr{F}$ as the set of differential and algebraic equations with the elements $(f, g) \in \mathscr{F}$. This tuples represents functions $f: \mathbb{R}^{n} \times \mathbb{R}^{m} \times \mathbb{R}^{\ell} \times \mathbb{R}^{r} \times \mathbb{R}$ the right side of the differential equation

$$
\dot{x}=f(x, u, z, p, t)
$$

and $g: \mathbb{R}^{n} \times \mathbb{R}^{m} \times \mathbb{R}^{\ell} \times \mathbb{R}^{r} \times \mathbb{R} \rightarrow \mathbb{R}^{u}$ represents the algebraic equation

$$
g(x, u, z, p, t)=0
$$

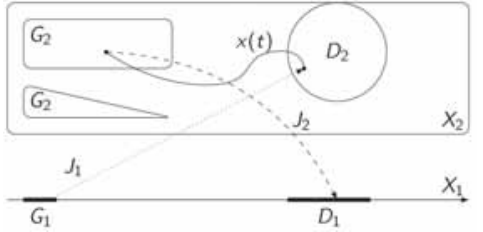

Figure 2: Example of a State Space Transition in an low dimensional Situation.

This set of differential algebraic equations represents the continuous dynamic of the model in a particular state. The discrete dynamic represents the transition from one continuous description to the other, either autonomous or controlled.

The collection of sets $G$ and $J$ implements the connection between the continuous state and the discrete transitions which are related by guard maps $G_{l}$ and jump transition maps $J_{l}$. The transitions are enabled by entering the guard region and the jump is performing the transition from one state space in the location $l$ to the other state space in the location $l^{\prime}$. A simple illustration for the one and two dimensional case is presented in Figure 2.

The introduced mathematical framework allows a model description on an abstract layer without limitation of simulation environments but with procedural structured situation. Therefore this mode framework is called a structural model.

\section{Prospects of a Mathematical Formalised Simulation Model}

Formalizing a mathematical model description offers possibility for theoretical consideration independent of a particular simulation environment. For a state event approach of a hybrid system this offers the possibility of separating numerical and modelling tasks in two different layers:

- Model Framwork

- Numerical Framwork

On the one hand this separation allows a better understanding of the abilities of a simulation environment, especially for benchmarking this separation is helpful. On the other hand the conceptual structure enables a range of theoretical considerations of models and scenarios. The particular type of transition in a hybrid model can be observed but also considerations regarding 


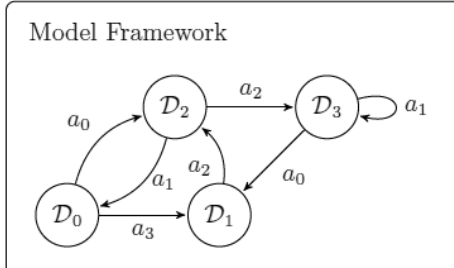

Figure 3: Illustration of the Structural Model Description.

optimization and improvement of the model itself can be addressed.

A hybrid model structured as illustrated in Figure 3 can not be optimized by optimizing each state for itself. The overall structure has to be optimised and this in a way, that maybe transition has to be redefined or particular continuous dynamics in an arbitrary state has to be reformulated. This way is enabled having a mathematical model description available.

\section{Conclusion and Outlook}

This work-in-progress paper shows the beginning of a conceptual work to formalise simulation models for state event modelling of hybrid systems. This contribution shows the first steps towards a conceptual simulation environment. A more detailed consideration related to mathematical characterizations of state events is done in [2].

The characterization of hybrid state event modelling should also support benchmarking and categorization of different existing optimization approaches as discussed in[1] and [5]. The Framework enables to formulate a general concept regarding optimization. The actions defined above lead to different algorithms as well as different cost functions. The questions is how to optimize a hybrid model in detail, perhaps using a weighted cost function including all subsystems. Is the optimization of every single subsystem the optimization of the complete hybrid system?

\section{References}

[1] Barton PI, Lee CK. Modeling, Simulation, Sensitivity Analysis, and Optimization of Hybrid Systems. ACM Transactions on Modeling and Computer Simulation. 2002;12:256-289.

[2] Körner A. Mathematical characterisation of state events in hybrid modelling. Ph.D. thesis, Technische Universität Wien. 2015.

[3] Ding XC. Real-time optimal Control of Autonomous Switched Systems. Ph.D. thesis, Georgia Institute of Technology. 2009.

[4] El-Ghezawi O, Zinober A. Variable Structure Systems and System Zeros. 1981. Research Report No. 157, University of Sheffield, England.

[5] Barton PI, Lee CK, Yunt M. Optimization of hybrid systems. Computer and Chemical Engineering. 2006; 30:1576-1589. 



\title{
Plant Disease Outbreak - Prediction by Advanced Data Analysis
}

\author{
Outi Mäyrä1 ${ }^{*}$, Mika Ruusunen ${ }^{1}$, Marja J alli², Lauri Jauhiainen², Kauko Leiviskä1 \\ ${ }^{1}$ Control Engineering, University of Oulu, P.O.Box 8000, FI-90014, Finland; * outi.mayra@oulu.fi \\ ${ }^{2}$ Natural Resources Institute Finland, Humppilantie 14, 31600 J okioinen, Finland
}

SNE 28(3), 2018, 113 - 115, DOI: 10.11128/sne.28.sn.10431

Received: Sept. 15, 2016 (Selected EUROSIM Congress 2016

Postconf. Publ.), Revised July 30, Accepted: August 25, 2018

SNE - Simulation Notes Europe, ARGESIM Publisher Vienna,

ISSN Print 2305-9974, Online 2306-0271, www.sne-journal.org

Abstract. In crop farming, pests and plant diseases cause losses for both grain yield and quality. The fungicides are used for yield protection. With the accurate plant disease prediction system, the farmers could optimize the chemical spraying and save money and environment. The plant disease modelling is challenging and widely discussed topic in modern agriculture. This short paper introduces the novel point of view for the net blotch prediction. In this approach, the weather measurements are combined with the historical net blotch observations and the data based prediction system is introduced. The estimation scheme is demonstrated with the example of the selected observation field data.

\section{I ntroduction}

The net blotch is a common barley disease caused by fungus Pyrenophora teres. It exists all over the world and affects both grain yield and malt quality [Bogacki et al. 2010]. For example, in Finland the net blotch was present in $86 \%$ of the investigated barley fields in 2009 (Jalli et al. 2011).

The weather has an influence on the occurrence of plant diseases and the different pathogens need different conditions leading into the infection. The prediction of the plant diseases can be a valuable tool for optimizing the use of the fungicides, but the reliable prediction is complicated. [Hardwick 2002].

The minimized usage of chemicals save money and environment and with the accurate prediction, the chemicals could be sprayed only when needed. The data analysis and modelling, but also knowledge about plant diseases, are the components for reliable disease forecasting [Hardwick 2006].
Cunniffe et al. (2015) discussed thirteen challenges in plant disease modelling. The authors focused particularly on disease prediction and control with epidemiological models. In that article, the challenges are partitioned into three groups: Modelling the plant host, modelling the pathogen, and modelling for control.

In this short paper, the data based modelling with feature generation is applied to the estimation of net blotch occurrence. The main principles of the prediction system are shortly described and the results are discussed. Generally, the aim of this research is the adequate prediction accuracy and the simple model structure for prediction the selected plant disease as in (Mäyrä et al. 2018).

\section{Materials and Methods}

Two different datasets - the weather data from the open database of Finnish Meteorological Institute (FMI) and the data of the net blotch observations are combined and utilized for net blotch prediction. The observations of the net blotch are collected and pre-processed by The Natural Resources Institute Finland (Luke) during the years 1991 - 2015. The data included the information about the net blotch observations in twenty different localities with the varying time scale. The fields, which are used as an example here, locate in the Southern part of Finland. The weather conditions and the beginning date of the growing season alternate between years during the observation period. To make different years comparable, the data was normalized and the time step 0 is the beginning of the growing season in every data set. The whole analysis and evaluation of the results are performed in the Matlab ${ }^{\circledR}$ software environment. The principle of this study - the utilization of data fusion and advanced data analysis is presented in Figure 1. 


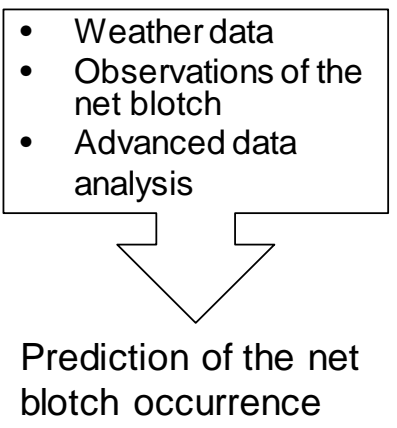

Figure 1: The principle of the net blotch prediction; the data fusion and the advanced data analysis.

The yearly weather measurements were divided into separate groups according to the occurrence of the net blotch. In addition, one group included the weather data of those years, when the net blotch was not observed. Later, the years with no net blotch is called as "normal situation'. The other dataset included weather measurements of those years, when the net blotch appeared. The variables included in the data analysis were

- the place of observation,

- the date of observation,

- the rainfall per day [mm],

- the average temperature per day, $(\mathrm{T}, \mathrm{avg})\left[{ }^{\circ} \mathrm{C}\right]$,

- the daily minimum temperature, $(\mathrm{T}, \mathrm{min})\left[{ }^{\circ} \mathrm{C}\right]$ and

- the daily maximum temperature, $(\mathrm{T}, \max )\left[{ }^{\circ} \mathrm{C}\right]$.

The datasets, which were used in this research, included the weather observations from the latest years, specifically four years with, and four years without the existence of the net blotch.

The statistical characteristics of the weather data were first computed to find out any differences between the data sets with or without the net blotch. The statistical characteristics are presented in Table 1.

The feature generation was performed to improve the information content of the data. More about the features and their use are presented, for example, by Dash and Liu (1997) Garcia-Torres et al. (2016), and Pérez-Rodríguez et al. (2015). In this study, feature generation technique presented by Ruusunen (2013, p. 50) was utilized. Briefly, in this method the features are generated by fusing the above listed variables with different mathematical operations. The feature values in the beginning of the growing season are then summed cumulatively. The aim is to separate the cumulative summed feature values according to the net blotch appearance. Weather conditions favouring the net blotch occurrence can be predicted with weather measurements and suitable features. For this case, the most suitable features were found by exhaustive search and visual inspection. Also T-test was tested in the feature selection step. Further research comprising several observation fields and the feature evaluation has to be automated for example by using T-test. The modelling procedure is demonstrated step by step in Figure 2.

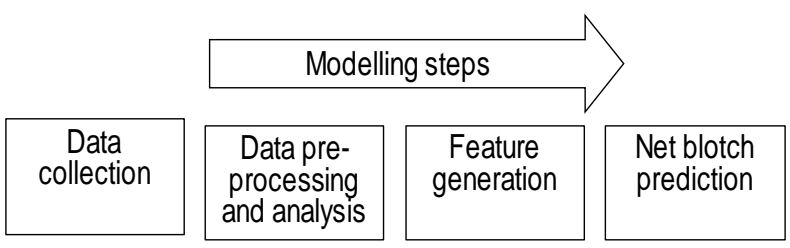

Figure 2: Modelling steps.

\section{Results and Discussion}

As presented in the Table 1., the datasets seem statistically similar. To find out those years that differs from the normal situation, the feature generation step was performed.

\begin{tabular}{lccc}
\hline $\begin{array}{l}\text { Obs. } \\
\text { field }\end{array}$ & Mean & Std & Median \\
\hline & No / Yes & No / Yes & No / Yes \\
\hline Rain fall & $1,2 / 1,6$ & $4,2 / 5,5$ & $0,0 / 0,0$ \\
\hline T, avg & $11,8 / 11,8$ & $5,7 / 5,6$ & $12,5 / 13,0$ \\
\hline T, min & $6,6, / 6,7$ & $5,6 / 5,9$ & $7,3 / 7,5$ \\
\hline T, max & $17,3 / 17,1$ & $6,4 / 6,1$ & $17,8 / 17,9$ \\
\hline
\end{tabular}

Table 1: The statistical characteristics of the observation field data. The characteristics are presented as per variables (the left column) according to the occurrence of the net blotch (No / Yes).

The grouping of the weather data sets (with or without the net blotch) was next studied with the combination of the feature generation and cumulative sum. Among the total of 110 generated alternatives, the suitable feature for this case was chosen as

$$
(\mathrm{x}+\mathrm{y}) / \mathrm{y} \text {, }
$$

where $\mathrm{x}$ is the rainfall per day and $\mathrm{y}$ is the average value of daily temperature.

The years without net blotch observations are presented with the solid lines and the years when the net blotch appeared are plotted with the dash lines in Figure 3 . The time scale ( $\mathrm{x}$-axis) is 10 days and the time step 0 is the beginning of growing season. 


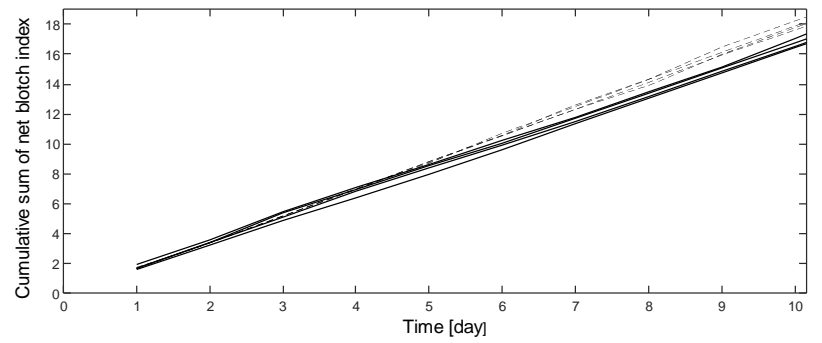

Figure 3: The datasets are grouped by using feature generation. The years with no net blotch (solid lines), the years with the net blotch (dashed lines).

In the presented example, grouping and separation of the data sets according to the appearance of the net blotch was possible by using the feature generation technique. As plotted in Figure 3, the charts forms own "pipes" and the years with the net blotch separate this way from the normal situation.

The results strongly indicate that the presented method is a simple but applicable tool for the prediction of the net blotch occurrence. The simple structure is easy to adapt to another observation fields thanks to non-parametric features. On the other hand, the evaluation of the presented method still needs more example cases. The scopes of the further research are the generalization and validation of the presented prediction method with data sets from different localities. Also the usability in the prediction of the different plant diseases has to be studied.

\section{Acknowledgements}

The Ministry of Agriculture and Forestry and Tekes are acknowledged of the financial support. The early results are achieved during the MMEA (Measurement, Monitoring and Environmental Efficiency Assessment, during 2010-2015) program and this work was partly supported by Tekes. The Ministry of Agriculture and Forestry in Finland finances the ongoing research project (2018- beginning of the 2020).

\section{References}

[1] Bogacki P, Keiper FJ, Oldach KH. 2010. Genetic structure of South Australian Pyrenophora teres populations as revealed by microsatellite analyses. Fungal Biology $114,834-841$.

[2] Jalli M, Laitinen P, Latvala S. 2011. The emergence of cereal fungal diseases and the incidence of leaf spot diseases in Finland. Agricultural and Food Science 20 1: 62-73.

[3] Hardwick NV. (2002) Weather and plant diseases. Weather, Vol 57, Issue 5, p. 184-190.

[4] Hardwick NV. (2006) Disease forecasting. The Epidemiology of Plant Diseases, Second edition, published by Springer in The Netherlands, p. 239-267.

[5] Cunniffe NJ, Koskella B, Metcalf CJE, Parnell S, Gottwald TR, Gilligan CA. (2015) Thirteen challenges in modelling plant diseases. Epidemics, Challenges in Modelling Infectious DIsease Dynamics 10, 6-10. https://doi.org/10.1016/j.epidem.2014.06.002

[6] Mäyrä O, Ruusunen M, Leiviskä K. (2018) Data based modelling and feature generation as a tool for plant disease forecasting. Accepted for the CAFEi2018 eProceeding (2018) The 4th International Conference on Agricultural and Food Engineering on 6th -8th November, 2018 at Kuala Lumpur, Malaysia.

[7] Dash M, Liu H. (1997) Feature selection for classification. Intelligent Data Analysis, Vol 1, p. 131-156.

[8] García-Torres M, Gómez-Vela F, Melián-Batista B, Moreno-Vega JM. (2016) High-dimensional feature selection via feature grouping: A Variable Neighborhood Search approach. Information Sciences, Vol. 326, p. 102-118.

[9] Pérez-Rodríguez J, Arroyo-Peña AG, García-Pedrajas N (2015) Simultaneous instance and feature selection and weighting using evolutionary computation: Proposal and study. Applied Soft Computing, Vol. 37 p. 416-443.

[10] Ruusunen M. (2013) Signal Correlations in Biomass Combustion - an Information Theoretic Analysis. Acta Univ Oulu C 459, 2013. PhD Thesis. 



\title{
Mean-Field Approximation of a Microscopic Population Model for Austria
}

\author{
Martin Bicher ${ }^{1 *}$, Niki Popper ${ }^{2}$ \\ ${ }^{1}$ Institute of Analysis and Scientific Computing, TU Wien, Wiedner Hauptstraße 8-10, \\ 1040 Vienna, Austria; * martin.bicher@tuwien.ac.at \\ ${ }^{2}$ dwh Simulation Services, dwh GmbH, Neustiftgasse 57-59, 1070 Vienna, Austria
}

SNE 28(3), 2018, 117-119 DOI: 10.11128/sne.28.sn.10432

Received: Sept. 15, 2016 (Selected EUROSIM Congress 2016 Postconf. Publ.), Revised July 30, Accepted: August 25, 2018

SNE - Simulation Notes Europe, ARGESIM Publisher Vienna, ISSN Print 2305-9974, Online 2306-0271, www.sne-journal.org

Abstract. Verification and validation of large agent bases models is a complicated process - to check for full functionality, the simulation has to be executed various times, which takes both time and computational resources. In this discussion-paper we present an approach that could generally improve this process, applied on an agent-based population model for Austria. A socalled mean-field model in this case a partial differential equation (PDE) is used for this aim. Execution of the PDE simulation only takes a very short time, hence the meanfield model can provide a fast prospect on results, behaviour and sensitivity of the agent-based model used.

\section{Introduction}

During the last decades a great number of population models have been developed all over the world (e.g. $[1,2,3]))$, which, in combination with economic and/or health models, can be used for supporting internal political decisions. Most of them are microscopic simulation models wherein the population is no longer simulated as a whole [4], but as a sum of individuals.

This type of population modelling is advantageous due to its flexibility with respect to model-extensions and hence plays an important role in the Comet founded healthcare project DEXHELPP. In the course of this project an agent based population model for Austria was developed and implemented [5] in order to create a solid foundation for generating decision-support models for Austria's health care system.

\section{An Agent-Based Population Model for Austria}

The basic rules for the agent-based population model are very intuitive. Each agent is assigned

- age (equivalent to a certain birth-date), and

- sex.

The model is simulated with equidistant time-steps of arbitrary length $d t$. With a certain age and time-steplength dependent probabilities each agent might die, emigrate or, in the case of female agents, reproduce. Additionally a certain number of immigrants is added at each step of the model. Thus the model requires the parameters

- initial population size [\#1],

- initial population distribution with respect to age and sex [\#2],

- immigration age/sex distribution for each simulated time-step [\#3],

- death [\#4], emigration [\#5] and reproduction [\#6] probabilities with respect to age, sex and time-step, and finally

- natural percentage for a male/female offspring [\#7].

These parameters were successfully worked out of requested data from the Austrian Bureau of Statistics [6]. The model was implemented in Python 3.

The simulation executed by CPython 3.4 is very slow. As a single simulation with 8 million agents and a timespan of 50 years with daily time steps takes about 10 hours, the verification and validation process turned out to be challenging. To support that process meanfield analysis was used. 


\section{Mean-Field Analysis}

\subsection{General Concept}

The so called mean-field perhaps poses the most applicable basis to analyse a microscopic model on the macroscopic level. Let $a_{i}(t), i=1 \ldots N$ denote the abstract state of agent $i$ at time $t$ then the mean-field $O(x, t)=\sum_{i=1}^{N} \mathbb{1}_{x}\left(a_{i}(t)\right)$ simply counts all agents in a certain state $x$ at a given time $t$.

In terms of the defined population model the meanfield corresponds to the aggregated numbers: "total population with age $a$ and sex $s$ at time t". As age is a continuous variable and the model is stochastic, the mean-field poses for a density function of a huge stochastic process.

The mean field of a microscopic model can have several useful properties and can even be analysed with analytical methods. One method is the mean-field approximation, which allows approximation of the mean value of the (stochastic) mean-field by a closed, aggregated equation based-model - a so called mean-field model. Usually a ordinary differential equation [7] or difference equation [8] model results, but in case states of agents are continuous (as in our case) the method results in a partial-differential equation (PDE) model[9].

Key to find this mean-field model is to apply a so called mean-field theorem [10], a statement closely related to the famous Kolmogorow equations for Markov processes. If applied correctly, this theorem provides information how stochastic analysis of the single agents in the $\mathrm{AB}$ model results in an aggregated model for the mean-field.

\subsection{Application}

In order to apply the cited mean-field theorem, the stochastic processes of the single agents need to be analysed. This process is quite long and technical. Hence we refer to [9] to get an idea about how this can be done.

Let $F(a, t)$ and $M(a, t)$ denote the density of female and male $a$-year old individuals in Austria at time $t$, then the following model describes their dynamics:

\section{Corollary 2.1 (Mean-Field Model.)}

$$
\begin{gathered}
\frac{\partial M}{\partial t}-\frac{\partial M}{\partial a}=\alpha_{1}+\gamma_{1} \mathbb{1}_{[0, d t)}(a) \Psi(a, t)-M \delta_{1} \\
\frac{\partial F}{\partial t}-\frac{\partial F}{\partial a}=\alpha_{1}+\gamma_{2} \mathbb{1}_{[0, d t)}(a) \Psi(a, t)-F \delta_{2}
\end{gathered}
$$

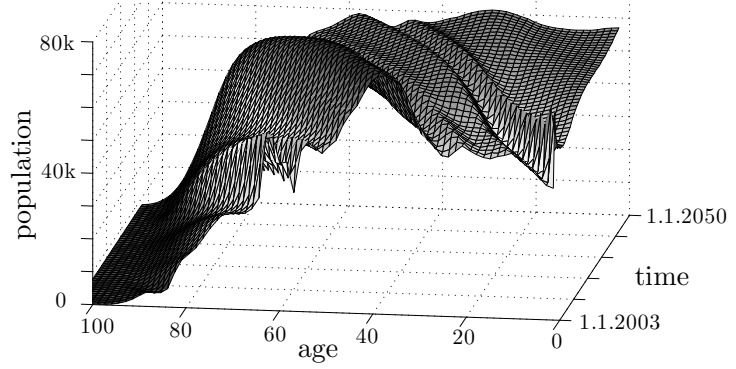

Figure 1: Simulation results for the PDE model. Density of male population for 47 simulated years.

with $\Psi(a, t):=\int_{\mathbb{R}^{+}} F(a, t) \beta(a, t) d a$. All $\alpha, \beta$ and $\gamma$ are functions of age and time and can directly be derived from [\#2]-[\#7]. The initial values are given by the initial density and the total population from [\#1] and [\#2]. Parameter dt poses for the AB model's time-step size.

The mean-field theorem guarantees asymptotic (with respect to the number of agents $N$ ) equivalence of the $\mathrm{PDE}$ solution and the $\mathrm{AB}$ population model. Hence the $\mathrm{AB}$ model qualitatively behaves according to some transport-equation.

Fig. 1 shows a surface-plot of the resulting density for male individuals from 2003-2050. The PDE model was simulated in MATLAB using a method-oflines scheme and its results almost perfectly match the results of the $A B$ model.

\section{Discussion}

While it takes almost half a day to simulate the $A B$ model the method of lines algorithm terminates after a few seconds. Hence it was possible to easily make quick scenario tests in order to verify the behaviour of the AB model. Also sensitivity analysis was supported: In case a parameter turned out to be very sensitive in the PDE model we paid close attention to it while analysing the $\mathrm{AB}$ model. Finally the $3 \mathrm{D}$ visualisation of the density in the PDE model inspired us to analyse diagonal cuts through the results of the $\mathrm{AB}$ model.

As the $\mathrm{AB}$ model is undoubted a much richer, applicable and flexible model, the PDE model is not intended to pose a substitute for it. Yet the time to derive, implement and execute the PDE model was still shorter than the duration of one single simulation run of the $A B$ model in Python, which made the mean-field model a useful tool to quickly gain first insights to support validation and verification in our case. 
Nevertheless it remains to be discussed: Is time invested into the derivation of this meta-model, not intended to be used directly, spent well?

\section{Acknowledgement}

K-Projekt DEXHELPP is supported by BMVIT, BMWFW and the state of Vienna via COMET - Competence Centers for Excellent Technologies. Programme COMET is processed by FFG.

\section{References}

[1] Andreassen L. Demographic Forecasting with a Dynamic Stochastic Microsimulation Model. 1993.

[2] Kelly S. Australia's Microsimulation Model DYNAMOD. 2003.

[3] Spielauer M. The LifePaths Microsimulation Model: An Overview. 2013.

[4] Malthus T. An Essay on the Principle of Population, as it Affects the Future Improvements of Society With Remarks on the Speculations of Mr. Godwin, M. Condorcet, and Other Writers. London. 1798.

[5] Bicher M, Glock B, Miksch F, Schneckenreither G, Popper N. Definition, Validation and Comparison of Two Population Models for Austria. In: Book of Abstracts, 4th International COnference on Business, Technology and Innovation 2015. Durres, Albania: UBT - Higher Education Institution. 2015; .

[6] Austria S. Demographisches Jahrbuch Österreich 2012. Verlag Österreich GmbH. 2012.

[7] Bicher M, Popper N. Agent-Based Derivation of the SIR - Differential Equations. In: Proceedings of the 8th EUROSIM Congress on Modelling and Simulation. Cardiff, Wales. 2013; pp. 306-311.

[8] Gast N, Gaujal B. A mean field approach for optimization in discrete time. Discrete Event Dynamic Systems. 2011;21(1):63-101.

[9] Deffuant G, Neau D, Amblard F, Weisbuch G. Mixing beliefs among interacting agents. Advances in Complex Systems. 2000;03(01n04):87-98.

[10] Tainaka Ki. Stationary pattern of vortices or strings in biological systems: Lattice version of the Lotka-Volterra model. Physical Review Letters. 1989; 63(24):2688-2691. 



\title{
Estimation of Discontinuities from Point Cloud Based on Variable-Box Segmentation Method
}

\author{
Shun Matsukawa ${ }^{1}$, Ken-ichi Itakura ${ }^{1}$, Yukinori Suzuki ${ }^{1}$, Akira Hayano ${ }^{2 *}$ \\ ${ }^{1}$ Muroran Institute of Technology, 27-1 Mizumoto-cho, Muroran, Japan \\ ${ }^{2}$ JAEA Horonobe Underground Research Center, Horonobe, Japan; *hayano.akira@jaea.go.jp
}

SNE 28(3), 2018, 121 - 123, DOI: 10.11128/sne.28.sn.10433

Received: Sept. 15, 2016 (Selected EUROSIM Congress 2016

Postconf. Publ.), Revised July 30, Accepted: August 25, 2018

SNE - Simulation Notes Europe, ARGESIM Publisher Vienna,

ISSN Print 2305-9974, Online 2306-0271, www.sne-journal.org

Abstract. For estimating discontinuities of a rock mass from point cloud (LiDAR) data, an algorithm called DiAnahas been used. It obtains a fracture plane from the valid point cloud inside a cubic bounding box. In DiAna, to extract the valid point cloud from the cubic bounding box, DiAna has to determine the threshold value to remove noises. It seems that this manual operation is hard work for long tunnels. To improve this manual operation, we devel-oped Variable-Box Segmentation (VBS) method for LiDAR data recorded from a tunnel. VBS has three processes, i.e., first segmentation, second segmentation, and combining. During the first segmentation, the point cloud is segmented into large bounding boxes and noise is removed. During the second segmentation, each box is divided into nine sub-boxies. Planes are estimated from point cloud data inside each sub-box. During combining, sub-boxies containing similar planes are joined. VBS was examined using LiDAR data including three sets of major discontinuities. Estimation results from VBS was compared with the reference planes decided from geological sketch. Results showed that similarity between reference planes and planes determined by VBS algorithm seems to be enough to find discontinuities from fractured planes..

\section{Introduction}

To construct the tunnel, geological mappings on the rock wall and faces by geologists are important for the design of optimal support, maintenance, and managing the tunnel for a long life cycle.
However, in a long tunnel, construction costs have become higher. Geologists must work under an unstable gallery for a long time. Furthermore, fracture maps by geologists can change individually. To avoid such problems, 3D laser scanning to acquire a high-resolution point cloud (LiDAR) has been introduced for tunnel construction (Fekete et al., 2010; Lato et al., 2009). In fact, LiDAR can provide detailed 3D characteristics and structures of the rock around the tunnel, along with information related to the rock discontinuity. In previous studies, some methods to estimate discontinuity from LiDAR were developed. Diederichs et al. (Lato et al., 2009) reconstructed surfaces using a polygonal model and grouped them as co-planar. Lato et al. (Vöge et al., 2013) developed "PlaneDetect", which consists of five processing stages: smoothing, edge detection, blast damage detection, discontinuity identification, and discontinuity set clustering.

Developed by Gigli et al. (Gigli and Casagli, 2011), DiAna is an algorithm used to estimate the discontinuities in a rock mass from facets semi-automatically. It segments the point cloud into cubic bounding boxes with fixed size and ascertains the plane of points using least squares method. When DiAna extracts the valid point cloud from the cubic bounding box, it has to determine the threshold value based on the standard deviation of distances between the points and plane in the box manually. However, it seems that this manual operation is hard work for long tunnels. To improve this manual operation, we developed Variable-Box Segmentation (VBS) method for LiDAR data recorded from the tunnel.

This paper presents Variable-Box Segmentation (VBS) method to produce suitable planes for estimating discontinuity in the tunnel automatically from a point cloud. VBS segments the point cloud into parallelepiped bounding boxes. Then it combines boxes to produce suitable planes at each part of the point cloud. 


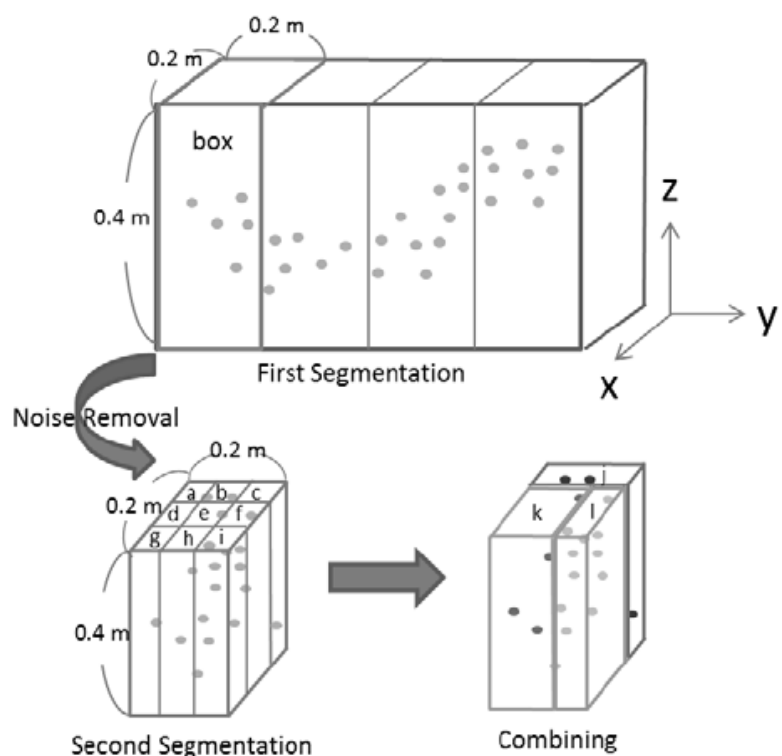

Figure 1. VBS algorithm. First, segment into a large box and remove noise (upper, red box). Next segment into nine sub-boxes a-i (lower left, sub-boxes). Finally, combine sub-boxes to produce suitable planes, e.g. j, $\mathrm{k}$ and I (lower right, purple, blue or green boxes).

In Section 1, details of the VBA algorithm are presented. Experimental results of VBA using the point cloud from LiDAR are presented in Section 2. Finally, this paper is concluded in Section 3.

\section{VBS Algorithm}

VBS has three processes as shown in Figure 1: first segmentation, second segmentation, and combining. In the first segmentation, the point cloud is segmented into large bounding boxes $(0.2 \times 0.2 \times 0.4 \mathrm{~m})$. Noise is removed from the boxes. To remove noise, each box is segmented again into mini-boxes $(0.02 \times 0.02 \times$ $0.02 \mathrm{~m}$ ). The points in that box are probably noise if the mini-boxes are sparse. Then VBS sums up the contained number of points from the sparsest box to the densest box until the summation becomes greater than $31.73 \%$ of all points. Then VBS removes the summed points as noise. This border of the summation is determined empirically. In the second segmentation, noise removed boxes are segmented into nine sub-boxes (smaller boxes) as shown in Figure 1. Planes are obtained from each sub-box using least squares method.
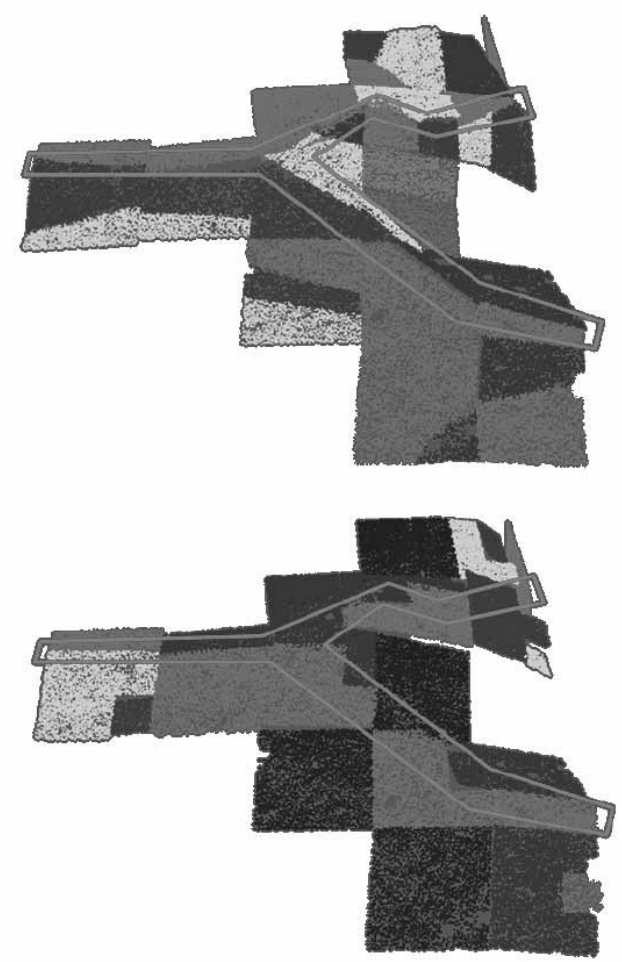

Figure 2. The images show planes for discontinuity 1. Upper and lower panels are the reference planes and those of planes determined by VBS algorithm. Color shows each planes. Red frames show the discontinuity.

Combining the process, each sub-box that has a similar normal vector of plane is combined as shown in Figure 1. The distances between the plane and points are computed for all points in the sub-box. If the box contains more than $68.27 \%$ of all points that is distance inside of the standard deviation, then the plane is combined by the region growing method. If not, the box is combined with the most similar box among its four neighbors.

\section{Examination and Results}

VBS has been examined using gallery data collected from the $-300 \mathrm{~m}$ Access/Research Gallery of the Mizunami Underground Research Laboratory using a LiDAR scanner. The examination was conducted for the following processes: First, three major fracture discontinuities (discontinuity 1 , discontinuity 2 , and discontinuity 3 ) observed by geological engineers were extracted from point cloud datasets and we obtained reference discontinuity planes (remove noises and make a cluster from large boxes, then compute these planes) manually. 
Next, planes were computed from the same datasets using VBS for $0.2 \times 0.2 \times 0.4(\mathrm{~m})$ boxes were calculated. The VBS results were compared with reference planes by geological sketch observations and cosine distances.

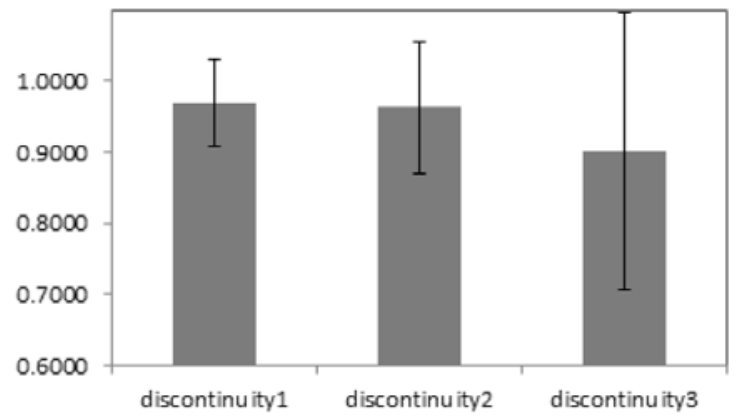

Figure 3. Average cosine distances with its standard deviation between reference planes and planes determined by VBS algorithm for three fracture discontinuities. discontinuity1: 0.9700 \pm 0.0617 , discontinuity2: $0.9631 \pm 0.0929$, discontinuity3: $0.9020 \pm 0.1942$.

Results of the discontinuity are presented in Figure 2 and Figure 3. The image in the upper in Figure 2 presents the reference planes. The image in the lower Figure 2 also presents the planes determined by VBS algorithm. In Sketch observation reveals that lower image describes the boundary of the discontinuity areas well fitting the reference. Figure 3 shows the average cosine distances between the normal vector of reference plane and that of plane determined by the developed algorithm. Since the cosine distances for all fracture discontinuities are more than 0.900 , the planes determined by VBS algorithm are enough similar to reference planes. From observing the geological sketch and cosine distances we can reason that planes determined by the developed algorithm seem to be enough similar to the reference planes to find discontinuities.

\section{Conclusion}

To estimate discontinuities of rocks around a tunnel from a point cloud, an algorithm called DiAna is effective. To extract the valid point cloud from the cubic bounding box, DiAna determined the threshold values manually. It seems to be hard work for long tunnels. To improve this manual operation, we developed VariableBox Segmentation (VBS) method for LiDAR data recorded from the tunnel. Similarity between reference planes and planes determined by the developed algorithm seems to be enough to find discontinuities from fractured planes.

\section{References}

[1] Fekete S, Diederichs M, and Lato M. Geotechnical and operational applications for three-dimensional laser scanning in drill and blast tunnels. Tunnelling and Underground Space Technology, 25:614-628, 2010.

[2] Gigli G and Casagli N. Semi-automatic extraction of rock mass structural data from high resolution lidar point clouds. Inter-national Journal of Rock Mechanics and Mining Sciences, 48 (2):187-198, 2011.

[3] Lato M, Diederichs MS, Hutchinson DJ, and Harrap R. Optimization of lidar scanning and processing for automated structural evaluation of discontinuities in rockmasses. International Journal of Rock Mechanics and Mining Sciences, 46 (1):194-199, 2009.

[4] Vöge M, Lato MJ, and Diederichs MS. Automated rockmass discontinuity mapping from three-dimensional surface data. Engineering Geology, 164:155-162, 2013. 



\title{
Synaptic Learning of the Resonator Network Interacting with Oscillatory Background and Noise
}

\author{
Taishi Matsumura, Tatsuo Kitajima, Tetsuya Yuasa, Siu Kang* \\ Department of Bio-Systems Engineering, Graduate School of Science and Engineering, Yamagata University, \\ Yonezawa, Yamagata, Japan; *siu@yz.yamagata-u.ac.jp
}

SNE 28(3), 2018, 125 - 127, DOI: 10.11128/sne.28.sn.10434 Received: Sept. 15, 2016 (Selected EUROSIM Congress 2016 Postconf. Publ.), Revised July 30, Accepted: August 25, 2018 SNE - Simulation Notes Europe, ARGESIM Publisher Vienna, ISSN Print 2305-9974, Online 2306-0271, www.sne-journal.org

Abstract. Rhythmic activities were widely observed in many brain regions. Human EEG recording revealed several frequency modulation of the oscillation reflecting internal brain states such as attentional modulation in visual systems. On the other hand, in vivo intracellular recordings suggested that individual neurons showed persistent membrane fluctuations and global oscillation originated from the activity of the neuronal fluctuations. Furthermore, it was found that some types of neuron showed membrane resonance in their subthreshold level. However, functional roles of the subthreshold resonance in a recurrent neural network are still unknown. Here, we computationally examined the behavior of resonator network driven by external inputs and organized through the spike-timing-dependent plasticity (STDP) under oscillatory background and noise. As a result, it was shown how the resonator network modified its responsiveness depending on frequency modulation and its connectivity through the STDP.

\section{Introduction}

Oscillatory activities in brain often reflect internal states. For example, attentional level in visual systems is characterized by the intensity of gamma frequency component in oscillation. In a sleep stage classification, rapid-eye-movement (REM) sleep and non-REM sleep are typically defined by theta and delta powers in EEG.

On the other hands, several intracellular recordings demonstrated membrane potential fluctuations in individual neurons. Importantly, theoretical and experi- mental studies revealed that the fluctuation did not mean a disadvantage but lead to high advantage of neural computation.

This work was supported by JSPS KAKENHI Grant Number 16K00386.

In addition, it is well known that synaptic plasticity is a key factor of brain computation such as learning and memory. Recent experimental study reported the STDP that potentiates transmission efficacy if pre-synaptic neuron elicits a spike before post-synaptic neuron. On the other hand, the STDP depresses it when post-firing proceeds pre-firing [1]. The STDP is considered as an important neural basis of transformation between spatial- and temporal-information because the plasticity includes relative timings of spikes. In addition, theoretical studies suggest that the STDP has computational advantage [2].

Furthermore, recent intracellular recording study reported that some types of neurons in hippocampus and entorhinal cortex showed a relatively strong response to specific frequency when they receive sinusoidal current injection whose frequency changes in time-dependent manner such as a chirp current. The response property of a resonator neuron in isolated condition was well examined and ionic mechanism on the generation of resonance was identified. However, how the resonators behave in recurrent networks, especially with synaptic learning, is still unclear.

Here, we performed numerical simulation of the network with subthreshold resonance. In our previous study, the frequency selectivity of network connectivity and automatic tuning for optimal noise intensity were already demonstrated under the fixed timing of external inputs [3]. In the present study, we examined how much the network organization was robust for the external stimuli with various temporal jitters and randomness. 


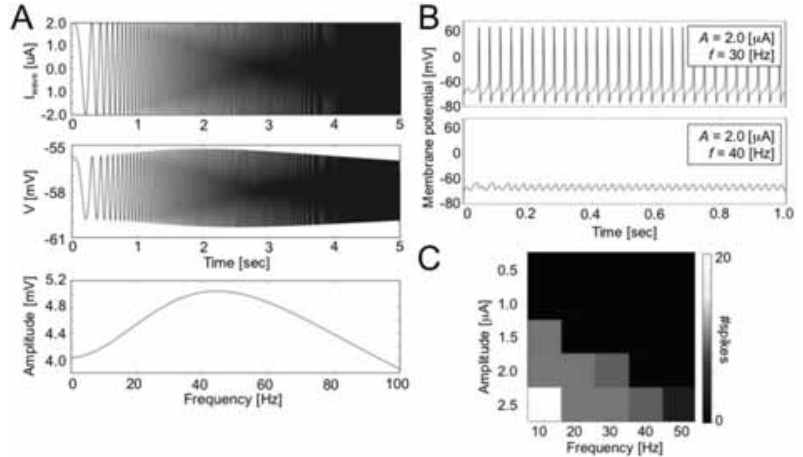

Figure 1. Neuronal response to oscillatory inputs.

\section{Method}

\subsection{Neuron model}

We employed the resonator neuron model described by Acker, et al. [4]. The resonator neuron exhibits subthreshold resonance under isolated conditions due to its intrinsic properties such as persistent sodium, slow and non-inactivating potassium, hyperpolarization-activated cation channels. Dynamics of the membrane potential is described with the Hodgkin-Huxley formalism.

\subsection{Network organization}

Our network included 100 excitatory neurons. All the neurons had excitatory synapses mediated by first order kinetics and all-to-all connectivity in the initial state. Self-excitation was prohibited and all synaptic weights were modified through the STDP. The STDP potentiated or depressed individual synapses depending on the temporal order between pre- and post-synaptic firings.

\section{$1.3 \quad$ Input currents}

Our model network receives four types of input currents. All neurons in the network receive a bias current, $I_{a p p}$, in order to generate subthreshold resonance the same as the original model. Background oscillatory activity, $I_{\text {wave }}$, is described as sinusoidal current injection whose frequency is modulated, corresponding to the internal state of a brain. Background noise, $I_{\text {noise }}$, is given as the Gaussian white noise with a diffusion constant $D$. External stimulations, $I_{\text {stim }}$, are applied onto 20 neurons, and their timing is 2 millisecond-earlier than every peaks of the $I_{\text {wave }}$. In some simulations, we introduced temporal jitters to these stimuli in the time-fixed or stochastic manner.
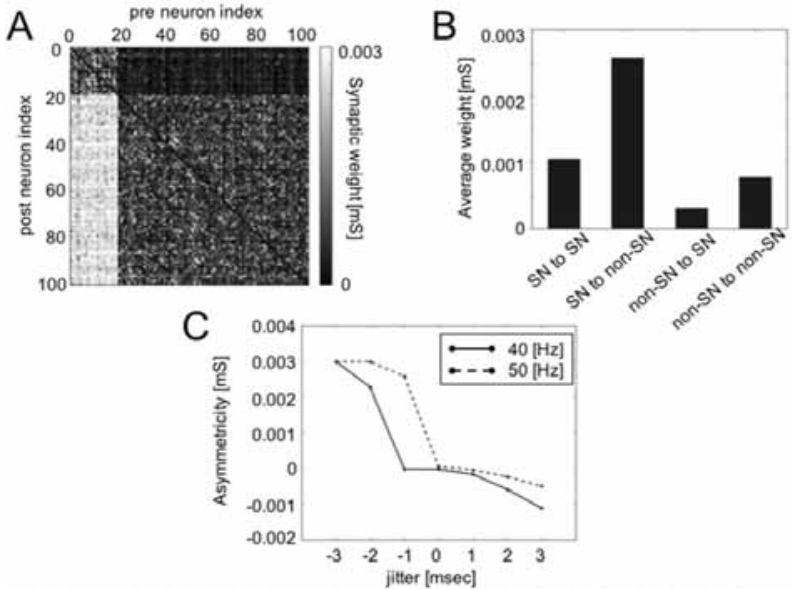

Figure 2. Synaptic weights after the STDP learning.

\section{Result}

\subsection{Responsiveness of single neuron to oscillatory inputs}

Neuronal responses to oscillatory inputs with various frequencies and amplitudes are shown in Figure 1. Each panel indicates an input current (upper), membrane potential as output (middle), and response amplitude (lower) (Figure 1A). The response to different frequencies is indicated in Figure 1B. Upper and lower panel respectively shows the time course of the membrane potential driven by $30 \mathrm{~Hz}$ and $40 \mathrm{~Hz}$ with the same amplitude. The neuron showed supra-threshold response, that is, spike firings in some parameter ranges. Figure 1C shows spike outputs for various parameters of oscillation. The heat map indicates the number of spikes. The $\mathrm{x}$-axis is frequency and the $\mathrm{y}$-axis the amplitude of the oscillatory current. Difference in responsiveness is most prominent in the modulation between $40 \mathrm{~Hz}$ or $50 \mathrm{~Hz}$ of oscillation.

\subsection{Synaptic learning through the STDP}

Figure 2 indicates the synaptic learning of the network driven by the external inputs under oscillation and noise. Through the STDP learning, the model network is gradually modified such that the synapses from the stimulated neurons (SN) to the non-stimulated neurons (non-SN) are potentiated. On the other hand, synapses from non-SN to $\mathrm{SN}$ are depressed (Figure 2A, B; $A=2 \mu \mathrm{A}, f=40 \mathrm{~Hz}$, jitter $=-2 \mathrm{msec})$. Furthermore, such an asymmetric connectivity was alternated through the frequency modulation of oscillatory background. 
The model network showed the automatic tuning of frequency selectivity for noise intensity such that 1) asymmetric connectivity or symmetric connectivity was organized frequency-independently under extremely weak or strong noise, respectively, 2) asymmetric and symmetric connectivity was frequency-dependently organized under the moderate noise intensity. Such the frequency selectivity robustly appeared even with the temporal jitter of external stimuli that proceeded to peaks of oscillation. On the other hand, if the timing of external stimuli had delay from the peaks, the frequency selectivity disappeared (Figure 2C).

\section{Disucussion}

The present computational study demonstrates several properties of a resonator network. Through the formation of non-uniform connectivity, the resonator network could store the spatial information of external stimuli in frequency-dependent manner. Furthermore, such the selectivity of frequency was automatically tuned for moderate noise even under the redundancy of external stimuli such as temporal jitter. It is possible to expect that frequency-dependent neural processing such as attentional modulation in visual systems had a neural basis shown in present study.

\section{Acknowledgement}

The authors thank Masanari Minamisawa, Kana Kimura for fruitful discussion on the research.

\section{References}

[1] Bi GQ, Poo MM. "Synaptic modifications in cultured hippocampal neurons: dependence on spike timing, synaptic strength, and postsynaptica cell type.”, The Journal of Neuroscence., 1998, Dec 15;18(24):10464-72.

[2] Song s, Miller KD, Abbott LF. "Competitive Hebbian learning through Spike-timing-dependent synaptic plasticity," Nature Neuroscience, Sep:3(9), 2000, 916-926.

[3] Kang S, Minamisawa M, Kimura K, Matsumura T, Kitajima T, Yuasa T. "The learning property of spiketiming-dependent plasticity in neural network with the subthreshold membrane resonance", Organized Session 15 "Complex Networks and Complex Systems" on International Conference on Simulation Technology, JSST2015.

[4] Acker CD, Kopell N, White JA: "Synchronization of Stronglly Coupled Excitatory Neurons: Relating Network Behavior to Biophysics", The Journal of Computational Neuroscience, 2001, 15:71-90. 



\title{
Falsification by Modelling and Simulation for Investigations in Hallstatt Archaeology
}

\author{
Johannes Tanzler ${ }^{1 *}$, Niki Popper ${ }^{1}$, Gabriel Wurzer ${ }^{2}$, Anke Bacher ${ }^{2}$, Kerstin Kowarik ${ }^{3}$, \\ Hans Reschreiter ${ }^{3}$, Felix Breitenecker ${ }^{1}$
}

${ }^{1}$ Institute of Analysis and Scientific Computing, TU Wien, Wiedner Hauptstraße 8-10, 1040 Vienna, Austria; *johannes.tanzler@tuwien.ac.at ${ }^{2}$ Institute of Architectural Sciences, TU Wien, Treitlstraße 3, 1040 Vienna, Austria

${ }^{3}$ Natural History Museum Vienna, Burgring 7, 1010 Vienna, Austria

SNE 28(3), 2018, 129 - 132, DOI: 10.11128/sne.28.sn.10436 Received: Sept. 15, 2016 (Selected EUROSIM Congress 2016 Postconf. Publ.), Revised Aug. 25, 2018, Accepted: Sept. 5, 2018 SNE - Simulation Notes Europe, ARGESIM Publisher Vienna, ISSN Print 2305-9974, Online 2306-0271, www.sne-journal.org

Abstract. The prehistoric salt mines of Hallstatt in Austria are subject of great interest for archaeologists. Salt mining activities are dated to 1458-1245 B.C. in the Bronze Age. Modelling and simulation as virtual computational experimental archaeology' can contribute important insights into different areas of archaeology as an addition to traditional experimental methods. In a cooperative project between the Natural History Museum Vienna and the TU Wien, questions regarding prehistoric mining processes, logistic processes, and population growth in the agricultural environment are analysed by modelling and simulation. This contribution presents simulation studies, which allow to study short-term mining processes and long-term population dynamics and agricultural working processes. Moreover, essentially, the simulation studies allow also excluding cases for these working processes. This fact underlines a special property of simulation in the area of archaeology: while classical modelling and simulation aims for verification of a certain assumptions, modelling and simulation in archaeology partly aims for falsification of assumptions of working processes or other historic events.

\section{Introduction}

The prehistoric salt mines of Hallstatt in Austria are subject of great interest for archaeologists, not only for their technological aspects, but also for their complex economic structure. Salt mining activities are dated to 1458-1245 B.C. in the Bronze Age $[1,2]$.

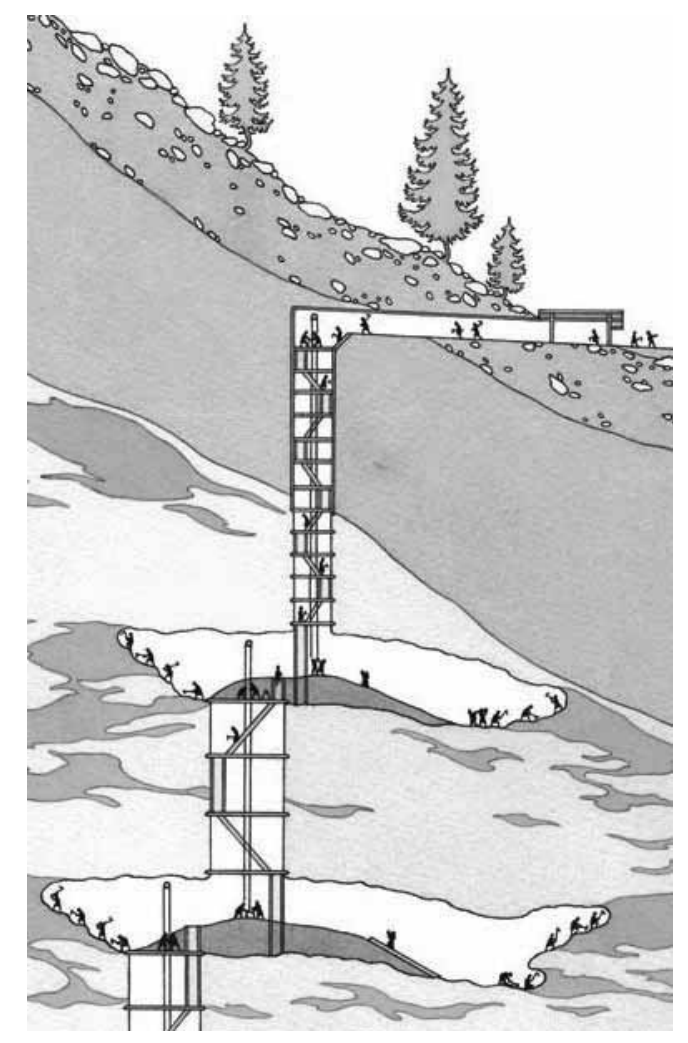

Figure 1: Schematic reconstruction of the mining halls and shaft structure with rope pull systems (๔ D. Gröbner, H. Reschreiter, NHM Vienna).

A large amount of archaeological findings of technical equipment and organic materials (timber, wooden tools, strings of bast, fur, etc.) and the perfect conditions of preservation in the mines due to the conserving properties of salt allow for a reconstruction of the working process in the mines and in the environment of the mines. Archaeologists develop a technological reconstruction in form of a mental model which suggests that mining was organized in an efficient, nearly industrial manner with highly specialized tools. 
Salt was mined in underground mining chambers (Figure 1) using special bronze picks. The broken salt was collected in buckets and carried to the vertical shaft where it was hoisted to the surface using a woolsack or cloth attached to a linden bast rope.

The high degree of specialization and functionality observable on certain tools and the design for high efficiency suggest that the workforce had highly specialized knowledge in mining technology and infrastructure [2]. Furthermore, the mineworkers were dependent on the population environment, including cultivating and harvesting the surrounding land, and on proper logistic transport processes for salt (outbound), necessary goods, which could not be, produced onsite (outbound), and partly on food delivery (in-bound).

The mental models - for the short-term mining process and for the long-term cultivation and harvesting processes and for the population dynamics raise further questions, which need to be formalized and - in case of the short-time processes - are typically investigated in experiments using re-constructions of prehistoric tools and utilities (experimental archaeology). Modelling and simulation as virtual computational experimental archaeology can also help to gain knowledge about technological issues and allow comparing different scenarios. Results of this work (experiments and simulation) and their interpretation then allow archaeologists to make conclusions about the technological concept and together with new excavation findings update their mental model leading to an iterative process.

Simulationists are faced with an interesting change of the aims of a simulation study. Because of only little evidence and only few findings, assumptions on the processes to be analysed by modelling and simulation cannot be really validated and verified - so an opposed strategy is often the better one: assumptions are falsified by modelling and simulation [3], so that after some 'falsifications' the nature of the processes comes up.

\section{Short-time Mining Processes}

Already in bronze age mining was a complex working task, with need for tools, and need for supply. Most important were tools for direct mining - bronze picks, tools for transport - buckets and rope systems, and tools for lightning.

Use of Bronze Picks. Archaeologists know from excavation findings that the salt was mined using bronze picks with wooden handle ([2], Figure 2).

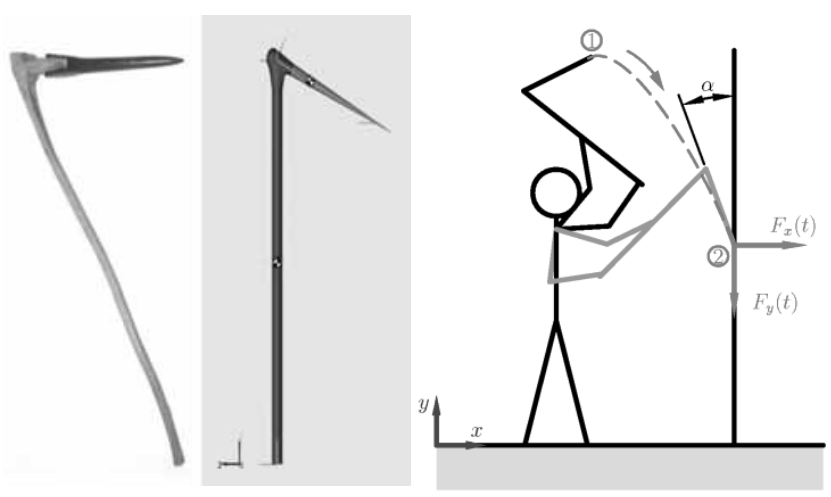

Figure 2. Bronze pick for salt mining: archaeological reconstruction (left; @ A. Rausch, NHM Vienna), pick rigid body model (midst), and supposed trajectories for use of the pick (right).

Highly interesting is the unusual shape of these picks with a typical angle between the shaft and tip of about 55 to 75 degrees. It is believed that this particular shape was adapted to the specific working conditions in the Hallstatt mines. The small angle does not allow typical circular hacking motion - it is not yet completely clear how such a pick was used.

Modelling the pick as a rigid body system (Figure 2, midst and right) allows dynamic simulation and evaluating possible movement scenarios. Two phases are considered in the model setup by mechanical component modelling ([4]): free motion - pick accelerates along a fixed trajectory, and when collision with the wall is detected - the body decelerates until it comes to a stop.

Different usage of the pick can be considered, e.g. breaking the salt on the wall or on the floor, different grip points, using one or two hands, etc. (detailed results in [4]). Other scenarios like mining the salt on horizontal or inclined surfaces are also currently investigated. However, simulation shows that mining on the floor seems more exhausting, requires more energy and is therefore less efficient than mining on the wall - an example for falsification by modelling and simulation.

Use of Rope Pull Systems. Rope pull systems were used to hoist the broken salt from the mining halls through shafts to the surface $([3,4]$, Figure 1 and Figure 3).

While there are archaeological findings of bast ropes and other appliances, there are still some matters regarding the construction, length and arrangement of the rope pull systems at issue. 

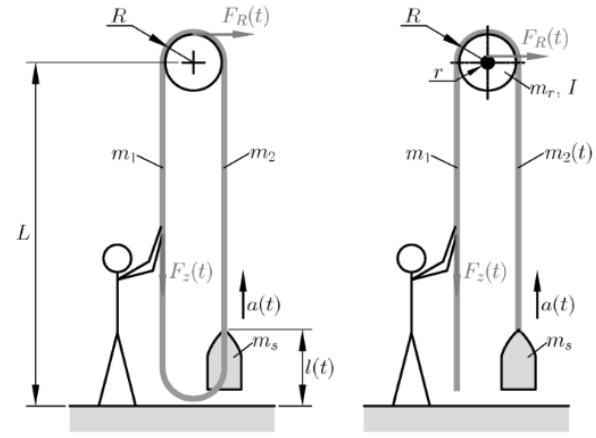

Figure 3. Different design options for the rope pull system with closed rope (left) or open rope (right).

To estimate and compare the time and strength requirements for transporting the salt, various options are analysed using simulation models. For example, two variants of the rope design, an open and a closed version, is analysed (Figure 3). An important issue also concerns modelling of the rope guide, for which two possibilities, one with sliding friction on a $\log$ and one with return pulley are considered.

Balance of forces, mass of the rope, forces of inertia, coulomb friction force lead to a partly nonlinear model for the rope dynamics [4]. The model was implemented in MATLAB. In summary, the simulation results show significant force requirement for the model with sliding friction, especially because of the high mass of the rope. This is also the reason for limitations regarding the maximum allowed shaft height (detailed results in [4]).

Woodchip, Lighting and Air Consumption. During mining, burning sticks of wood served as the only illumination in the mining halls (Figure 1). Burnt down woodchips were found during excavation in large quantities. The resulting light intensity depending on the number of burning woodchips can be estimated using a uniform arrangement in a mining hall.

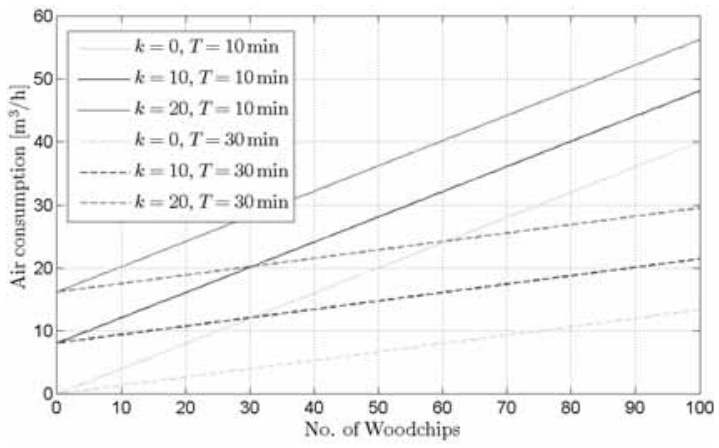

Figure 5. Simulation results for air consumption depending on number of woodchips, burning time $T$ and workers $k$.
Furthermore, some static calculations help estimating the oxygen consumption of the flames, which, in addition to the oxygen demand of the workers, give information about the necessary air ventilation. Figure 5 shows interesting simulation results with respect to air consumption - giving hints for possible numbers of miners and length of mining shifts.

\section{Long-time Working Processes and Supply of Population}

Long-time case studies give a clue how many people, including the mine workers, could have been fed by harvesting the surrounding land. It seems likely that some of the gathered salt was used to be exchanged for food, but the question is how much additional food was needed. Basis for these case studies is agent-based modelling and simulation of the population dynamics and working dynamics, from mining to harvesting.

Generally, the village is assumed to be located close to the mine and almost all fields beside the grass fields are located in the valley (Figure 5).

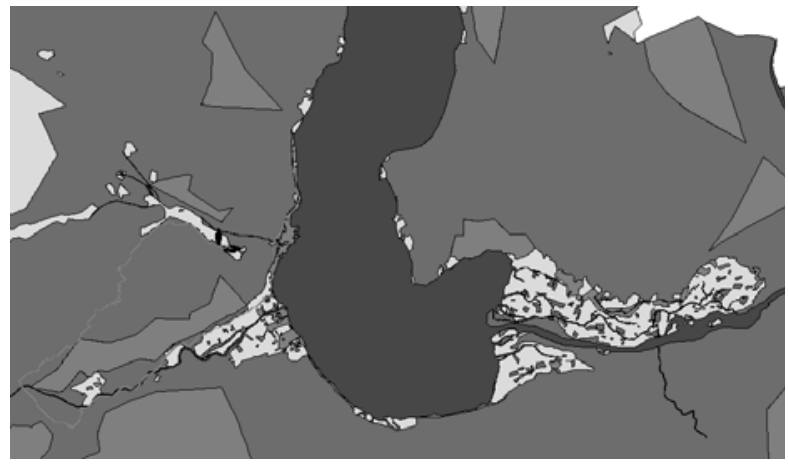

Figure 5: Map of Hallstatt area: at left hill with mining area and mining village, at right valley with agricultural area (lake - blue, garden -red, field - brown, grass - light green, wood - dark green, rock -grey).

Possible Stable Population. A basic question is, how many people lived in the Hallstatt prehistoric village. Based on the nutrition facts and the average energy consumption of a person, an agent-based model for the population can be derived ([5]). Simulations over 300 years result in a partly stable population for survival.

Various scenarios are simulated and allow falsification of unrealistic assumptions. For instance, depending on weather influences simulation is used to show the amount of each type of nutrition that has to be bought or that is over produced (Figure 6). 


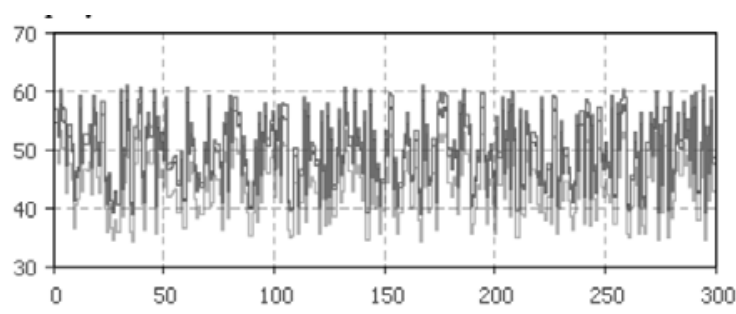

Figure 6. Simulation results with variation of food composition (green: available/used meat, red: available/used beans, blue: available/used grain)

Overall Working Processes. In bronze age, in Hallstatt complex working processes have been set up. Agent-based modelling and simulation allows to study the co-operation of these processes, from mining via food supply to harvesting and socialising.

Basis is a population dynamic with estimated birth and death gathered from another project. The relevant working procedures are:

- seeding and mowing

- harvesting

- wood production

- wood chip production

- salt mining

The scheduling of the workload is highly dependent on the date especially concerning the agricultural tasks. When the optimal day for a specific task has come, an agent gets a task assigned in the morning, then goes to the location and performs it. Afterwards the agent gets the next task and directly heads to the next area which has not been processed yet. To minimize the walking time, it is estimated how many people have to work on the specific area.

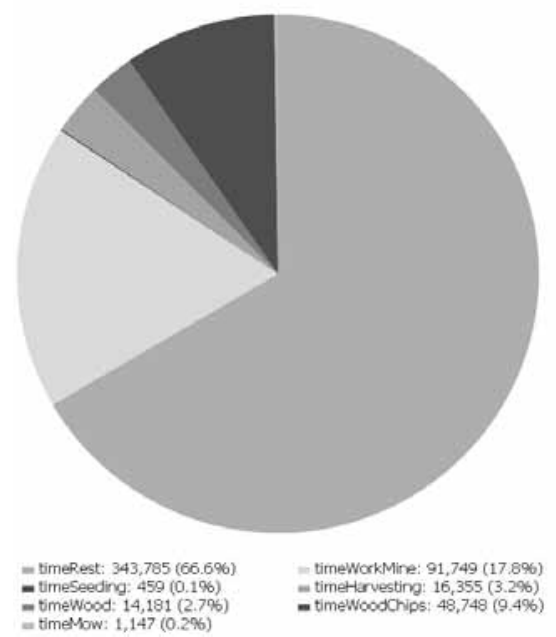

Figure 7: Overall distribution for working processes.
On days without agricultural work, the agents are assigned to work in the mine if there are enough woodchips in the stock to light the mine. Otherwise the task is to make wood chips, or if there is not enough wood, to manage to get some.

The results of these simulations studies are mainly individual and overall time distributions for the working processes. Emphasis is put on working time in the mine, which allows to estimate the salt production. Figure 7 shows an overall distribution for the working processes

Second Settlement. The miners' village is assumed to be located close to the mine, and almost all fields are located in the valley. This raises the guess for a second settlement in the valley (on place of nowadays Hallstatt) with advantages of shorter distances for harvesting.

The model allows such a case study, and indeed the simulation results show that the assumption of a second village in the valley is a promising alternative, with a better efficiency of workload scheduling.

\section{Conclusion}

The simulation case studies presented indeed allowed to exclude some assumptions on working processes in the salt mine and in the agricultural environment - underlining the importance of modelling and simulation for 'falsification' in archaeological research.

\section{References}

[1] Grabner M, Reschreiter H, Barth F E, Klein A, Geihofer D, Wimmer R. Die Dendrochronologie in Hallstatt. Archäologie Österreichs, 17(1), pp. 49-58.

[2] Reschreiter H, Kowarik K. The Bronze Age. In: Kern et al. Kingdom of Salt: 7000 Years of Hallstatt. Vienna: VPA3, Natural History Museum Vienna, 2009, pp. 48-64

[3] Popper N. Comparative Modelling and Simulation: A Concept for Modular Modelling and Hybrid Simulation of Complex Systems. PhD Thesis, TU Vienna, 2015.

[4] Heinzl B, Auer E, Slowacki B, Kowarik K, Reschreiter H, Popper N, Breitenecker F. Physical Modelling for Hallstatt Archaeology. Simulation Notes Europe SNE 22(1), 2015, pp 25-32, doi: 10.11128/sne.22.tn.10109

[5] Tanzler J, Pichler P, Kowarik K, Reschreiter H, Wurzer $\mathrm{G}$, Bacher A, Breitenecker F. Modelling agricultural constraints for population size in prehistoric Hallstatt. Proc. ERK Conference Portoroz Sept. 2013, IEEE Slovenia Publ., 2013, pp 157-160

[6] Breitenecker F, Bicher M, Wurzer G. Agent-based modeling and simulation in archaeology, chapter: AgentBased Simulation in Archaeology: A Characterization. [S.1.]: Springer, 2013. 


\title{
A Simulation Model of a School's Evacuation
}

\author{
Aleksandrs Korolko, Valdis Abrams, Natalja Kucerenko*, Dins Lolans
}

Riga Secondary School nr 80, Andromedas gate 11, 1084 Riga, Latvia; ${ }^{*}$ r80vs@riga.Iv

SNE 28(3), 2018, 133 - 135, DOI: 10.11128/sne.28.sn.10437

Received: Sept. 15, 2016 (Selected EUROSIM Congress 2016 Postconf. Publ.), Revised July 30, Accepted: August 25, 2018

SNE - Simulation Notes Europe, ARGESIM Publisher Vienna, ISSN Print 2305-9974, Online 2306-0271, www.sne-journal.org

Abstract. This research paper describes a simulation model that was implemented as an evacuation efficiency evaluation software tool. Currently, according to experts, evaluation of the evacuation schemes in Latvia is done based on field experiments. This has been shown to result in an inefficient allocation of human resources and interruption of the study process at school. Consequently, a simulation model for a school's evaluation was required that does not rely on field experimentation. Using (a) the data provided by the school's administration and (b) simulation modelling methodology, a decision support system for an evaluation of an evacuation process was developed and tested. This system supplies the school's administration with information about the problem areas in the current evacuation process. The simulation process results are analyzed in a data collection environment (graphs, diagrams, tables etc.) that was developed using the JAVA programming language. The hypothesis of a successful simulation model was tested applying the Mann-Whitney test and found to be credible. Based on the findings, a number of recommendations were developed for increasing the efficiency of the evacuation process in buildings sharing the layout of the school tested here. With necessary adjustments, the developed simulation model can be recommended for evaluating evacuation schemes in buildings with similar layouts, and possibly for implementation beyond Latvia.

\section{Introduction}

As a result of significant developments in computer science it has become easier to solve complex tasks, especially ones that require considerable time and financial investment. Among the most popular such developments is simulation modelling (SM).
Modelling means to replace the original object of research with a defined image or other object (model), studying the attributes of the original. The model is then deployed in experiments in the place of the original, delivering data about the research object [1]. The simulation modelling method is considered one of the most efficient methods in the study of complex systems, because "SM enables experimentation with real or applied systems, in instances when the real object is unavailable or its use is not desired" [2]. With the help of the agent based modelling (ABM) method, simulation modelling agents are able to independently evaluate situations, make decisions and act based on them according to the system settings [3].

In this instance, a simulation model was implemented as an evacuation process efficiency evaluation software tool. According to experts, the evaluation of the evacuation schemes in Latvia currently relies on field experiments. This includes the hospital, kindergarten, and school evacuation systems and leads to inefficient allocation of human resources and finances. Consequently, this scientific work attempted to solve the task of developing a decision making system serving as a simulation model of a school's evacuation. Its main function is to evaluate the efficiency of the evacuation process without interrupting the study process. This scientific work serves as a school-university partnership example. This partnership enables one to find a future university degree track and opens opportunities for scientific research already at the high school level.

\section{Methodological Foundation of the Scientific Research Work}

The theoretical section of this scientific research work includes an introduction to simulation modelling with an emphasis on agent based simulation (ABM); a comparison of various computer based simulation modelling systems; an overview of pertinent literature and sources; an overview of simulation modelling methodology; an analysis of AnyLogic simulation software. 
$\mathrm{ABM}$ is defined as follows: "Agent is an entity with an autonomous behaviour, able to make decisions based on given parameters, interact with the surrounding environment, and adapt to the changes therein" [4].

The following entities can act as agents: transport, devices, non-material objects, organizations and people (for example: children, students, teachers). The task of ABM simulation consists of: (a) defining the parameters of agents and the environment and (b) studying the agents' behaviour in various environments and interaction scenarios. By situating various agents in a defined space and within the corresponding interaction parameters, it is possible to predict the behaviour of the entire system [5].

As is known, the field of simulation modelling employs the following software (to name a few): GPSS, SYMULA, Arena, AutoMod, Enterprise Dynamics, FlexSim (in discrete event simulation); Net Logo, Swarm, Repast, ASCAPE, Extend (in agent based simulation); VenSim, PowerSim, AnyLogic, iSink (in system dynamic simulation). AnyLogic software, however, is applicable in all three types of simulation [6]. Based on a comparison of these simulation modelling systems it was concluded that the AnyLogic system offered the widest range of functions. Consequently, AnyLogic SM system was selected for the development of the simulation model in this scientific work.

\section{Development of a Simulation Model}

Based on the AnyLogic methodology, a simulation model was created for a school's evacuation. The model's development consisted of eight stages: designing the system structure with the help of the Pedestrian library; classifying the active objects; entering the standard block parameters; entering the additional parameters; designing the animation; calibrating the model; validating the model; experimental approbation of the finished model. The following data was supplied by the school's administration in order to make a validation of the model: school layout, evacuation schemes, number of students in each classroom, number of school staff, and evacuation times over three years of fire drills.

The development began with selecting an appropriate scale for an authentic reflection of the school's layout.
The AnyLogic agents were created along with algorithms of their behaviour (movement, decisions etc.) in emergency situations. A schematic algorithm was created connecting the evacuation paths for students with school emergency exits. The following standard block parameters were entered: Ped Source, Ped Go To, Ped Change Ground, Ped Group Assemble, Camera. Additional parameters included histograms timing the evacuation process, as well as a Java function (Last Exit) taking and depicting the time of the last agent's exit.

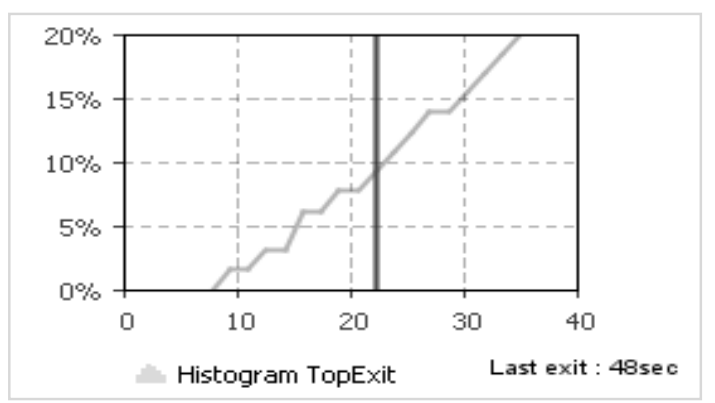

Figure 1. Simulation model activity histogram.

The 2D and 3D animation featured a special 3D log and a Camera object showing a fixed layout sector. A special program interface was created for expedited switching between floors, histograms and 3D model animation. Pedestrian library images were used to designate various members of the school personnel.

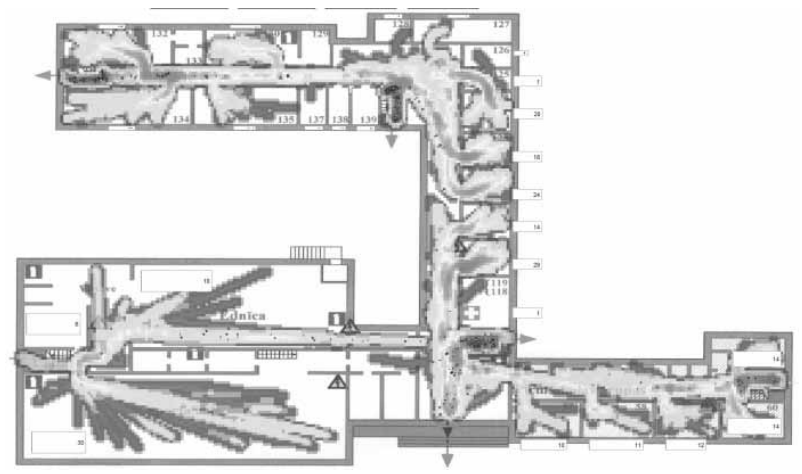

Figure 2. Simulation model animation in 2D.

A statistical hypothesis test was implemented applying the Mann-Whitney test. It confirmed the main hypothesis: data discrepancy between the model-based test and real data is not significant. The following MannWhitney U test was used:

$$
U=N M+\frac{N(N+1)}{2}-\sum_{x_{1}} \operatorname{Rank}\left(x_{i}\right)
$$

As a result, the simulation model (SM) was found to be credible. 


\section{Conclusion}

This scientific research work contains a simulation model for a school's evaluation that does not rely on field experimentation. The pertinent theory is studied and the existing approaches to simulation modelling (based on the ABM method) are surveyed. Various simulation software systems are compared and AnyLogic methodology is studied closely. Employing the AnyLogic system, in the practical section of the research work a decision support system is produced evaluating the efficiency of a school's evacuation and informing the school's administration about the problem areas in the evacuation process.

The model's flexibility and credibility allows for its easy adaptation not only in buildings with similar layouts in Latvia (for example: schools or kindergartens), but also abroad. The development's authors are open to partnership, plan to further optimize the model, and can offer recommendations and instructions for the model's implementation. This material reflects the scientific research work of M. Savrasov (Dr. Sc. Ing., Assistant professor), N. Kucerenko (Mag. Paed.), V. Zemlanikins (Tech. consultant).

\section{References}

[1] A.M. Law and W.D. Kelton, "Simulation ModelingModelling and Analysis. McGraw-Hill Series in Industrial Engineering and Management Science," 3rd ed. McGraw-Hill: New York, 2000, pp. 529-551.

[2] В.П. Строгалев, И.О. Толкачева, "Имитационное моделирование: Учеб. пособие.” МГТУ: Москва, 2008, 7 стр.

[3] E. Bonabeau. (2002). Agent-based modeling: Methods and techniques for simulating human systems [online]. Available: http://www.pnas.org/content/99/suppl_3/7280.full.pdf

[4] В. Маликов. (2013). Практикум по моделированию сложных систем в среде AnyLogic 6 [online]. Available: http://simulation.su/uploads/files/default/2013malikov-praktikum-anylogic-6.pdf

[5] AnyLogic Portal [online]. Available: http://www.anylogic.com/agent-based-modeling

[6] А. Г. Купряшкин. (2015). Основы моделирования систем [online]. Available : http://www.anylogic.ru/upload/pdf/osnovi_modelirovani a_sistem.pdf 



\title{
Interactive Modelling and Simulation of Micromirror MEMS Devices
}

\author{
Sarbast Rasheed \\ Department of Engineering, American University of Iraq, Sulaimani (AUIS), Sulaimani, Iraq; \\ *sarbast.rasheed@auis.edu.krd
}

SNE 28(3), 2018, 137 - 140, DOI: 10.11128/sne.28.sn.10438

Received: Sept. 15, 2016 (Selected EUROSIM Congress 2016 Postconf. Publ.), Revised August 25, Accepted: Sept. 5, 2018 SNE - Simulation Notes Europe, ARGESIM Publisher Vienna, ISSN Print 2305-9974, Online 2306-0271, www.sne-journal.org

Abstract. This paper presents an interactive software package for the modelling and simulation of microelectromechanical system (MEMS) devices utilizing the MATLAB high-level programming language and its interactive environment. The package provides a dynamic analysis and frequency responses of a 1-D torsional micromirror electrostatically actuated with staggered vertical combdrives. Applying a frequency sweep to the micromirror equation, the torsional mode natural frequency may be estimated. The developed package consists of several graphical user interfaces used for modeling MEMS devices. The software package is useful for computing the forces and torques for different micromirror geometries.

\section{Introduction}

Behaviour of microelectromechanical system (MEMS) is often very sensitive to geometry and applied voltages; and their responses could be very non-linear. Therefore, mathematical modelling becomes a very important technique for gaining physical understanding of these systems. To predict the behaviour of MEMS, the shape and material properties are used as inputs with a goal to develop models to enable better understanding of MEMS performance and help in the design and fabrication of MEMS to achieve optimum performance. For this purpose, an interactive system is developed for modeling micromirror MEMS devices. The developed system exhibits a style of control and works as an interactive environment for modeling MEMS devices. It provides users with a full control of the process of predicting the behaviour of micromirror MEMS devices.
Modeling the performance of MEMS devices involves computing the deformations and stresses on structures subjected to electric fields, and hence electrostatic forces. The change of shape changes the capacitance [1] of these structures and this in turn changes the forces on them. The final configuration must satisfy both the electric field as well as the mechanics of equations.

The dynamic analysis of MEMS devices is complicated by the fact that there are two physical domains: electrical and mechanical with nonlinear coupling between them. In this paper, we are interested in investigating the linear and nonlinear dynamical behavior of a micromirror actuated with single-sided and doublesided vertical combdrives [2] in an interactive fashion. We investigate the electromechanical response of a scanning micromirror in the linear and nonlinear regions of the electrostatic torque induced by its actuators. The nonlinear behavior of the frequency response with small and large scanning angles is examined using upsweep (increasing) frequency mode and down sweep (decreasing) frequency mode.

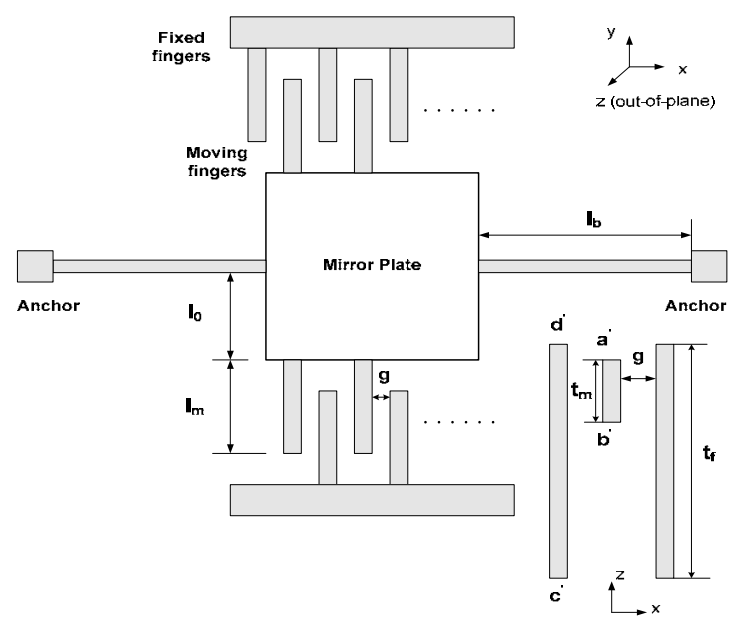

Figure 1. Schematic diagram of a micromirror actuated with double-sided staggered vertical combdrives. 


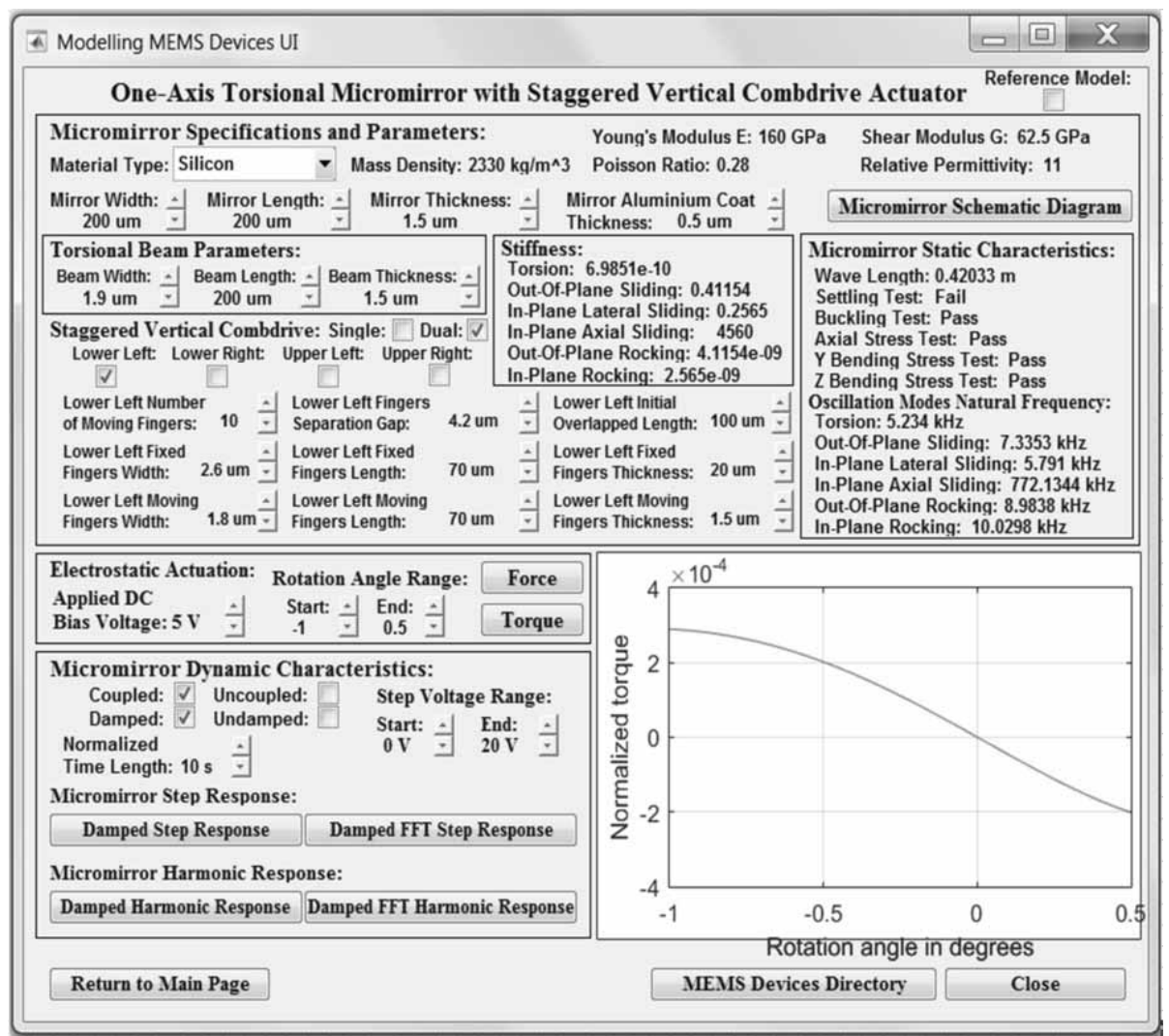

Figure 2. The MATLAB user interface for modeling a scanning micromirror with dual staggered vertical combdrive actuator.

\section{Staggered Vertical Combdrive}

Out-of-plane rotational scanning may be achieved within micromirrors using staggered vertical combdrive (SVC) actuators as shown in Figure 1. SVC requires a vertical offset between the moving fingers (rotor) and the fixed fingers (stator) for out-of-plane rotation. An electrostatic field between these two sets of combs will produce an out-of-plane force and a torque around the torsional axis of the mirror as a result of the fringing field applied to the movable fingers.

The equation of motion of the micromirror rotation around the $\mathrm{x}$-axis using a lumped-mass model can be written as:

$$
I_{m} \frac{d^{2} \theta}{d t^{2}}+C_{d} \frac{d \theta}{d t}+K_{s} \theta=T_{e}(\theta)
$$

where $I_{m}$ is the mass moment of inertia of the micromirror; $C_{d}$ is the damping coefficient; $K_{s}$ is the torsion stiffness; $\theta$ is the tilt angle of the micromirror; and $T_{e}$ is the torque contributed by the electrostatic force between the fixed fingers and movable fingers of the SVC actuator.

\section{Design of SVC Actuator}

The angular motion induced by the SVC actuator is due to the generated torque, $T_{e}$, given by [3], [4]:

$$
\begin{aligned}
& T_{e}=2 N_{f} \frac{\varepsilon_{0} \pi^{2} V^{2}}{4 g} \int_{l_{0}}^{l_{0}+l_{m}} \frac{1}{(a-b)}\left(a \frac{b-d}{a-d}-b \frac{a-c}{b-c}\right) \\
& \frac{z d z}{[F(\partial(u=0), q)+F(\kappa(u=0), q)]^{2}} .
\end{aligned}
$$

where $V$ is the voltage difference between the combs; $\varepsilon_{0}$ is the free-space permittivity, $N_{f}$ is the number of movable fingers, $g$ is the gap between the fingers, $l_{0}$ is the distance from the axis of rotation to the root of the moving fingers, $l_{m}$ is the distance from the root to the tip of the moving finger, $F$ denotes the incomplete elliptic function of the first kind, and the dimensionless parameters $\partial, \kappa$, and $q$ are defined as follows: 
$q=\sqrt{\frac{(b-c)(a-d)}{(a-c)(b-d)}}, \quad \partial=\sin ^{-1} \sqrt{\frac{(b-d)(u-c)}{(b-c)(u-d)}}$,

$\kappa=\sin ^{-1} \sqrt{\frac{(a-c)(b-u)}{(b-c)(a-u)}}$.

Assuming the width of the comb fingers to be infinitely small, the parameters $a, b, c, d$ represent the conformal mapping of the $\mathrm{x}-\mathrm{z}$ plane boundaries of a combdrive unit comprised of half a movable finger $a^{\prime}, b^{\prime}$ and half a fixed finger $c^{\prime}, d^{\prime}$ into the w-plane using the transformation function $w=e^{\pi z / g}$, where $w=u+j v$.

The plot inside the user interface of Figure 2 shows the normalized torque per unit combdrive as a function of $\theta$, where $T_{e}=2 N_{f} \cdot T_{\text {unit }}$. For small angular displacement, $T_{\text {unit }}$ can be approximated by a fourth-order polynomial in $\theta$ such that:

$$
T_{\text {unit }} \approx \frac{\varepsilon_{0} \pi^{2} V^{2}}{4}\left(p_{4} \theta^{4}+p_{3} \theta^{3}+p_{2} \theta^{2}+p_{1} \theta+p_{0}\right)
$$

where $p_{4}, p_{3}, p_{2}, p_{1}, p_{0}$ are the coefficients of the polynomial fit. Then the nonlinear equation of motion (1) can be solved numerically to determine the micromirror response.

\section{Interactive Micromirror Dynamic Analysis}

The goal of the interactive dynamic analysis is to develop a convenient model for estimating the fundamental (first) natural frequency (the torsional mode). The dynamic modelling in this paper is based on geometric dimensions of a micromirror presented below:

$$
\begin{array}{ll}
\text { Torsional bars } & \text { length } l_{b}=200 \mu \mathrm{m} \\
& \text { width } w_{b}=1.9 \mu \mathrm{m} \\
& \text { thickness } t_{b}=1.5 \mu \mathrm{m} \\
\text { Micromirror } & \text { length } l_{r}=200 \mu \mathrm{m} \\
& \text { width } w_{r}=200 \mu \mathrm{m} \\
& \text { thickness } t_{r}=1.5 \mu \mathrm{m} \\
\text { Movable fingers } & \text { length } l_{m}=70 \mu \mathrm{m} \\
& \text { width } w_{m}=1.8 \mu \mathrm{m} \\
& \text { thickness } t_{m}=1.5 \mu \mathrm{m}
\end{array}
$$

Fixed fingers length $l_{f}=70 \mu \mathrm{m}$

width $w_{f}=2.6 \mu \mathrm{m}$

thickness $t_{f}=20 \mu \mathrm{m}$

Separation gap between fingers $g=4.2 \mu \mathrm{m}$

Number of moving fingers $N_{f}=10$.

The above micromirror and comb-drive geometric dimensions; and the material properties have been specified in the control objects of the user interface shown in Figure 2 for a double-sided vertical comb-drive. Figure 2 also shows the plot of the unit torque $T_{\text {unit }}$ versus tilt angle $\theta$ varied from -1.0 to 0.5 degrees.

To determine the micromirror response, shown in Figure 4 and Figure 5, a 5 volt amplitude sinusoidal excitation voltage with upsweep frequency ranges $\Omega$ is applied for 50 seconds, as shown in Figure 3, starting from $4200 \mathrm{~Hz}$ and then solving the equation of motion numerically. From Figure 4, we can estimate the torsional mode natural frequency to be $4340 \mathrm{~Hz}$.

For a single-sided vertical comb-drive, Figure 6 shows the specification of the micromirror and combdrive geometric dimensions; and the material properties in the control objects of the user interface. Figure 6 also shows the plot of the unit torque $T_{\text {unit }}$ versus tilt angle $\theta$ varied from -2.0 to 3.0 degrees.

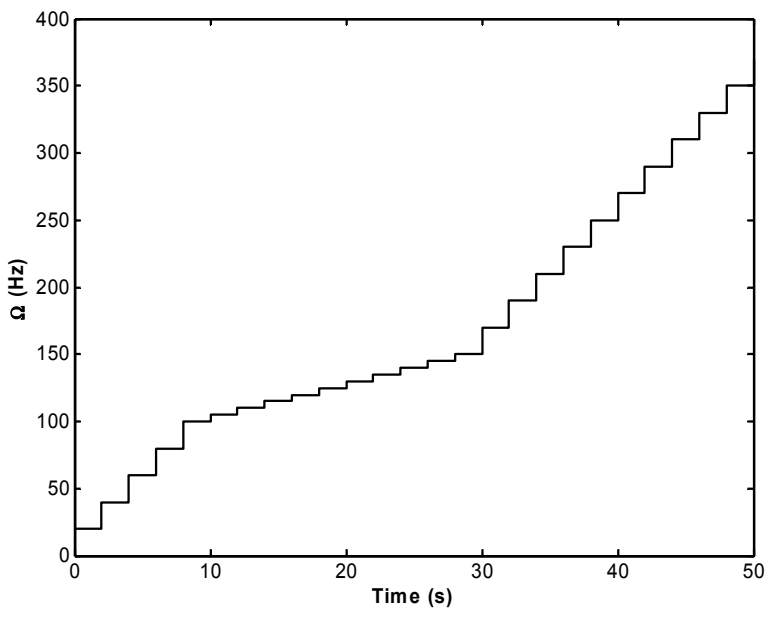

Figure 3. Upsweep frequency $\Omega$ function for $50 \mathrm{~s}$. 


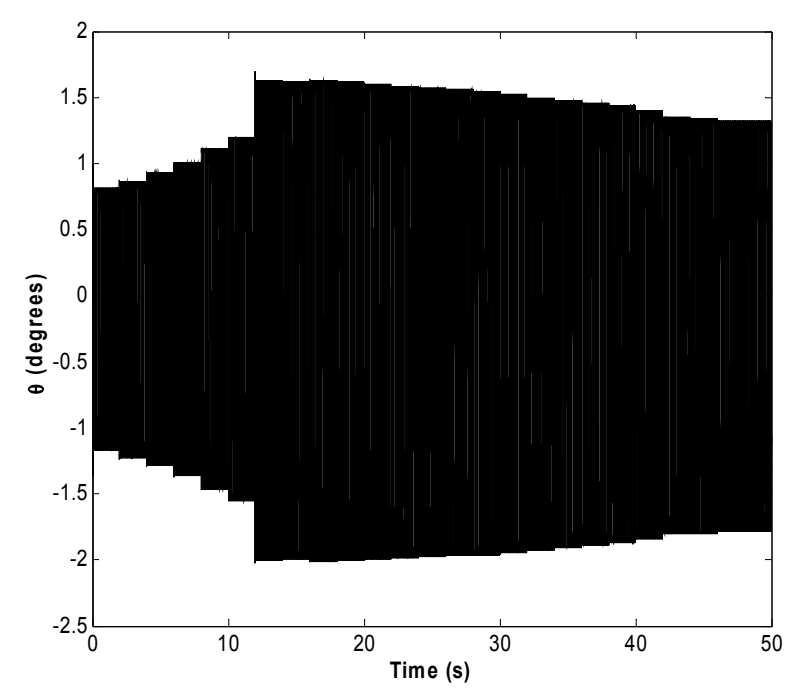

Figure 4. Micromirror response due to sinusoidal excitation voltage with upsweep frequency ranges.

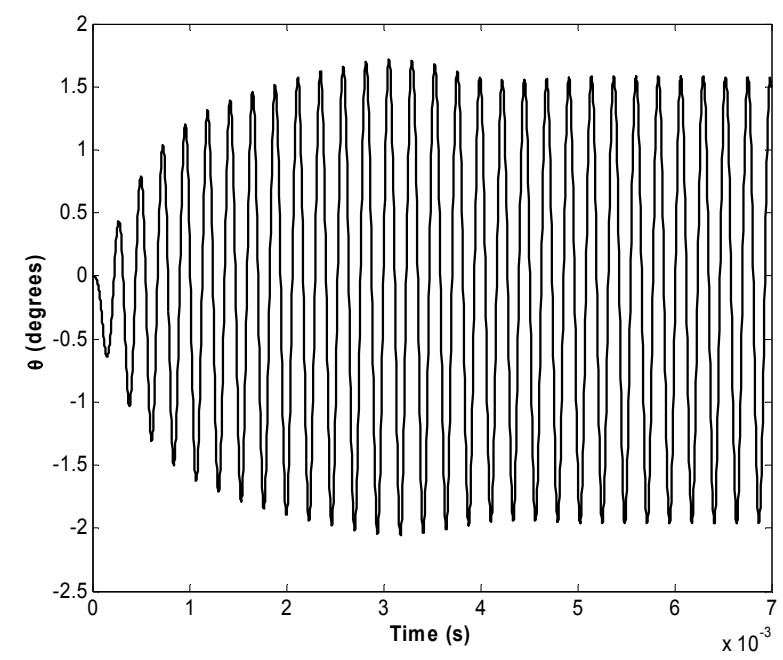

Figure 5. Micromirror response for $7 \mathrm{~ms}$ driven at the estimated natural frequency $4340 \mathrm{~Hz}$.

\section{Conclusion}

An automated method for the modeling and simulation of MEMS devices in the form of an interactive modeling software package had been constructed. The package provides users with a full control of the process and allows them to experiment with different configurations and parameters that can be selected and changed using the displayed control objects of the user interface. The developed environment is convenient and easy to use and change as it involves multiple runs designed to investigate the effects of different system parameters, initial conditions, and model changes.

\section{References}

[1] Chang CM, Wang SY, Chen R, Yeh JA, Hou MT. "A comb-drive actuator driven by capacitively-coupledpower," Sensors, vol. 12, no. 8, pp. 10881-10889, 2012.

[2] Rasheed S, Yeow J, McPhee J. "Dynamic analysis of micromirrors with staggered vertical combdrives actuation,"in Proceedings of the 21st Canadian Congress of Applied Mechanics (CANCAM) 2007 Conference, Ryerson University, Toronto, Canada, June 3-7, 2007, pp. 585-586.

[3] Yeh JLA, Hui CY, Tien NC. "Electrostatic model for an asymmetric combdrive," IEEE Journal of Microelectromechanical Systems, vol. 9, no. 1, pp. 126-135, March 2000.

[4] Hui CY, Yeh JLA, Tien NC. "Calculation of electrostatic forces and torques in MEMS using path-independent integrals," Journal of Micromechanics and Microengineering, vol. 10, no. 3, pp. 477-482, 2000. 


\section{SNE Simulation News}

\section{EUROSIM Data and Quick Info}
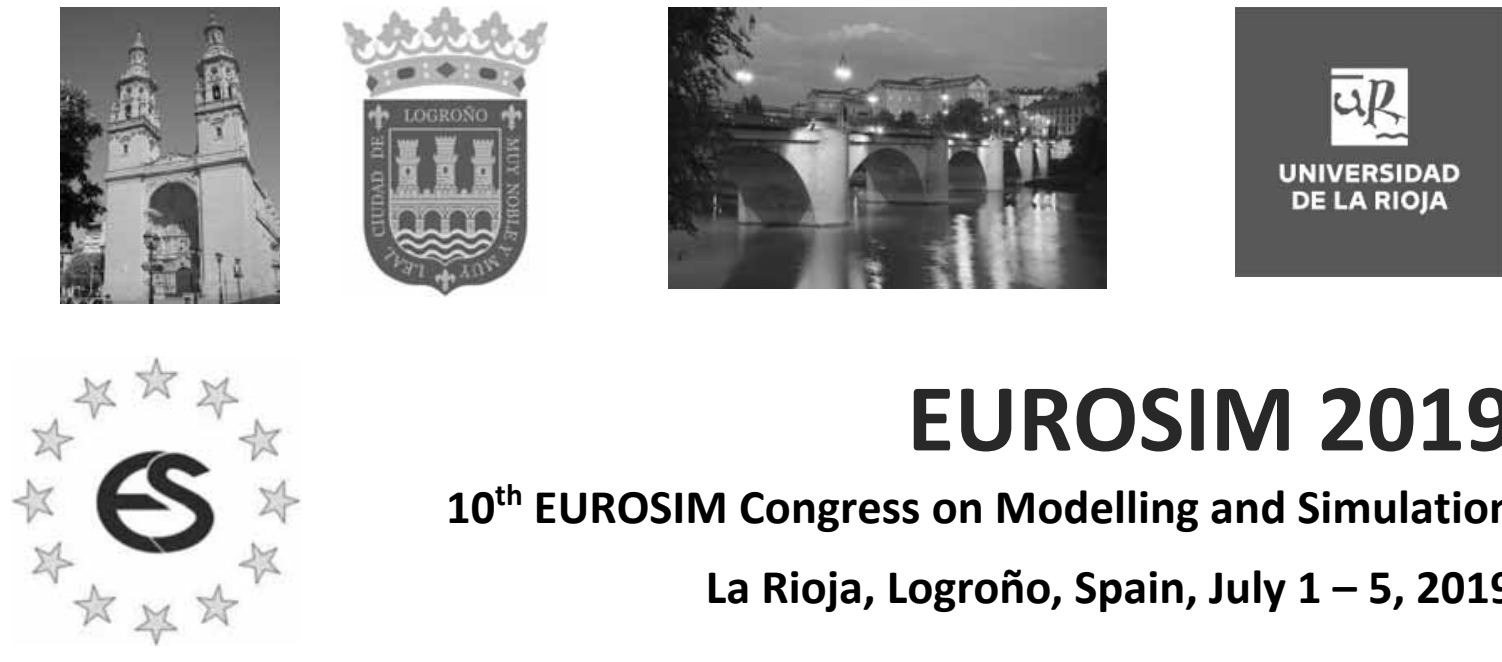

EUROSIM 2019

$10^{\text {th }}$ EUROSIM Congress on Modelling and Simulation

La Rioja, Logroño, Spain, July 1 - 5, 2019

Contents

Short Info EUROSIM N2

Short Info ASIM, CEA-SMSG N3

Short Info CSSS, DBSS, LIOPHANT, LSS N4

Short Info KA-SIM, MIMOS, NSSM, PSCS N5

Short Info SIMS, SLOSIM, UKSIM ..N6

Short Info ROMSIM, Albanian Society .N7

Simulation Notes Europe SNE is the official membership journal of EUROSIM and distributed / available to members of the EUROSIM Societies as part of the membership benefits.

If you have any information, announcement, etc. you want to see published, please contact a member of the editorial board in your country or the editorial office. For scientific publications, please contact the EiC.

This EUROSIM Data \& Quick Info compiles data from EUROSIM societies and groups: addresses, weblinks, and officers of societies with function and email, to be published regularly in SNE issues. This information is also published at EUROSIM's website www.eurosim.info.

\section{SNE Reports Editorial Board}

EUROSIM Emilio Jiménez, emilio.jimenez@unirioja.es Andreas Körner, andreas.koerner@tuwien.ac.at Miguel Mujica Mota,m.mujica.mota@hva.nl

ASIM A. Körner, andreas.koerner@tuwien.ac.at CEA-SMSG Emilio Jiménez, emilio.jimenez@unirioja.es cSSS Mikuláš Alexík,alexik@frtk.utc.sk DBSS M. Mujica Mota,m.mujica.mota@hva.nl LIOPHANT F. Longo,f.longo@unical.it LSS Yuri Merkuryev,merkur@itl.rtu.lv KA-SIM Edmond Hajrizi, info@ka-sim.com MIMOSPaolo Proietti,roma@mimos.it NSSM Y. Senichenkov, senyb@dcn.icc.spbstu.ru PSCS Zenon Sosnowski, zenon@ii.pb.bialystok.pl SIMS Esko Juuso,esko.juuso@oulu.fi SLOSIM Vito Logar, vito.logar@fe.uni-lj.si UKSIM A. Orsoni, A.Orsoni@kingston.ac.uk ROMSIM Marius Radulescu, mradulescu@ici.ro Albanian Society Kozeta Sevrani, kozeta.sevrani@unitir.edu.al

\section{SNE Editorial Office /ARGESIM}

$\rightarrow$ www.sne-journal.org, www.eurosim.info 䒠-office@sne-journal.org,eic@sne-journal.org

$\square$ SNE Editorial Office

Johannes Tanzler (Layout, Organisation)

Irmgard Husinsky (Web, Electronic Publishing)

Felix Breitenecker EiC (Organisation, Authors)

ARGESIM/Math. Modelling \& Simulation Group,

Inst. of Analysis and Scientific Computing, TU Wien

Wiedner Hauptstrasse 8-10, 1040 Vienna, Austria 


\section{EUROSIM}

\section{Federation of European Simulation Societies}

General Information. EUROSIM, the Federation of European Simulation Societies, was set up in 1989. The purpose of EUROSIM is to provide a European forum for simulation societies and groups to promote advancement of modelling and simulation in industry, research, and development. $\rightarrow$ www.eurosim.info

Member Societies. EUROSIM members may be national simulation societies and regional or international societies and groups dealing with modelling and simulation. At present EUROSIM has Full Members and $\mathrm{Ob}$ server Members, and member candidates.

\begin{tabular}{|c|c|}
\hline ASIM & $\begin{array}{l}\text { Arbeitsgemeinschaft Simulation } \\
\text { Austria, Germany, Switzerland }\end{array}$ \\
\hline CEA-SMSG & $\begin{array}{l}\text { Spanish Modelling and Simulation Group } \\
\text { Spain }\end{array}$ \\
\hline CSSS & $\begin{array}{l}\text { Czech and Slovak Simulation Society } \\
\text { Czech Republic, Slovak Republic }\end{array}$ \\
\hline DBSS & $\begin{array}{l}\text { Dutch Benelux Simulation Society } \\
\text { Belgium, Netherlands }\end{array}$ \\
\hline KA-SIM & Kosovo Simulation Society, Kosovo \\
\hline LIOPHANT & $\begin{array}{l}\text { LIOPHANT Simulation Club } \\
\text { Italy \& International }\end{array}$ \\
\hline LSS & Latvian Simulation Society; Latvia \\
\hline PSCS & $\begin{array}{l}\text { Polish Society for Computer Simulation } \\
\text { Poland }\end{array}$ \\
\hline MIMOS & $\begin{array}{l}\text { Italian Modelling and Simulation } \\
\text { Association, Italy, Observer Member }\end{array}$ \\
\hline NSSM & $\begin{array}{l}\text { Russian National Simulation Society } \\
\text { Russian Federation }\end{array}$ \\
\hline ROMSIM & $\begin{array}{l}\text { Romanian Society for Modelling and Simu- } \\
\text { lation, Romania, Observer Member }\end{array}$ \\
\hline SIMS & $\begin{array}{l}\text { Simulation Society of Scandinavia } \\
\text { Denmark, Finland, Norway, Sweden }\end{array}$ \\
\hline SLOSIM & $\begin{array}{l}\text { Slovenian Simulation Society } \\
\text { Slovenia }\end{array}$ \\
\hline UKSIM & $\begin{array}{l}\text { United Kingdom Simulation Society } \\
\text { UK, Ireland }\end{array}$ \\
\hline \multicolumn{2}{|c|}{ Societies in Re-Organisation: } \\
\hline CROSSIM & $\begin{array}{l}\text { Croatian Society for Simulation Modeling } \\
\text { Croatia }\end{array}$ \\
\hline FRANCOSIM & $\begin{array}{l}\text { Société Francophone de Simulation } \\
\text { Belgium, France }\end{array}$ \\
\hline HSS & Hungarian Simulation Society; Hungary \\
\hline ISCS & $\begin{array}{l}\text { Italian Society for Computer Simulation } \\
\text { Italy }\end{array}$ \\
\hline
\end{tabular}

EUROSIM Board / Officers. EUROSIM is governed by a board consisting of one representative of each member society, president and past president, and representatives for SNE Simulation Notes Europe. The President is nominated by the society organising the next EUROSIM Congress. Secretary, Secretary to the Board, and Treasurer are elected out of members of the board.

\begin{tabular}{ll}
\hline President & $\begin{array}{l}\text { Emilio Jiménez (CAE-SMSG), } \\
\text { emilio.jimenez@unirioja.es }\end{array}$ \\
\hline Past President & $\begin{array}{l}\text { Esko Juuso (SIMS) } \\
\text { esko.juuso@oulu.fi }\end{array}$ \\
\hline Secretary & $\begin{array}{l}\text { M. Mujica Mota (DBSS), } \\
\text { m.mujica.mota@hva.nl }\end{array}$ \\
\hline Treasurer & $\begin{array}{l}\text { Felix Breitenecker (ASIM) } \\
\text { felix.breitenecker@tuwien.ac.at }\end{array}$ \\
\hline Secretary to the & $\begin{array}{l}\text { Andreas Körner } \\
\text { andreas.koerner@tuwien.ac.at }\end{array}$ \\
\hline Board & I. Husinsky, irmgard.husinsky@tuwien.ac.at \\
\hline Webmaster & Felix Breitenecker \\
\hline SNE & felix.breitenecker@tuwien.ac.at \\
Representative
\end{tabular}

SNE - Simulation Notes Europe. SNE is a scientific journal with reviewed contributions as well as a membership newsletter for EUROSIM with information from the societies in the News Section. EUROSIM societies are offered to distribute to their members the journal SNE as official membership journal. SNE Publishers are EUROSIM, ARGESIM and ASIM.

\begin{tabular}{ll}
\hline SNE & Felix Breitenecker \\
Editor-in-Chief & felix.breitenecker@tuwien.ac.at \\
\hline
\end{tabular}

$\rightarrow$ www.sne-journal.org,

莑 office@sne-journal.org

EUROSIM Congress. EUROSIM is running the triennial conference series EUROSIM Congress. The congress is organised by one of the EUROSIM societies.

EUROSIM 2019, the $10^{\text {th }}$ EUROSIM Congress, will be organised by CAE-SMSG, the Spanish simulation society, in La Rioja, Logroño, Spain, July 1 - 5, 2019.

\begin{tabular}{l} 
Chairs / Team EUROSIM 2019 \\
\hline $\begin{array}{r}\text { Emilio Jiménez, EUROSIM President, } \\
\text { emilio.jimenez@unirioja.es }\end{array}$ \\
Juan Ignacio Latorre, juanignacio.latorre@unavarra.es \\
\hline www.eurosim.info
\end{tabular}




\section{EUROSIM Member Societies}

\section{ASIM}

\section{German Simulation Society \\ Arbeitsgemeinschaft Simulation}

ASIM (Arbeitsgemeinschaft Simulation) is the association for simulation in the German speaking area, servicing mainly Germany, Switzerland and Austria. ASIM was founded in 1981 and has now about 500 individual members, and 90 institutional or industrial members.

$\rightarrow$ www.asim-gi.org with members' area

邫info@asim-gi.org,admin@asim-gi.org

$\triangle$ ASIM - Inst. of Analysis and Scientific Computing

Vienna University of Technology (TU Wien)

Wiedner Hauptstraße 8-10, 1040 Vienna, Austria

\begin{tabular}{ll}
\hline ASIM Officers & \\
\hline President & $\begin{array}{l}\text { Felix Breitenecker } \\
\text { felix.breitenecker@tuwien.ac.at }\end{array}$ \\
\hline Vice presidents & Sigrid Wenzel, s.wenzel@uni-kassel.de \\
\cline { 2 - 2 } & T. Pawletta, thorsten.pawletta@hs-wismar.de \\
\cline { 2 - 2 } & A. Körner, andreas.koerner@tuwien.ac.at \\
\hline Secretary & Ch. Deatcu, christina.deatcu@hs-wismar.de \\
\hline Treasurer & I. Husinsky, Irmgard.husinsky@tuwien.ac.at \\
\hline Membership & S. Wenzel, s.wenzel@ uni-kassel.de \\
\cline { 2 - 2 } Affairs & Ch. Deatcu, christina.deatcu@hs-wismar.de \\
\cline { 2 - 2 } & F. Breitenecker, felix.breitenecker@tuwien.ac.at \\
\hline Repr. EuRoSıM & F. Breitenecker, felix.breitenecker@tuwien.ac.at \\
\cline { 2 - 2 } & A. Körner, andreas.koerner@tuwien.ac.at \\
\hline Internat. Affairs & O. Rose, Oliver.Rose@tu-dresden.de \\
\cline { 2 - 2 } - GI Contact & N. Popper, niki.popper@dwh.at \\
\hline Editorial Board & T. Pawletta, thorsten.pawletta@hs-wismar.de \\
\cline { 2 - 2 } SNE & Ch. Deatcu, christina.deatcu@hs-wismar.de \\
\hline Web EuRoSıM & I. Husinsky, Irmgard.husinsky@tuwien.ac.at \\
\hline
\end{tabular}

ASIM is organising / co-organising the following international conferences:

- ASIM Int. Conference 'Simulation in Production and Logistics' - biannual

- ASIM 'Symposium Simulation Technique'

- biannual

- MATHMOD Int. Vienna Conference on

Mathmatical Modelling - triennial

Furthermore, ASIM is co-sponsor of WSC - Winter Simulation Conference, of SCS conferences SpringSim and SummerSim, and of I3M and Simutech conference series.

\begin{tabular}{|c|c|}
\hline \multicolumn{2}{|c|}{ ASIM Working Committees } \\
\hline GMMS & $\begin{array}{l}\text { Methods in Modelling and Simulation } \\
\text { Th. Pawletta, thorsten.pawletta@hs-wismar.de }\end{array}$ \\
\hline SUG & $\begin{array}{l}\text { Simulation in Environmental Systems } \\
\text { Jochen Wittmann, } \\
\text { wittmann@informatik.uni-hamburg.de }\end{array}$ \\
\hline STS & $\begin{array}{l}\text { Simulation of Technical Systems } \\
\text { Walter Commerell, commerell@hs-ulm.de }\end{array}$ \\
\hline SPL & $\begin{array}{l}\text { Simulation in Production and Logistics } \\
\text { Sigrid Wenzel, s.wenzel@uni-kassel.de }\end{array}$ \\
\hline EDU & $\begin{array}{l}\text { Simulation in Education/Education in Simulation } \\
\text { A. Körner, andreas.koerner@tuwien.ac.at }\end{array}$ \\
\hline $\begin{array}{l}\text { BIG } \\
\text { DATA }\end{array}$ & $\begin{array}{l}\text { Working Group Data-driven Simulation in Life } \\
\text { Sciences; niki.popper@dwh.at }\end{array}$ \\
\hline $\begin{array}{l}\text { WORKING } \\
\text { GROUPS }\end{array}$ & $\begin{array}{l}\text { Simulation in Business Administration, in Traffic } \\
\text { Systems, for Standardisation, etc. }\end{array}$ \\
\hline
\end{tabular}

\section{CEA-SMSG - Spanish Modelling and Simulation Group}

CEA is the Spanish Society on Automation and Control and it is the national member of IFAC (International Federation of Automatic Control) in Spain. Since 1968 CEAIFAC looks after the development of the Automation in Spain, in its different issues: automatic control, robotics, SIMULATION, etc. The association is divided into national thematic groups, one of which is centered on Modeling, Simulation and Optimization, constituting the CEA Spanish Modeling and Simulation Group (CEA-SMSG). It looks after the development of the Modelling and Simulation (M\&S) in Spain, working basically on all the issues concerning the use of $M \& S$ techniques as essential engineering tools for decision-making and optimization.

$\rightarrow$ http://www.ceautomatica.es/grupos/

$\rightarrow$ emilio.jimenez@unirioja.es simulacion@cea-ifac.es

$\triangle$ CEA-SMSG / Emilio Jiménez, Department of Electrical Engineering, University of La Rioja, San José de Calasanz 31, 26004 Logroño (La Rioja), SPAIN

\begin{tabular}{ll}
\hline CEA - SMSG Officers \\
\hline President & $\begin{array}{l}\text { Emilio Jiménez, } \\
\text { emilio.jimenez@unirioja.es }\end{array}$ \\
\hline Vice president & $\begin{array}{l}\text { Juan Ignacio Latorre, } \\
\text { juanignacio.latorre@unavarra.es }\end{array}$ \\
\hline Repr. EUROSIM & Emilio Jiménez, emilio.jimenez@unirioja.es \\
\hline Edit. Board SNE & $\begin{array}{l}\text { Juan Ignacio Latorre, } \\
\text { juanignacio.latorre@unavarra.es }\end{array}$ \\
\hline Web EURoSIM & Mercedes Perez mercedes.perez@unirioja.es \\
\hline
\end{tabular}
Last data update February 2018 


\section{Ch CSSS - Czech and Slovak cSsS Simulation Society}

CSSS -The Czech and Slovak Simulation Society has about 150 members working in Czech and Slovak national scientific and technical societies (Czech Society for Applied Cybernetics and Informatics, Slovak Society for Applied Cybernetics and Informatics). CSSS main objectives are: development of education and training in the field of modelling and simulation, organising professional workshops and conferences, disseminating information about modelling and simulation activities in Europe. Since 1992, CSSS is full member of EUROSIM.

$\rightarrow$ www.fit.vutbr.cz/CSSS

奉”。 snorek@fel.cvut.cz

$\triangle$ CSSS / Miroslav Šnorek, CTU Prague

FEE, Dept. Computer Science and Engineering,

Karlovo nam. 13, 12135 Praha 2, Czech Republic

\begin{tabular}{ll}
\hline CSSS Officers & \\
\hline President & Miroslav Šnorek, snorek@fel.cvut.cz \\
\hline Vice president & Mikuláš Alexík, alexik@frtk.fri.utc.sk \\
\hline Scientific Secr. & A. Kavička, Antonin.Kavicka@upce.cz \\
\hline Repr. EURoSıM & Miroslav Šnorek, snorek@fel.cvut.cz \\
\hline Edit. Board SNE & Mikuláš Alexík, alexik@frtk.fri.utc.sk \\
\hline Web EURoSıM & Petr Peringer, peringer@fit.vutbr.cz \\
\hline
\end{tabular}

\section{DBSS - Dutch Benelux Simulation Society}

The Dutch Benelux Simulation Society (DBSS) was founded in July 1986 in order to create an organisation of simulation professionals within the Dutch language area. DBSS has actively promoted creation of similar organisations in other language areas. DBSS is a member of EUROSIM and works in close cooperation with its members and with affiliated societies.

$\rightarrow$ www.DutchBSS.org

莑-1.w.heemink@its.tudelft.nl

$\triangle$ DBSS / A. W. Heemink

Delft University of Technology, ITS - twi,

Mekelweg 4, 2628 CD Delft, The Netherlands

\begin{tabular}{ll}
\hline DBSS Officers & \\
\hline President & M. Mujica Mota, m.mujica.mota@hva.nl \\
\hline Vice president & A. Heemink, a.w.heemink@its.tudelft.nl \\
\hline Treasurer & A. Heemink, a.w.heemink@its.tudelft.nl \\
\hline Secretary & P. M. Scala, p.m.scala@hva.nl \\
\hline Repr. EuROSIM & M. Mujica Mota, m.mujica.mota@hva.nl \\
\hline Edit. SNE/Web & M. Mujica Mota, m.mujica.mota@hva.nl \\
\hline & Last data update June 2016
\end{tabular}

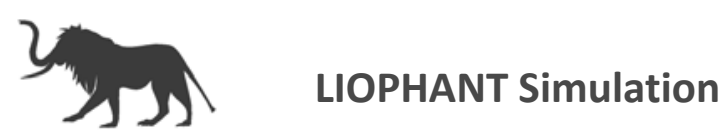

Liophant Simulation is a non-profit association born in order to be a trait-d'union among simulation developers and users; Liophant is devoted to promote and diffuse the simulation techniques and methodologies; the Association promotes exchange of students, sabbatical years, organization of International Conferences, courses and internships focused on M\&S applications.

$\rightarrow$ www.liophant.org

麦=7info@liophant.org

$\triangle$ LIOPHANT Simulation, c/o Agostino G. Bruzzone, DIME, University of Genoa, Savona Campus via Molinero 1, 17100 Savona (SV), Italy

\begin{tabular}{ll}
\hline \multicolumn{2}{l}{ LIOPHANT Officers } \\
\hline President & A.G. Bruzzone, agostino@itim.unige.it \\
\hline Director & E. Bocca, enrico.bocca@liophant.org \\
\hline Secretary & A. Devoti, devoti.a@iveco.com \\
\hline Treasurer & Marina Massei, massei@itim.unige.it \\
\hline Repr. EuroSIM & A.G. Bruzzone, agostino@itim.unige.it \\
\hline Deputy & F. Longo, f.longo@unical.it \\
\hline Edit. Board SNE & F. Longo, f.longo@unical.it \\
\hline Web EUROSIM & F. Longo, f.longo@unical.it \\
\hline & \multicolumn{1}{c}{ Last data update June 2016}
\end{tabular}

\section{LSS - Latvian Simulation Society}

The Latvian Simulation Society (LSS) has been founded in 1990 as the first professional simulation organisation in the field of Modelling and simulation in the post-Soviet area. Its members represent the main simulation centres in Latvia, including both academic and industrial sectors.

$\rightarrow$ briedis.itl.rtu.lv/imb/

莑=7merkur@itl.rtu.lv

$\triangle$ LSS / Yuri Merkuryev, Dept. of Modelling and Simulation Riga Technical University Kalku street 1, Riga, LV-1658, LATVIA

\begin{tabular}{ll}
\hline LSS Officers & \\
\hline President & Yuri Merkuryev, merkur@itl.rtu.Iv \\
\hline Secretary & Artis Teilans, Artis.Teilans@exigenservices.com \\
\hline Repr. EuroSıM & Yuri Merkuryev, merkur@itl.rtu.Iv \\
\hline Deputy & Artis Teilans, Artis.Teilans@exigenservices.com \\
\hline Edit. Board SNE & Yuri Merkuryev, merkur@itl.rtu.Iv \\
\hline Web EuROSıM & Vitaly Bolshakov, vitalijs.bolsakovs@rtu.Iv \\
\hline
\end{tabular}




\section{KA-SIM Kosovo Simulation Society}

Kosova Association for Modeling and Simulation (KASIM, founded in 2009), is part of Kosova Association of Control, Automation and Systems Engineering (KACASE). KA-CASE was registered in 2006 as non Profit Organization and since 2009 is National Member of IFAC - International Federation of Automatic Control. KA-SIM joined EUROSIM as Observer Member in 2011. In 2016, KA-SIM became full member.

KA-SIM has about 50 members, and is organizing the international conference series International Conference in Business, Technology and Innovation, in November, in Durrhes, Albania, and IFAC Simulation Workshops in Pristina.

$\rightarrow$ www.ubt-uni.net/ka-case

拝”= ehajrizi@ubt-uni.net

$\checkmark$ MOD\&SIM KA-CASE; Att. Dr. Edmond Hajrizi

Univ. for Business and Technology (UBT)

Lagjja Kalabria p.n., 10000 Prishtina, Kosovo

\begin{tabular}{ll}
\hline KA-SIM Officers & \\
\hline President & Edmond Hajrizi, ehajrizi@ubt-uni.net \\
\hline Vice president & Muzafer Shala, info@ka-sim.com \\
\hline Secretary & Lulzim Beqiri, info@ka-sim.com \\
\hline Treasurer & Selman Berisha, info@ka-sim.com \\
\hline Repr. EUROSIM & Edmond Hajrizi, ehajrizi@ubt-uni.net \\
\hline Deputy & Muzafer Shala, info@ka-sim.com \\
\hline Edit. Board SNE & Edmond Hajrizi, ehajrizi@ubt-uni.net \\
\hline Web EUROSIM & Betim Gashi, info@ka-sim.com \\
\hline & \multicolumn{1}{c}{ Last data update December 2016 }
\end{tabular}

\section{MIMOS - Italian Modelling and}

\section{Simulation Association}

MIMos (Movimento Italiano Modellazione e Simulazione - Italian Modelling and Simulation Association) is the Italian association grouping companies, professionals, universities, and research institutions working in the field of modelling, simulation, virtual reality and 3D, with the aim of enhancing the culture of 'virtuality' in Italy, in every application area.

MIMOS became EUROSIM Observer Member in 2016 and EUROSIM Full Member in September 2018.

$\rightarrow$ www.mimos.it

麦引roma@mimos.it-info@mimos.it

$\triangle$ MIMOS - Movimento Italiano Modellazione e Simulazione; via Ugo Foscolo 4, 10126 Torino via Laurentina 760, 00143 Roma

\begin{tabular}{ll}
\hline MIMOS Officers & \\
\hline President & Paolo Proietti, roma@mimos.it \\
\hline Secretary & Davide Borra, segreteria@mimos.it \\
\hline Treasurer & Davide Borra, segreteria@mimos.it \\
\hline Repr. EuRoSIM & Paolo Proietti, roma@mimos.it \\
\hline Deputy & Agostino Bruzzone, ago- \\
& stino@itim.unige.it \\
\hline Edit. Board SNE & Paolo Proietti, roma@mimos.it \\
\hline & \multicolumn{1}{c}{ Last data update December 2016 }
\end{tabular}

\section{NSSM - National Society for Simulation Modelling (Russia)}

NSSM - The Russian National Simulation Society (Национальное Общество Имитационного Моделирования - НОИМ) was officially registered in Russian Federation on February 11, 2011. In February 2012 NSS has been accepted as an observer member of EUROSIM, and in 2015 NSSM has become full member.

$\rightarrow$ www.simulation.su

麦”yusupov@iias.spb.su

$\triangle$ NSSM / R. M. Yusupov,

St. Petersburg Institute of Informatics and Automation

RAS, 199178, St. Petersburg, 14th lin. V.O, 39

\begin{tabular}{ll}
\hline NSSM Officers & \\
\hline President & R. M. Yusupov, yusupov@iias.spb.su \\
\hline Chair Man. Board & A. Plotnikov, plotnikov@sstc.spb.ru \\
\hline Secretary & M. Dolmatov, dolmatov@simulation.su \\
\hline Repr. EuRoSıM & $\begin{array}{l}\text { R.M. Yusupov, yusupov@iias.spb.su } \\
\text { Y. Senichenkov, } \\
\text { senyb@dcn.icc.spbstu.ru }\end{array}$ \\
\hline Deputy & B. Sokolov, sokol@iias.spb.su \\
\hline Edit. Board SNE & Y. Senichenkov, senyb@mail.ru, \\
& senyb@dcn.icc.spbstu.ru, \\
\hline
\end{tabular}

\section{PSCS - Polish Society for Computer}

\section{Simulation}

PSCS was founded in 1993 in Warsaw. PSCS is a scientific, non-profit association of members from universities, research institutes and industry in Poland with common interests in variety of methods of computer simulations and its applications. At present PSCS counts 257 members. 
$\rightarrow$ www.eurosim.info, www.ptsk.pl/

麦三leon@ibib.waw.pl

$\triangle$ PSCS / Leon Bobrowski, c/o IBIB PAN, ul. Trojdena 4 (p.416), 02-109 Warszawa, Poland

\begin{tabular}{ll}
\hline PSCS Officers & \\
\hline President & Leon Bobrowski, leon@ibib.waw.pl \\
\hline Vice president & Tadeusz Nowicki, \\
& Tadeusz.Nowicki@wat.edu.pl \\
\hline Treasurer & Z. Sosnowski, zenon@ii.pb.bialystok.pl \\
\hline Secretary & Zdzislaw Galkowski, \\
& Zdzislaw.Galkowski@simr.pw.edu.pl \\
\hline Repr. EuRoSıM & Leon Bobrowski, leon@ibib.waw.pl \\
\hline Deputy & Tadeusz Nowicki, tadeusz.nowicki@wat.edu.pl \\
\hline Edit. Board SNE & Zenon Sosnowski, z.sosnowski@pb.ed.pl \\
\hline Web EuroSıM & Magdalena Topczewska \\
& m.topczewska@pb.edu.pl \\
\hline
\end{tabular}

\section{SIMS - Scandinavian Simulation Society}

SIMS is the Scandinavian Simulation Society with members from the five Nordic countries Denmark, Finland, Iceland, Norway and Sweden. The SIMS history goes back to 1959. SIMS practical matters are taken care of by the SIMS board consisting of two representatives from each Nordic country (Iceland one board member).

SIMS Structure. SIMS is organised as federation of regional societies. There are FinSim (Finnish Simulation Forum), MoSis (Society for Modelling and Simulation in Sweden), DKSIM (Dansk Simuleringsforening) and NFA (Norsk Forening for Automatisering).

\section{$\rightarrow \quad$ www.scansims.org}

奉三erik.dahlquist@mdh.se

$\bowtie$ SIMS / Erik Dahlquist, School of Business, Society and Engineering, Department of Energy, Building and Environment, Mälardalen University, P.O.Box 883, 72123 Västerås, Sweden

\begin{tabular}{ll}
\hline SIMS Officers & \\
\hline President & Erik Dahlquist, erik.dahlquist@mdh.se \\
\hline Vice president & Bernt Lie, Bernt.Lie@ @sn.no \\
\hline Treasurer & $\begin{array}{l}\text { Vadim Engelson, } \\
\text { vadim.engelson@mathcore.com }\end{array}$ \\
\hline Repr. EURoSIM & Erik Dahlquist, erik.dahlquist@mdh.se \\
\hline Edit. Board SNE & Esko Juuso, esko.juuso@oulu.fi \\
\hline Web EUROSIM & $\begin{array}{l}\text { Vadim Engelson, } \\
\text { vadim.engelson@mathcore.com }\end{array}$ \\
\hline
\end{tabular}

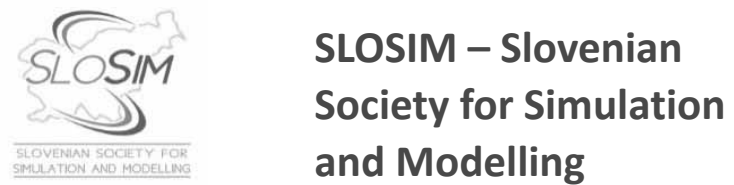

SLOSIM - Slovenian Society for Simulation and Modelling was established in 1994 and became the full member of EUROSIM in 1996. Currently it has 90 members from both Slovenian universities, institutes, and industry. It promotes modelling and simulation approaches to problem solving in industrial as well as in academic environments by establishing communication and cooperation among corresponding teams.

$\rightarrow$ www.slosim.si

拝三slosim@fe.uni-lj.si

$\triangle$ SLOSIM / Vito Logar, Faculty of Electrical

Engineering, University of Ljubljana,

Tržaška 25, 1000 Ljubljana, Slovenia

\begin{tabular}{ll}
\hline \multicolumn{2}{l}{ SLOSIM Officers } \\
\hline President & Vito Logar, vito.logar@fe.uni-lj.si \\
\hline Vice president & Božidar Šarler, bozidar.sarler@ung.si \\
\hline Secretary & Aleš Belič, ales.belic@sandoz.com \\
\hline Treasurer & Milan Simčič, milan.simcic@fe.uni-lj.si \\
\hline Repr. EUROSıM & B.Zupančič, borut.zupancic@fe.uni-lj.si \\
\hline Deputy & Vito Logar, vito.logar@fe.uni-lj.si \\
\hline Edit. Board SNE & R. Karba, rihard.karba@fe.uni-lj.si \\
\hline Web EUROSıM & Vito Logar, vito.logar@fe.uni-lj.si \\
\hline
\end{tabular}

\section{UKSIM - United Kingdom Simulation Society}

The UK Simulation Society is very active in organizing conferences, meetings and workshops. UKSim holds its annual conference in the March-April period. In recent years the conference has always been held at Emmanuel College, Cambridge. The Asia Modelling and Simulation Section (AMSS) of UKSim holds 4-5 conferences per year including the EMS (European Modelling Symposium), an event mainly aimed at young researchers, organized each year by UKSim in different European cities. Membership of the UK Simulation Society is free to participants of any of our conferences and their co-authors.

$\rightarrow$ uksim.info

莑=7david.al-dabass@ntu.ac.uk

$\triangle$ UKSIM / Prof. David Al-Dabass

Computing \& Informatics,

Nottingham Trent University

Clifton lane, Nottingham, NG11 8NS, United Kingdom 


\begin{tabular}{ll}
\hline UKSIM Officers & \\
\hline President & $\begin{array}{l}\text { David Al-Dabass, } \\
\text { david.al-dabass@ntu.ac.uk }\end{array}$ \\
\hline Secretary & A. Orsoni, A.Orsoni@kingston.ac.uk \\
\hline Treasurer & A. Orsoni, A.Orsoni@kingston.ac.uk \\
\hline $\begin{array}{l}\text { Membership } \\
\text { chair }\end{array}$ & G. Jenkins, glenn.l.jenkins@smu.ac.uk \\
\hline Local/Venue chair & Richard Cant, richard.cant@ntu.ac.uk \\
\hline Repr. EUROSIM & A. Orsoni, A.Orsoni@kingston.ac.uk \\
\hline Deputy & G. Jenkins, glenn.l.jenkins@smu.ac.uk \\
\hline Edit. Board SNE & A. Orsoni, A.Orsoni@kingston.ac.uk \\
\hline &
\end{tabular}

\section{EUROSIM Observer Members}

\section{ROMSIM - Romanian Modelling and Simulation Society}

ROMSIM has been founded in 1990 as a non-profit society, devoted to theoretical and applied aspects of modelling and simulation of systems. ROMSIM currently has about 100 members from Romania and Moldavia.

$\rightarrow$ www.eurosim.info (www.ici.ro/romsim)

麦=”sflorin@ici.ro

$\triangle$ ROMSIM / Florin Hartescu,

National Institute for Research in Informatics, Averescu Av. 8 - 10, 71316 Bucharest, Romania

\begin{tabular}{lc}
\hline ROMSIM Officers \\
\hline President & \\
\hline Vice president & $\begin{array}{c}\text { Florin Hartescu, flory@ici.ro } \\
\text { Marius Radulescu, } \\
\text { mradulescu.csmro@yahoo.com }\end{array}$ \\
\hline Repr. EUROSIM & $\begin{array}{c}\text { Marius Radulescu, } \\
\text { mradulescu.csmro@yahoo.com }\end{array}$ \\
\hline Deputy & Florin Hartescu, flory@ici.ro \\
\hline Edit. Board SNE & Constanta Zoe Radulescu, zoe@ici.ro \\
\hline Web EURoSIM & Florin Hartescu, flory@ici.ro \\
\hline
\end{tabular}

\section{Member CANDidates}

\section{Albanian SIMULATION Society}

At the Department of Statistics and Applied Informatics, Faculty of Economy, University of Tirana, Prof. Dr. Kozeta Sevrani at present is setting up an Albanian Simulation Society. Kozeta Sevrani, professor of Computer Science and Management Information Systems, and head of the Department of Mathematics, Statistics and Applied Informatic, has attended the a EUROSIM board meeting in Vienna Feb. 2016.
There she has presented simulation activities in Albania and the new simulation society.

The society - constitution and bylaws are being worked out - will be involved in different international and local simulation projects, and will be engaged in the organisation of the conference series ISTI - Information Systems and Technology. The society intends to become a EUROSIM Observer Member.

莑”kozeta.sevrani@unitir.edu.al

$\triangle$ Albanian Simulation Goup, attn. Kozeta Sevrani University of Tirana, Faculty of Economy rr. Elbasanit, Tirana 355 Albania

\begin{tabular}{lc}
\hline Albanian Simulation Society- Officers (Planned) \\
\hline President & $\begin{array}{c}\text { Kozeta Sevrani, } \\
\text { kozeta.sevrani@ unitir.edu.al }\end{array}$ \\
\hline Secretary & \\
\hline Treasurer & $\begin{array}{c}\text { Kozeta Sevrani, } \\
\text { kozeta.sevrani@ unitir.edu.al }\end{array}$ \\
\hline Repr. EURoSıM & $\begin{array}{c}\text { Albana Gorishti, } \\
\text { albana.gorishti@ unitir.edu.al } \\
\text { Majlinda Godolja, } \\
\text { majlinda.godolja@fshn.edu.al } \\
\text { Edit. Board SNE }\end{array}$ \\
\hline
\end{tabular}

\section{Societies in Re-Organisation}

The following societies are at present inactive or under re-organisation:

- CROSSIM Croatian Society for Simulation Modelling

- FranCOSIM - Société Francophone de Simulation

- HSS - Hungarian Simulation Society

- ISCS - Italian Society for Computer Simulation 

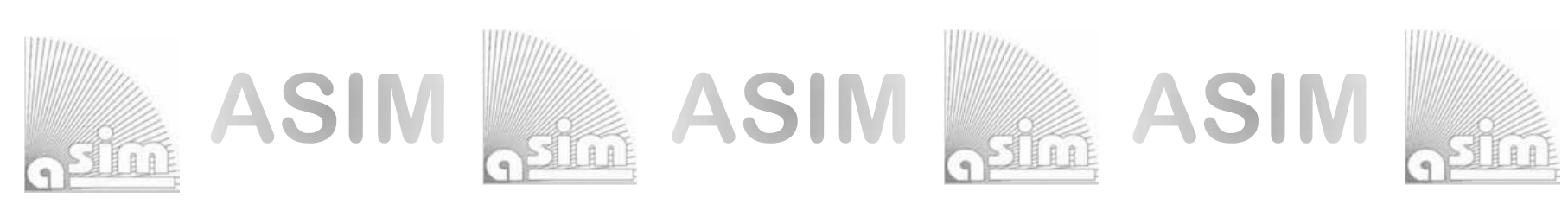

\section{ASIM - Buchreihen / ASIM Book Series}

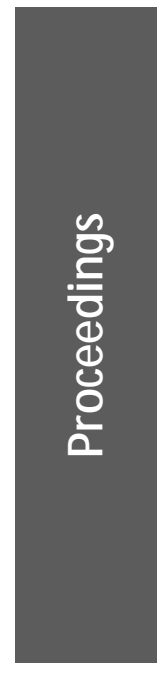

Simulation in Production and Logistics 2017 - 17. ASIM Fachtagung Simulation in Produktion und Logistik Sigrid Wenzel, Tim Peter (Hrsg.); kassel university press GmbH, Kassel, 2017; ISBN 978-3-7376-0192-4 (print), ISBN 978-3-7376-0193-1 (e-book); ASIM M itteilung AM 164.

Simulation in Production und Logistics 2015 - 16. ASIM-Fachtagung Simulation in Produktion und Logistik M. Raabe, U. Clausen (Hrsg.); ISBN 978-3-8396-0936-1, Stuttgart: Fraunhofer Verlag, 2015.

Simulation in Produktion und Logistik 2013: Entscheidungsunterstützung von der Planung bis zur Steuerung W. Dangelmaier, C. Laroque, A. Klaas (Hrsg.); ISBN 978-3-942647-35-9, HNI-Verlagsschriftenreihe, Heinz Nixdorf Institut, Paderborn, 2013.

Modellierung, Regelung und Simulation in Automotive und Prozessautomation - Proc. 5. ASIM-Workshop Wismar 2011. C. Deatcu, P. Dünow, T. Pawletta, S. Pawletta (eds.), ISBN 978-3-901608-36-0, ASIM/ARGESIM, Wien, 2011.

Simulation in Produktion und Logistik 2010: Integrationsaspekte der Simulation - Technik, Organisation und Personal. G. Zülch, P. Stock, (Hrsg.), ISBN 978-3-86644-558-1, KIT Scientific Publ. Karlsruhe, 2010.

Simulation und Optimierung in Produktion und Logistik - Praxisorientierter Leitfaden mit Fallbeispielen. L. März, W. Krug, O. Rose, G. Weigert , G. (Hrsg.); ISBN 978-3-642-14535-3, Springer, 2011.

Verifikation und Validierung für die Simulation in Produktion und Logistik - Vorgehensmodelle und Techniken. M. Rabe, S. Spieckermann, S. Wenzel (eds.); ISBN: 978-3-540-35281-5, Springer, Berlin, 2008.

Qualitätskriterien für die Simulation in Produktion und Logistik - Planung und Durchführung von Simulationsstudien. S. Wenzel, M. Weiß, S. Collisi - Böhmer, H. Pitsch, O. Rose (Hrsg.); ISBN: 978-3-540-35281-5, Springer, Berlin, 2008.

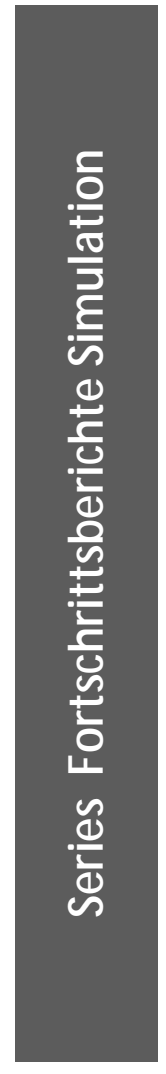

Patrick Einzinger: A Comparative Analysis of System Dynamics and Agent-Based M odelling for Health Care Reimbursement Systems. FBS 24; ISBN 978-3-901608-75-9, ASIM/ARGESIM Vienna, 2014; www.tuverlag.at - print-on-demand.

$M$ artin Bruckner: Agentenbasierte Simulation von Personenströmen mit unterschiedlichen Charakteristiken. FBS 23; ISBN 978-3-901608-74-2 (ebook), ASIM/ARGESIM Vienna, 2014; www.tuverlag.at - print-on-demand

Stefan Emrich: Deployment of Mathematical Simulation Models for Space Management. FBS 22; ISBN 978-3-901608-73-5 (ebook), ASIM / ARGESIM Vienna, 2013; www.tuverlag.at - print-on-demand

Xenia Descovich: Lattice Boltzmann Modeling and Simulation of Incompressible Flows in Distensible Tubes for Applications in Hemodynamics. FBS 21; ISBN 978-3-901608-71-1 (ebook), ASIM /ARGESIM Vienna, 2012; www.tuverlag.at - print-on-demand

Florian Miksch: Mathematical Modeling for New Insights into Epidemics by Herd Immunity and Serotype Shift. FBS 20, ISBN 978-3-901608-70-4 (ebook), ASIM / ARGESIM Vienna, 2012; www.tuverlag.at - print-on-demand

Shabnam Tauböck: Integration of Agent Based Modelling in DEVS for Utilisation Analysis: The MoreSpace Project at TU Vienna. FBS 19; ISBN 978-3-901608-69-8 (ebook), ASIM / ARGESIM Vienna, 2012; www.tuverlag.at - print-on-demand

Christian Steinbrecher: Ein Beitrag zur prädiktiven Regelung verbrennungsmotorischer Prozesse. FBS 18; ISBN 978-3-901608-68-1 (print), 978-3-901608-72-8 (ebook), ASIM/ARGESIM Vienna, 2010.

Olaf Hagendorf: Simulation-based Parameter and Structure Optimisation of Discrete Event Systems FBS 17; ISBN 978-3-901608-67-4 (print), 978-3-901608-99-5 (ebook), ASIM/ARGESIM Vienna, 2010. 


\section{$*^{* * *} \quad$ EUROSIM 2019}

\section{$10^{\text {th }}$ EUROSIM Congress on Modelling and Simulation}

\section{La Rioja, Logroño, Spain, July 1 - 5, 2019}
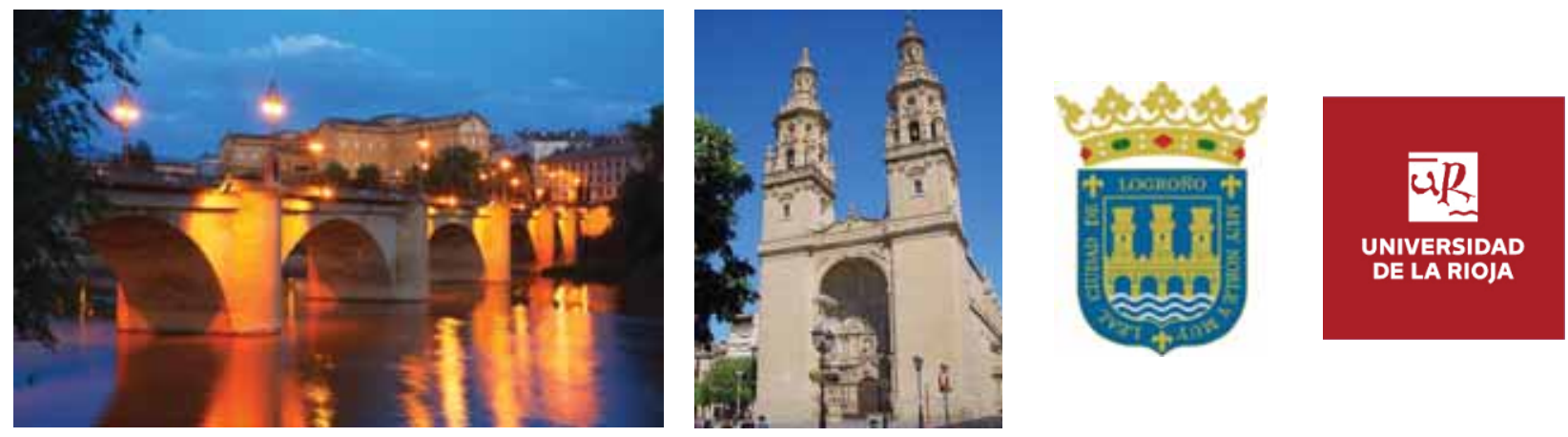

EUROSIM Congresses are the most important modelling and simulation events in Europe. For EUROSIM 2019, we are soliciting original submissions describing novel research and developments in the following (and related) areas of interest: Continuous, discrete (event) and hybrid modelling, simulation, identification and optimization approaches. Two basic contribution motivations are expected: M\&S Methods and Technologies and M\&S Applications. Contributions from both technical and non-technical areas are welcome.

Congress Topics The EUROSIM 2019 Congress will include invited talks, parallel, special and poster sessions, exhibition and versatile technical and social tours. The Congress topics of interest include, but are not limited to:

Intelligent Systems and Applications Hybrid and Soft Computing

Data \& Semantic Mining

Neural Networks, Fuzzy Systems \&

Evolutionary Computation

Image, Speech \& Signal Processing

Systems Intelligence and

Intelligence Systems

Autonomous Systems

Energy and Power Systems

Mining and Metal Industry

Forest Industry

Buildings and Construction

Communication Systems

Circuits, Sensors and Devices

Security Modelling and Simulation
Bioinformatics, Medicine, Pharmacy and Bioengineering

Water and Wastewater Treatment,

Sludge Management and Biogas Production

Condition monitoring, Mechatronics and maintenance

Automotive applications

e-Science and e-Systems

Industry, Business, Management, Human Factors and Social Issues

Virtual Reality, Visualization, Computer Art and Games

Internet Modelling, Semantic Web and Ontologies

Computational Finance \& Economics
Simulation Methodologies and Tools

Parallel and Distributed

Architectures and Systems

Operations Research

Discrete Event Systems

Manufacturing and Workflows

Adaptive Dynamic Programming and Reinforcement Learning

Mobile/Ad hoc wireless networks, mobicast, sensor placement, target tracking

Control of Intelligent Systems

Robotics, Cybernetics, Control Engineering, \& Manufacturing

Transport, Logistics, Harbour, Shipping and Marine Simulation

Congress Venue / Social Events The Congress will be held in the City of Logroño, Capital of La Rioja, Northern Spain. The main venue and the exhibition site is the University of La Rioja (UR), located on a modern campus in Logroño, capital of La Rioja, where 7500 students are registered. The UR is the only University in this small, quiet region in Northern Spain. La Rioja is where the Monasteries of San Millán de la Cogolla, cradle of the first words written in the Spanish language, are situated, sites included in UNESCO's World Heritage List in 1996. Of course, social events will reflect this heritage - and the famous wines in la Rioja.

Congress Team: The Congress is organised by CAE CAE-SMSG, the Spanish simulation society, and Universidad de la Rioja.

Info: Emilio Jiménez, EUROSIM President, emilio.jimenez@unirioja.es 

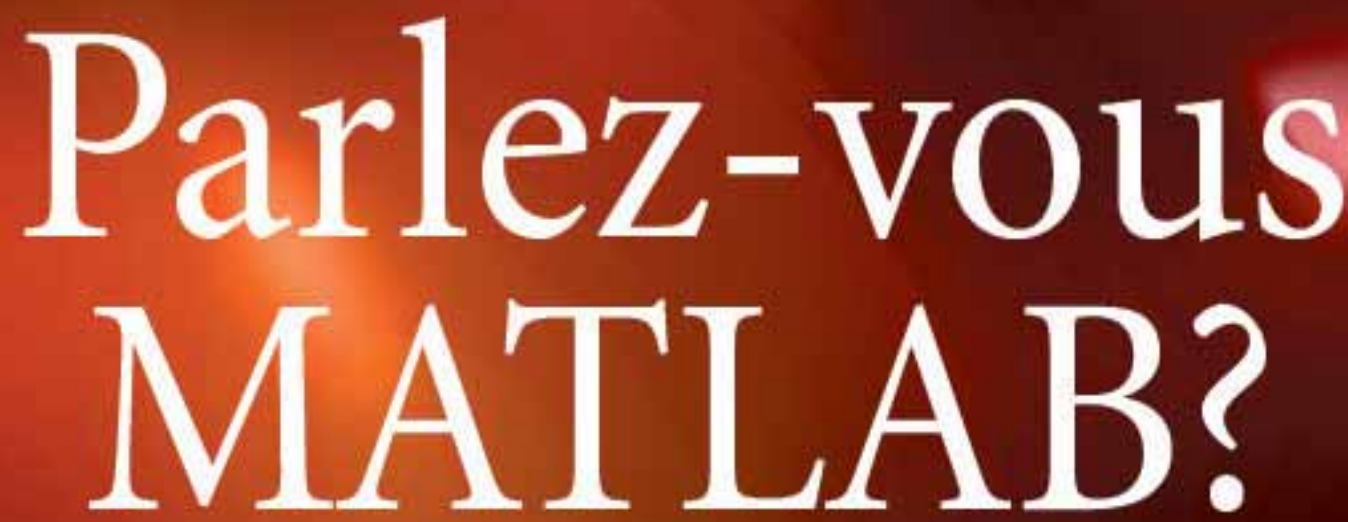

Ober eine Million Menschen wel twe it sprechen MATLAB. Ingenieure und Wissenschaftler in allen Bereichen - von der Luft- und Raumfahit tuber die Halbleiterindustrie bis zur Biotechnologie, Finanzdienstleistungen und Geo- und Mereswissenschuften - mutzen MATLAB, um ihre Ideen auszudrudken. Sprechen Sie MATLAB?

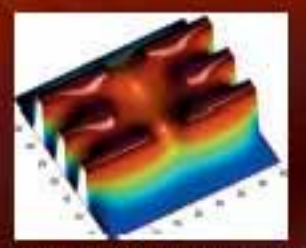

Modelliernug cines elektrischen Potestials in cinsm Qunumam Dot.

Dieses Reispiel finden Sie unters mwwimathworks dellic

The language of technical computing 